\title{
The development and evaluation of a community and a mass media approach to smoking cessation
}

Citation for published version (APA):

Mudde, A. N. (1994). The development and evaluation of a community and a mass media approach to smoking cessation. [Doctoral Thesis, Maastricht University]. Rijksuniversiteit Limburg. https://doi.org/10.26481/dis.19941208am

Document status and date:

Published: 01/01/1994

DOI:

10.26481/dis.19941208am

Document Version:

Publisher's PDF, also known as Version of record

\section{Please check the document version of this publication:}

- A submitted manuscript is the version of the article upon submission and before peer-review. There can be important differences between the submitted version and the official published version of record.

People interested in the research are advised to contact the author for the final version of the publication, or visit the DOI to the publisher's website.

- The final author version and the galley proof are versions of the publication after peer review.

- The final published version features the final layout of the paper including the volume, issue and page numbers.

Link to publication

\footnotetext{
General rights rights.

- You may freely distribute the URL identifying the publication in the public portal. please follow below link for the End User Agreement:

www.umlib.nl/taverne-license

Take down policy

If you believe that this document breaches copyright please contact us at:

repository@maastrichtuniversity.nl

providing details and we will investigate your claim.
}

Copyright and moral rights for the publications made accessible in the public portal are retained by the authors and/or other copyright owners and it is a condition of accessing publications that users recognise and abide by the legal requirements associated with these

- Users may download and print one copy of any publication from the public portal for the purpose of private study or research.

- You may not further distribute the material or use it for any profit-making activity or commercial gain

If the publication is distributed under the terms of Article $25 \mathrm{fa}$ of the Dutch Copyright Act, indicated by the "Taverne" license above, 


\section{THE DeVelopment and Evaluation OF A COMMUNITY AND A MASS MEDIA APPROACH TO SMOKING CESSATION}

\section{PROEFSCHRIFT}

ter verkrijging van de graad van doctor aan de Rijksuniversiteit Limburg te Maastricht, op gezag van de Rector Magnificus, Prof.dr. H. Philipsen, volgens het College van Dekanen, in het openbaar te verdedigen op donderdag 8 december 1994 om 16.00 uur

door

Aart Nicolaas Mudde

geboren te Eindhoven op 16 november 1953 
Promotor:

Prof.dr. G.J. Kok

Co-promotor:

Dr. H. de Vries

Beoordelingscommissie:

Prof.dr. J.A. Knottnerus (voorzitter)

Prof.dr B. Flay (University of Illinois, Chicago, USA)

Dr. R.A. Knibbe

Prof.dr. F. Nijhuis

Prof.dr. J. Vinck (Limburgs Universitair Centrum, Diepenbeek België)

The studies described in chapters 3, 4 and 5 of this dissertation were financially supported by the Dutch Cancer Society (grant IKL 88-06). The study described in chapter 6 was financed by the Dutch Smoking and Health Foundation.

ISBN 90-9007731-6

- Aart N. Mudde 


\section{ACKNOWLEDGEMENTS}

In the first place I would like to express my gratitude for the opportunity to carry out the research projects described in this dissertation to both funding organizations, the Dutch Cancer Society and the Dutch Smoking and Health Foundation, as well as promotor Gerjo Kok and co-promotor Hein de Vries. Hein's expertise was essential for the accomplishment of this dissertation. I am also thank Vic Strecher for his constructive advise in the various stages of the research projects. Furthermore, I thank the research assistants who worked with me on implementing programs and gathering and analyzing data: Marc Willemsen, Paul Geelen, Esther Bakbier, and last but certainly not least, Maria Dolders. Maria, thanks for your input and laughs. I would also like to thank the many students who conducted thousands and thousands of telephone interviews, and the people they troubled. Finally, the contributions of 'organizations in the field' to practice-oriented research cannot be valued enough: my respect for the Dutch Smoking and Health Foundation, the Municipal Health Service in Den Bosch, Teleac, KRO, and many others. 



\section{CONTENTS}

1. GENERAL OVERVIEW

2. SELF-EFFICACY AS A PREDICTOR FOR THE CESSATION OF SMOKING: METHODOLOGICAL ISSUES AND IMPLICATIONS FOR SMOKING CESSATION PROGRAMS.

Mudde AN, Kok GJ, Strecher VJ. Accepted for publication in Psycbology and Health 1995;10.

3. DEVELOPMENT AND ISTILIZATION OF A SELF-HELP MANUAL FOR COMMUNITY SMOKING CESSATION INTERVENTIONS.

Mudde $A N$, De Vries $H$, Willemsen MC, Van Assema P. In: Richmond $R$, editor. Interventions for smokers: An international perspective. New York: Williams \& Wilkins; 1994:293322.

4. EVAluation OF A DUTCH COMMUNTTY-BASED SMOKING CESSATION INTERVENTION.

Mudde AN, De Vries H, Dolders MGT. Accepted for publication in Preventive Medicine 1995;1.

5. COST-EFFICIENCY AND COST-EFFECTTVENESS OF SMOKING CESSATION MODALITIES: COMPARING APPLES WITH ORANGES.

Submitted for publication.

6. REACH AND EFFECTIVENESS OF A NATIONAL MASS-MEDIALED SMOKING CESSATION CAMPAIGN IN THE NETHERLANDS.

Submitted for publication.

SUMMARY

SAMENVATTING 


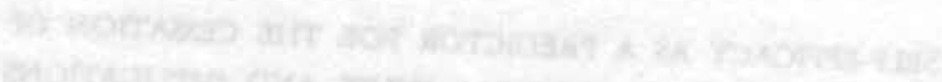

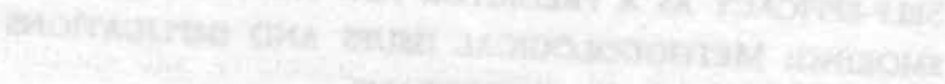

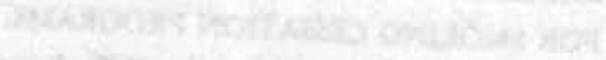

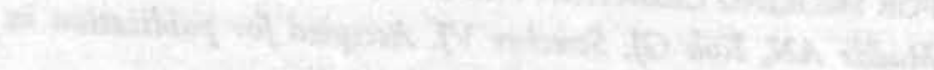

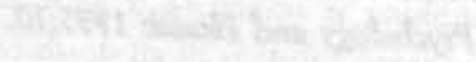

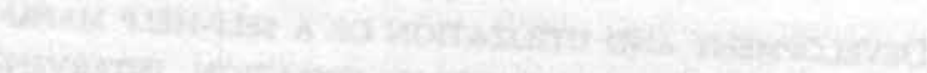

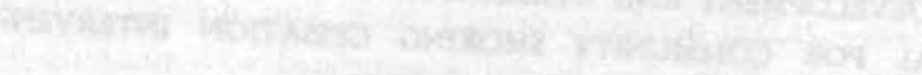

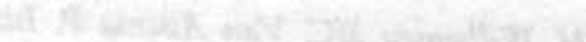

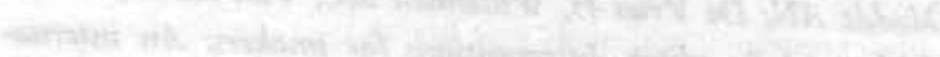

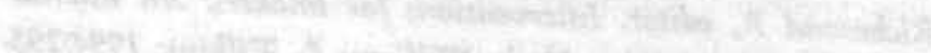

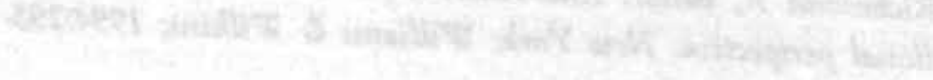

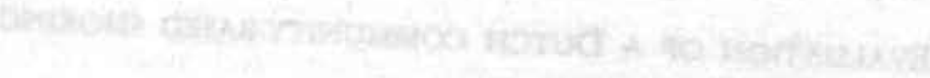

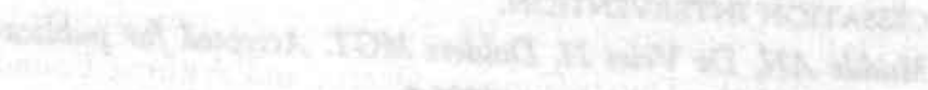

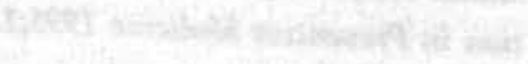

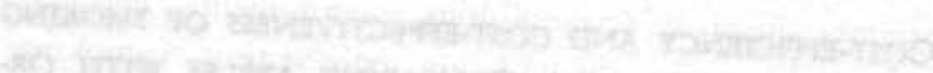

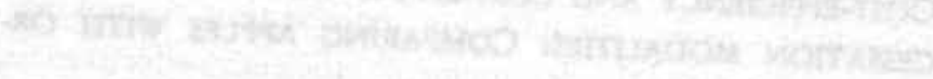

wark

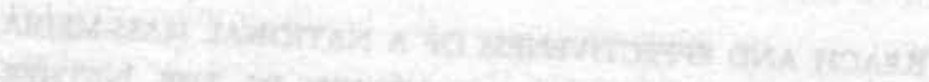

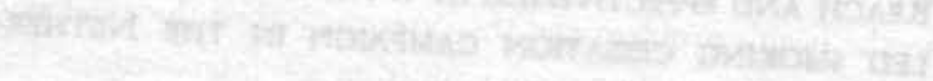




\section{1 \\ GENERAL OVERVIEW}

\section{INTRODUCTION}

Smoking is the leading cause of preventable morbidity and mortality in the Netherlands. Approximately $33 \%$ of the people in the Netherlands smoke (1). Cigarette smoking is linked to a wide array of diseases. Deaths attributable to smoking accounted for $49 \%$ of all death caused by chronic obstructive pulmonary disease, lung cancer, coronary heart disease and stroke. In 1993, in the Netherlands over 28,000 deaths caused by these four diseases were ascribed to smoking (1). The morbidity and mortality associated with smoking have serious implications for society's expenditures and economic productivity, as well as for individuals' life expectancy and quality of life $(2,3)$.

The intention of the Dutch government is to reduce the smoking prevalence in the year 2000 to $20 \%$ (4). However, until now governmental policies and financial strategies with respect to tobacco control have been limited, and the achievement of this goal is questioned $(1,5)$. In the past, the Dutch Cancer Foundation has subsidized tobacco control efforts and since 1974 the Dutch Smoking and Health Foundation (DSHF), the collective educational service with respect to smoking of the Dutch Cancer-, Heart-, and Asthma Foundations and the governmental department of public health, implemented various tobacco control programs, aimed at accomplishing environmental changes as well as changes in individuals affecting the initiation and cessation of smoking.

This dissertation examines the development, efficiency, effectiveness, costs and continuation of several smoking cessation interventions in the Netherlands. Development of interventions that succeed in changing risk behaviors requires a systematic approach, including analyses of the health problem, the behaviors that contribute to the health problem and the determinants of these behaviors, as well as development, implementation and evaluation of interventions that possibly enhance behavior change. Finally, continuation of effective interventions is essential to accomplish large scale risk reduction (6).

In this overview, the already extensively and thoroughly investigated evidence concerning the relation between smoking and the resulting health damage and the state of the art of smoking cessation interventions will be shortly summarized. Consequently, a broad outline of the various projects and studies is given, and 
the main results are reported. Furthermore, perspectives over the studies are provided. Finally, implications for further research and programs are discussed.

\section{SYSTEMATIC APPROACH}

In his $A B C$-framework for cancer prevention planning, de Vries ( 7$)$ differentiates three basic phases in the process of health education and promotion: Analysis of the problem, Behavior Change and Continued Prevention (see figure 1). In the Analysis phase four issues are identified: problem identification, the identification of behaviors that are related with the problem, defining target groups, and analyzing the factors that determine a person's behavior. In the case of smoking, epidemiological and medical research already provided firm evidence for the relations between smoking and cancer, heart disease and respiratory disorders, and set priorities with respect to target groups for smoking prevention and cessation. The next paragraph provides a resume of this data. Studies described in this dissertation focussed on smoking cessation, although prevention of the onset of smoking is also an important goal in health education, since the effectiveness of cessation interventions has only been limited until now.

The last issue in the Analysis phase is to examine why people engage in the unhealthy behavior. Analyzing the motives of unhealthy behaviors is essential before developing programs and campaigns. Behavioral research indicated that the following factors are important as determinants of behavior: demographic factors (e.g., age, gender, socio-economic status), environmental factors (e.g., legislation controlling availability of tobacco, restrictions for tobacco promotion, smoking bans in public buildings), and cognitive factors (e.g., attitudes, perceptions of social pressure and self-efficacy). In the case of smoking cessation, several theories have been used to gain insight in this last factor. A common factor in the Theory of Planned Behavior (8), the analogous ASE-model (ASE stands for Attitude, Social influence, and Self-efficacy) (9), the Health Belief Model (10), and the Social Learning Theory (11), is self-efficacy or the related concept of behavioral control. In these theories, self-efficacy concerns the individuals perception of his or her situation specific ability to perform a certain behavior. In the case of smoking cessation, this behavior is refraining from smoking. The other concepts in the various theories, such as attitude, social influence, perceived severity and susceptibility, and behavioral efficacy, only showed modest predictiveness for cessation success while self-efficacy showed promising results (12). Chapter 2 of 
this dissertation provides a description of a study in which the predictive value of self-efficacy, the proposed principal cognitive factor in smoking cessation, is examined in detail in participants in a smoking cessation group program. The results of the Analysis phase may provide essential ingredients to formulate ideas on which issues need to be addressed in programs and campaigns, and how these issues can be managed.

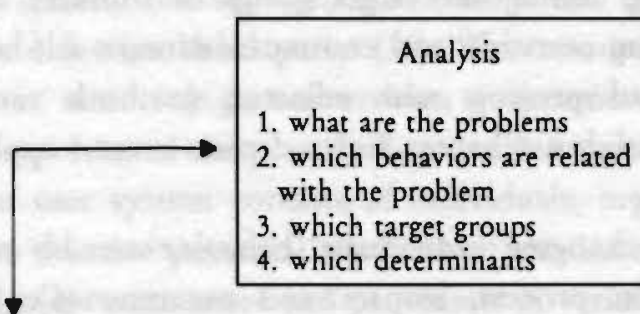

\begin{tabular}{|l|}
\hline \multicolumn{1}{|c|}{ Behavioral change } \\
1. education or legislation \\
2. which type of prevention \\
3. program development \\
4. pretesting and evaluation" \\
\hline
\end{tabular}

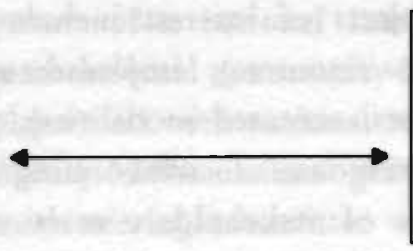

Continuation

1. diffusion strategies

2. intersectoral approach

3. supportive strategies;

Figure 1. The ABC planning model (7)

In the phase of Behavior Change a choice is made on whether behavior needs to be changed by interventions directed at individuals, providing facilities, and regulation or legislation to change the smoking environment, or combinations of interventions. Moreover, decisions are to be made on what type of prevention is needed (primary, secondary or tertiary prevention), and what the program goals will be. A program-matrix, as proposed by Kok (13), in which these issues are incorporated, may be helpful to plan programs. Furthermore, developed interventions are to be pre-tested, and the potential effects of the intervention can be assessed in a pilot study. The planning-matrix of McGuire (14) is an efficient tool in the developmental phases of an intervention, and may serve as a checklist when decisions made during development are to be checked on accuracy in a pretest. Many strategies to reduce smoking prevalence were tried and tested (see page 6). Moreover, the effects of regulation and legislation, although hard to evaluate definitively, showed to be very promising (15). However, in the Netherlands long term political debate did not provide constructive resolutions to reduce smoking 
prevalence (5). Thus, the likelihood of an effective synergism between interventions aimed at individuals and environments at the one hand and legislation and regulation on the other hand seems rather small.

Based on the evidence from the study on self-efficacy as described in chapter 2 and other studies, interventions can been developed to change the determinants of smoking cessation through providing a range of smoking cessation modalities. The comprehensive development of one strategy is described in chapter 3. Through repeatedly pretesting among the target group of smokers and among experts in the fields of smoking cessation and communication, a self-help manual for use in community based projects was adjusted to both target group characteristics and scientific insights. Chapter 3 also depicts several applications of the manual in various settings.

Interventions that aim at changing individuals' behavior can be evaluated at one or more of three levels: process, impact and outcome (6). In process evaluation, the potential objects of interest include all program inputs (e.g., policy, specificity of goals, resources), implementation activities (e.g., staff performance, media broadcasts, executed modalities), and stakeholders reactions (e.g., level of participation, response of collaborating organizations, participants evaluations). The evaluation of stakeholders reactions is also referred to as program evaluation. Impact evaluation assesses the immediate effect the program has on target behaviors and their behavioral determinants or influential environmental factors. A specific domain of evaluation that links elements of the process and impact evaluation is cost-efficiency and costs-effectiveness evaluation, in which mostly behavioral impact is expressed in terms of costs (e.g., costs per participant or successful quitter). Outcome evaluation refers to the evaluation of the program in terms of health status and quality-of-life indicators. They are typically referenced in terms of mortality, disease or disability rates, unemployment and homelessness rates, etc.. In chapter 4, a preliminary study is reported on the evaluation of the first Dutch community-based smoking cessation intervention in which the self-help manual was applied. Elements of process and impact evaluation are discussed. Chapter 5 concentrates on determining the costefficiency and cost-effectiveness of two smoking cessation modalities that were part of the community-based project.

Cancer prevention interventions will only be effective if programs, strategies and campaigns are used on a large scale during a substantial period of time: the phase of Continuation. The development of an effective program does not imply that such a program will be implemented widely. To enhance continued 
utilization of effective programs or program elements, diffusion strategies are. needed. One approach to enhance later diffusion and adoption of programs is the so-called linkage approach (16). This approach suggests collaboration among three systems during the development and implementation of an innovation: resource system, linkage system, and user system. The resource system can consist among others of developers, consultants, experts, trainers, services, and resources (e.g., materials, protocols, funds). The linkage system can include representatives from the resource system and representatives from the user system, but it can also consist of an objective third party (16). The resource and user systems usually contain various sectors (e.g., universities, government, health care). When these sectors are represented in the linkage system, an intersectoral approach is achieved. The user system consists of individuals, organizations, agencies, groups and networks that are potential adopters of the innovation. The linkage system bridges the gap between users and providers. A variation of the linkage approach was applied in the development of a national mass-media-led campaign that contained almost all elements of the local community-based intervention that was described in chapter 4 , complemented with national mass media components: tvand radio broadcasts, and publicity in the national printed media. Initiated by the DSHF, an intersectoral national steering committee was formed that functioned as a linkage system. In this steering committee experts in the fields of smoking cessation and mass media, researchers, representatives from the DSHF, and governmental representatives represented the resource system, while network delegates and health educators of local health services represented the user system. The linkage system developed, coordinated and evaluated a national mass-medialed intervention. In chapter 6 , the results of this national mass-media-led smoking cessation campaign are reported.

Continuation may be promoted by the availability of supportive strategies. In the case of smoking cessation, supportive health promotion policies need to guarantee minimal conditions for health education to be feasible and effective. One year before the mass-media-led campaign was implemented, the Dutch government accorded a smoking ban for public rooms of civil buildings, although this mandate did not comprise any sanctions. Moreover, several health insurance companies started to reimburse charges for participants in smoking cessation group programs. At the other hand, in 1990 in the Netherlands expenditures on tobacco promotion increased with $72 \%$, from 66 million US-dollars in 1989 to 113 million US-dollars in 1990 (5). For a comparison: the budget of the DSHF was about 3.5 million US-dollars in 1991 (1). Furthermore, the Dutch 
government does not prevent exposure of the public to ambivalent messages: at the one hand governmental financial support is provided to the DSHF that provides anti-tobacco messages, at the other hand tobacco promotion is hardly restricted by governmental regulations, and the government collects large sums of tobacco excise taxes (over 1,4 billion US-dollars in 1990) (5). In contrast with a number of state governments in the United States, who have allocated a portion of the tobacco taxes to general health-promotion activities and a few who dedicated some portion of the taxes to anti tobacco activities, and who inform the general public about the destination of tobacco taxes (17), the Dutch government does not communicate the allocation of the taxes to the general public. This does not add to a consistent 'healthy image' for the Dutch government. The conclusion emerges that the minimal conditions for feasible and effective smoking cessation education at a national level in 1991 were not met. Since then, this situation did not improve: no alterations were made in legislation and policies, and tobacco promotion expenditures increased gradually (1).

\section{SMOKING PREVALENCE AND HEALTH CONSEQUENCES}

In this section, epidemiological and medical evidence for the analysis phase of the $\mathrm{ABC}$ planning model is summarized. In the Netherlands, approximately $33 \%$ of the people aged 15 years and above smoke (1). The percentage of smokers in the male population has decreased gradually from $90 \%$ in 1958 to $37 \%$ in 1993 . However, the smoking prevalence in women increased from $29 \%$ to $30 \%$ in the same period. Female smoking prevalence peaked in 1967 at $42 \%$ but has been declining since 1970 . In 1993, smoking prevalence in teenagers aged 10 to 14 years was $11 \%$ ( $10 \%$ for boys and $11 \%$ for girls), while the prevalence in older adolescents ( $15-19$ years of age) was $45 \%$ ( $45 \%$ in boys and $44 \%$ in girls, measured in absence of parents). From 1988, smoking prevalence in the general population is stalled at approximately $34 \%$, caused by constant or even slightly increasing prevalence in age categories between 19 and 65 years, and a substantial increasing prevalence in adolescents between 10 and 14 year ( $9 \%$ in 1988 and $11 \%$ in 1992) and adolescents between 15 and 19 year (18\% in 1989 and $22 \%$ in 1993, measured in presence of parents) (1). The increasing prevalence supports the effectiveness of tobacco promotion, since almost all promotional activities are aimed at minors (5). 
As in the United States (3), in the Netherlands smoking is more and more regarded as a social problem. There is evidence that smoking prevalence is higher in groups with a lower socio-economic status (SES). A survey using a four category division of SES, conducted in 1989, found that $33 \%$ of the adults in the highest SES category were smokers, compared with $46 \%$ in the lowest SES category (18). Furthermore, $69 \%$ of smokers in the lower SES category rolled their own cigarettes from tobacco thus putting them at greater risk of developing tobacco-related diseases because hand-rolled cigarettes contain higher levels of nicotine and tar than manufactured cigarettes. By comparison only $38 \%$ of smokers in the highest SES category rolled their own cigarettes.

Despite the decrease in smoking prevalence rates, the mean daily cigarette consumption has increased from 13 cigarettes per day in 1967 to 20 per day in 1993 (1). Two separate factors are thought to be partly responsible for this increase. First, the introduction of cigarettes with lower nicotine content may mean that nicotine dependent smokers need to smoke more cigarettes in order to reach the desired nicotine level. Second, it is possible that light smokers may have been successful in quitting, thus leaving the heavy tobacco consumers as the smoking population. Furthermore, hand-rolled cigarettes accounted for a growing segment of the total consumption. In $1967,35 \%$ of all smoked cigarettes were hand-rolled, against $47 \%$ in 1993 (1). This might be caused by the fact that in lower socio-economic groups, in which relatively more hand-rolled cigarettes are smoked, smoking prevalence remained higher than in higher socio-economic groups, but the substantial price advantage of hand-rolled cigarettes may also have contributed (manufactured cigarettes cost about twice as much as hand-rolled cigarettes).

Smoking caused substantial health damage in the Netherlands. It was estimated that in 1993 over 28,000 Dutchmen died prematurely from diseases caused by smoking. Table 1 provides an overview of preventable smoking related death caused by three major diseases in the Netherlands. At present just under $20 \%$ of all death in developed countries are attributed to tobacco, suggesting that on current smoking patterns just over $20 \%$ of those now living in those countries will eventually be killed by tobacco (19). Further estimations of Peto, Lopez, Boreham, Thun and Heath (19) pertaining to tobacco related death in developed countries, suggest that in the 1990 s about $30 \%$ of all death at $35-69$ will be caused by tobacco (making it the largest single cause of premature death) plus about $14 \%$ of all death at older age. Those killed by tobacco at 35-69 will lose an average of 
about 23 years of life, while those killed at older ages are on average almost 80 years old, and thus do not lose a substantial part of their potential life span.

Table 1. Death causes by four smoking related diseases in 1992 (1).

\begin{tabular}{lrrr}
\hline & Total death & $\begin{array}{r}\text { Death caused } \\
\text { by smoking }\end{array}$ & \\
\hline Lungcancer * & 9,088 & 8,045 & $89 \%$ \\
Obstructive lung disease & 5,588 & 4,376 & $78 \%$ \\
Coronary heart disease & 21,094 & 9,040 & $43 \%$ \\
Stroke & 12,926 & 7,356 & $57 \%$ \\
Total & 48,696 & 28,817 & $59 \%$ \\
\hline
\end{tabular}

* other respiratory cancers included

In extensive reviews by the Surgeon General (20-23) numerous conclusions were formulated with respect to the health consequences of smoking. The major findings are: smoking is linked with mortality and morbidity in smokers and passive smokers. Moreover, for those who are occupationally exposed to toxic agents smoking constitutes an even greater risk. Furthermore, prenatal and perinatal morbidity and mortality are enhanced by maternal smoking.

\section{SELF-EFFICACY AS A PREDICTOR FOR SMOKING CESSATION}

The fourth issue in the analysis phase of the ABC-framework (7) is to find determinants of the intended behavior change. In smoking cessation research, selfefficacy emerged as a major cognitive determinant of future abstinence, relating partly directly and partly mediated by intention with abstinence $(24,25)$. According to Bandura (11), a change in belief about one's ability to successfully execute a given action (self-efficacy) mediates the initiation and maintenance of behavior change. Many studies emphasized the predictive value of self-efficacy for cessation among treatment participants $(26,27)$. The consensus of these studies is as follows: pre-treatment self-efficacy was generally not predictive for smoking status after treatment. Self-efficacy increased during treatment and therapies of different types. Post-treatment self-efficacy expectations were significant predictors 
for short-term maintenance of smoking cessation (three to six months after treatment). This relationship held true even when post-treatment smoking status was controlled for and only subjects, who were abstinent after treatment, were included.

We conducted a prospective study to asses the predictive value of pre- and post-treatment self-efficacy for short and long-term smoking cessation of 123 participants in the standard group program of the Life and Health Foundation (later incorporated in the DSHF). In chapter 2 of this dissertation, this study is reported in detail. A secondary goal was to determine which of three measures, representing three dimensions of self-efficacy as proposed by Bandura (11), is the strongest predictor for cessation. A third aspiration of this study was to detect sub-scales of the applied self-efficacy scales $(28,29)$ and to assess their predictive powers. Measures of smoking behavior and self-efficacy were obtained by questionnaires at pre- and post-treatment and after follow-up periods of six weeks and one year after treatment. The quit-rate after one year follow-up was $24 \%$, which is comparable with the median success rates reported internationally varying between $24 \%$ and $36 \%$ (30).

\section{Prediction of success.}

The main conclusion emerging from this study is that self-efficacy was predictive for cessation success. Pre-treatment self-efficacy conceptualized as perceived difficulty was a predictor for short-term cessation (post-treatment and post 6weeks follow-up), although confidence intervals indicated considerable variance of this predictive power. Post-treatment perceived ability, as well as the increase of perceived ability during treatment, predicted abstinence at post 6-weeks followup. Since none of the post-treatment smokers succeeded in quitting again during the 1 year follow-up period, prediction of future abstinence was pointless in this group. However, in post-treatment abstainers continued non-smoking and relapse took place. Post 1-year abstinence of those subjects who were abstinent after treatment, was predicted by both post-treatment self-efficacy and the increase of self-efficacy during treatment (conceptualized as perceived ability).

This study showed that self-efficacy is a determinant of future behavior, opposing the critique that self-efficacy is merely a reflection of former behavior (31). This conclusion corresponds with the Theory of Planned Behavior (8), that asserts that the performance of a certain behavior is determined by both the intention to perform the behavior and self-efficacy. This study supports the direct relation between self-efficacy and smoking behavior. Moreover, self-efficacy 
conceptualized as perceived ability and measured by a single item showed to be the strongest predictor. Factor analyses suggested that the negative/affective items of self-efficacy scales were the critical elements for prediction of future abstinence, in contrast to the positive/social and habit/addictive factors.

\section{Implications for smoking cessation programs}

The results of this study indicate that in order to enhance the efficacy of group programs, participants' self-efficacy towards non-smoking should be enhanced sufficiently during treatment. Various studies have suggested strategies to raise self-efficacy levels in group sessions $(11,32)$, and in individual counseling $(33,34)$. Moreover, the single-item ability measure could be used as an indicator for tailoring of follow-up treatments to smokers who do not report a sufficient level of self-efficacy.

Finally, the results of the group program in this study accentuate the importance of relapse prevention. Subjects who experienced a initial lapse during treatment were not able to overcome this lapse and went back to smoking in the long term. Marlatt and Gordon (32) describe a number of useful strategies for relapse prevention. Therefore, instructions about how to prevent lapses, and how to handle a potential relapse, should be part of a smoking cessation program.

\section{SMOKING CESSATION INTERVENTIONS}

The outcomes of the analyses phase, as indicated in the ABC planning model (7), led to the development of numerous smoking cessation interventions, which can be placed in the stage of behavior change of the $A B C$ planning model. The earliest responses to the scientific data that established the risk of smoking were information campaigns to communicate the health risks of cigarette smoking with the expectation that relaying the risk information to the smoking public would lead to changes in smoking behavior (35). The expected change in smoking behavior did occur in many countries, but it was far more limited than had been hoped. Although such campaigns were found to motivate non-smokers to temporarily refrain from smoking, cigarette advertising was suggested to have substantial influence on a young person's decision to start smoking (17). Moreover, the recognition that most smokers who wanted to quit were unable to do so on their own, led to the development of programs that would produce change within smokers that would help them to break their addiction. The goals 
of these programs included providing smokers with the tools to change their behavior, changing the behavioral conditions surrounding smoking, and altering the coping strategies used by smokers. However, the common link in all of these approaches was the attempt to motivate the individual and to provide him or her with skills and confidence so that he or she could make the desired change in behavior in spite of environmental influences that promote smoking (30). The limited impact of clinic-based cessation programs, together with growing recognition of the importance of environmental factors in smoking behavior, led to a shift in tobacco control strategies towards influencing the environment, such as shrinking the social acceptability of smoking, and raising the cost of cigarettes (30). School-based health education programs and programs that raise adolescents' self-esteem, as well as efforts to restrict advertising and promotional activities, were aimed at preventing the transition to regular smoking (17). The current state of the art in controlling tobacco use combines multiple environmental changes with multiple programs directed to individuals in different stages of the initiation and cessation processes. It recognizes that no single approach is best for all smokers and that different smokers are most attracted to and most affected by different programs (19).

\section{DEVELOPMENT OF A SMOKING CESSATION SELF-HELP MANUAL}

A national sample surveying 1,100 adult smokers in the Netherlands found that $29 \%$ of the sample intended to quit within the next 6 months (36). With a national population of 4 million smokers, it can be estimated that there are about $1,160,000$ smokers wanting to quit. However, in 1992 another survey showed that 200 group programs were carried out, reaching about 2000 smokers (37). Other studies also suggested that the vast majority of smokers prefer quitting on their own or with minimal assistance $(38,39)$. Therefore, there is a large group of Dutch smokers (around 1,158,000) wishing to quit, for whom smoking cessation self-help materials may be helpful.

To enhance the effectiveness of unaided or minimally assisted quit attempts, self-help manuals have been developed in the United States, teaching smokers skills and strategies to assist them stop smoking. Self-help materials have a number of advantages which make them a critical element in many comprehensive smoking cessation interventions: their acceptability to many smokers, their relatively low costs (40), and their potential to reach much more 
smokers than do clinical interventions. They also offer the opportunity to tailor messages to particular subgroups of smokers in a cost-effective way. For example, self-help materials can be focussed on various demographic groups or on smokers at different stages of readiness to change (35). Steps three and four of the behavior change phase of the $\mathrm{ABC}$-framework (7) incorporate the development of lacking materials, and pretesting them among the intended target groups. Since no comprehensive smoking cessation self-help materials were available in the Netherlands, a comprehensive development process for a Dutch self-help manual was designed in which pretesting was applied as a strategy to ensure optimal adjustment to the needs and preferences of the target group.

\section{Pre-test Route}

The development process of the self-help manual consisted of a number of phases in which concepts were produced, pre-tested and revised. This process is described in detail in chapter 3 of this dissertation. Target group participation was facilitated by involving two separate samples of the Dutch smoking population ( $n=177$, and $n=178$ ) who expressed interest in individual quitting, so that the content and presentation of the manual could be adjusted to suit their particular characteristics.

Eight experts in the field of health education and communication were consulted to evaluate the conceptualizations of theoretical principles applied in the manual. The manual distributed by the American Lung Association (ALA), 'Freedom from smoking, for you and your family' (41) was chosen as a model (with permission from the ALA) for the following reasons: it applied the most recent insights in smoking cessation, such as the stages of change theory (42), and principles of relapse prevention (32), and it had been pre-tested among target group members and experts in the U.S. (43). Cultural differences between the United States and the Netherlands were considered and it was decided to intensively pretest layout and illustrations of the Dutch self-help manual in order to comply with Dutch customs and preferences.

The pretests revealed that many elements of the American manual were not suitable for use in the Netherlands, and translation alone would have been insufficient. Thus, thorough adaptation of elements and replacement of sections was needed. Pretesting resulted in changes in the strategy of the manual as well as in the manner of addressing smokers and in lay-out matters. By checking whether the message contributed to the realization of the intervention goals, it was 
expected that pretesting would enhance the future effectiveness of the final version of the manual (44).

\section{Applications of the manual in community interventions}

Three community-based applications of the manual, are presented in chapter 3 of this dissertation: a community-based smoking cessation project in Den Bosch (of which the effect evaluation is reported in chapter 4 of this dissertation), a workplace smoking cessation project in one of the districts of the PTT-Telecom company, and a local health project 'Healthy Bergeyk' in a small municipality, which covered four risk behaviors including smoking. In all three applications, participants could chose between quitting on their own or participating in a group program. The smokers who preferred to quit on their own received a free self-help manual. The workplace project was the most effective in disseminating the manual: $24 \%$ of the smokers (155 manuals in 645 smokers) received a manual, versus $4 \%$ in Den Bosch (1,412 manuals in 33,000 smokers) and $1 \%$ in Bergeyk (37 manuals in 3,000 smokers).

Within the smokers who entered the three studies with the intention to quit, we found a $13 \%$ quit rate among smokers who requested the manual in Den Bosch (6 months follow-up), $8 \%$ in the PTT-Telecom workplace ( 3 months follow-up), and $18 \%$ in Bergeyk ( 6 weeks follow-up). For a comparison, Schwartz (30) reported a median quit rates of $17 \%$ in 11 self-help trials with at least 6 month follow-ups. In these trials, participants mostly had to pay for a manual, which might mean that the manuals were obtained by highly motivated smokers. The differences between the quit rates of the three projects may be caused by the variation in follow-up periods and also by the differences in efforts required to receive self-help manual. In the workplace project the effort required was minimal, as all smokers who indicated some interest in quitting were sent a manual, while in Den Bosch and Bergeyk, the smokers who wished to have a manual had to call or visit the referral point. The manual was evaluated positively by its users, and many of them stated that they would reuse the manual in future quit attempts.

An indicator for the existence of a specific target group for self-help manuals is that the vast majority of the applicants knew of the availability of a group program but still preferred the self-help method. It was concluded that the incorporation of pretesting in the development process of a self-help manual enhanced the probability of adoption of the manual by potential users. 


\section{EVALUATION OF A COMMUNITY-BASED SMOKING CESSATION INTERVENTION}

The fourth step in the behavior change phase of the ABC-framework (7) incorporates the evaluation of interventions that aim at behavior change in pilot studies. Topics in this evaluation are, among others, analysis of the process of implementation, determining its behavioral impact, and computing the costefficiency and cost-effectiveness of treatment modalities. Until 1990, only limited numbers of smokers were reached with smoking cessation information (45). It was hypothesized that the community approach is a strategy that has great potential to reach larger segments of the smoking population for sustained periods (46).

The goal of the studies reported in more detail in chapters 4 and 5 , is to analyze the results of a multi-media Dutch community-based smoking cessation intervention by describing the process of implementation, evaluating separate treatment modalities, determining the effectiveness in the general smoking population, and finally calculating the cost-efficiency and cost-effectiveness of treatment modalities.

\section{Implementation process of the intervention}

A treatment city (Den Bosch) and a control city (Apeldoorn), were employed. in the treatment city, a community inventory carried out by the research tearn in August 1989 led to the formation of a local steering committee, in which three local health care organizations agreed to participate: the Municipal Health Service (MHS), the Consultancy for Alcohol and other Drugs (CAD), and the Community Association for Home Care (CAHC). The committee was responsible for development and implementation of the intervention in cooperation with the research team. Although it was intended to complete the group with representatives of formal and voluntary community organizations, low involvement with health matters within these organizations blocked this plan.

The dissemination strategy incorporated local media, posters and the involvement of general practitioners in order to attract the attention of smokers and to motivate them to call a telephone quit-line. The quit-line was staffed with trained counsellors who advised smokers about the choice between modalities: a free self-help manual (44), or a three-week group program at $\$ 15$ (US-dollars). Telephone counselling was optional for all applicants, and general practitioners were intended to counsel patients whom they advised to quit in follow-up 
consultations. A brief protocol was developed to facilitate general practitioners to advise and counsel their smoking patients more effectively (47).

The intervention started in March 1990. Only incidental media attention was achieved in the local media. Posters and leaflets were send out to community and health centers. Although half of the 40 general practitioners in the treatment city signalled their interest in the protocol and received written instruction or optional training; very few of the smokers who were prompted by their physician called the quit-line, and few physicians conducted follow-up consultations. In total 1,412 manuals were disseminated and 118 smokers participated in a group program. To enhance dissemination of the self-help manual in health care consumers, the steering committee distributed self-help manuals among all cooperating general practitioners and the majority of the local pharmacies. The telephone quit-line answered 417 calls. Almost all calls on the quit-line resulted in either the sending of a self-help manual or participation in a group. Very few smokers addressed the quit-line for counselling.

During the study period, intensive mass media campaigns were conducted by both the Dutch government and the united tobacco producers with respect to the introduction of a mandatory smoking ban for public buildings. This introduction was unforeseen, since the smoking ban had been a topic of political debate since 1979.

\section{Effect evaluation}

The behavioral impact of the intervention at a population level was investigated through a population study, applying a random panel of smokers in the treatment city and a similar panel in the control city. The panel in the control city was potentially exposed to all national smoking cessation activities and messages such as a national quit-line and leaflets, while the panel in the treatment city was possibly exposed to the intervention messages and modalities as well. The population panels of initial smokers were subjected to three computer-assisted telephone interviews in October 1989, June 1990 and December 1990, which was the end of the study period. The base-line interview was conducted before the start of the development of the intervention to avoid the influence of conceivable media-coverage. The intervention caused modest but significant differences in awareness of the smoking population of modalities in favour of the treatment city, compared to the control city. However, the confounding media campaigns about the mandatory smoking ban in public buildings were significantly better known. In the treatment city $6-11 \%$ of the potential target population were 
actively reached by intervention elements (self-help manual, group program, physician advice, telephone quit-line).

To obtain an indication of the quality of the intervention, the effectiveness of two treatment modalities in the treatment city was examined in groups of participants. The results of the group program and the self-help manual showed post-six months results of respectively $22 \%$ and $13 \%$ abstinent rates, that are comparable to other studies (30).

On a population level, no differences were found between treatment and control city concerning numbers of quit attempts during the study $(44 \%$ in the treatment city and $46 \%$ in the control city) and abstinence at the end of the study ( $7 \%$ in the treatment city and $9 \%$ in the control city). However, success rates of first quit attempts differed between cities in two periods of the study: in the first 8 months of the study quit attempts in the control city were more successful, while in the second period of six months smokers in the treatment city were more successful. Since two-thirds of the intervention activities were conducted in the second period of the study, the differing success rates may suggest an intervention effect in the treatment city. However, logistic regression analysis did not confirm a possible intervention effect. Moreover, the absence of a relation between exposure to intervention elements and quitting behavior weakens the effect claim for the intervention.

Interventions may fail to reach their intended goals due to an inadequate diffusion, caused by intervention and implementation deficits. The theory of diffusion of innovations suggests five types of failures (48), of which innovation failure (ineffective materials and strategies) is the least likely to have occurred, since the results of treatment modalities were comparable to other studies. The intensive media coverage of the mandatory smoking ban and increased tobacco promotion may have caused a communication failure through desensitization of smokers for a local intervention. However, reach in the present study was comparable with other similar projects (see chapter 4). The limited reach of community-based smoking cessation interventions indicates partial adoption failure on the smokers level. Cooperation of only a part of the general practitioners, indifference of the local press and non-participation of social organizations in the steering group may demonstrate an adoption failure at an intermediate level. Monitoring of the implementation and the behavioral results of the modalities showed that the implementation of most of the elements and modalities was satisfactory, since all applicants were incorporated in group programs or received self-help manuals, according to their wish. However, a 
partly implementation failure occurred as a result of the failing media strategy and incorporation of only a part of the physicians. The intervention did obviously not succeed in raising awareness, and attracting greater groups of smokers. Although all intervention elements were provided on a regular basis within the implementation period of 10 months, the last failure, maintenance failure, occurred on the level of incorporation of various sectors of the local society which might have secured consolidation of the intervention and consequently may have led to long term maintenance (46).

A final conclusion emerges that present community-based intervention was comparable to other programs with respect to reach and modality outcomes, but that the occurrence of several implementation and methodological inadequacies on the one hand may have decreased the impact of the intervention and on the other hand may have muddled definite interpretation of a possible intervention effect on a population level.

\section{Cost-effectiveness of two smoking cessation modalities}

A special topic in the evaluation of behavior change interventions is the estimation of costs in relation with the behavioral outcomes of the intervention. In this study, a comparison was made between costs of the two treatment modalities of the community-based smoking cessation intervention in Den Bosch, that was described in the previous sections. Cost-efficiency and cost-effectiveness analyses are used for the comparative analysis of two or more programs or interventions, when outcomes cannot be valued in economic terms. In the case of smoking prevention, cost-efficiency ratios are often presented in terms of dollars per participant (49) and cost-effectiveness ratios in terms of dollars per quitter, since the evaluation of benefits of smoking cessation require costly long term cohort studies. In this study, costs were analyzed from two perspectives: the perspective of the local steering group that developed and implemented the program, and the perspective of participants in both modalities. Furthermore, characteristics of both groups of participants were compared and contrasted with a population sample of smokers in Den Bosch in order to explore the differential attraction of different types of programs, that was suggested by Elixhauser (50).

During 1990, 1412 self-help manuals were distributed in Den Bosch: 118 were used in the group program, 294 were requested on the quit-line for individual use, and 1000 were distributed via general practices and pharmacies. Since the behavioral outcomes of the latter dissemination strategy were not evaluated, cost- 
efficiency and cost-effectiveness analyses were limited to the group program and self-help manuals requested on the quit-line.

Program costs were seen as the extra costs that had to be made by the organizations participating in the steering group for the execution of the programs. Overhead costs, such as the organizational costs of these organizations, and the costs of the evaluation study were not taken into account, since this study was financed externally by the Dutch Cancer Foundation. For the comparison of both program modalities, we considered operating costs per modality, leaving out start-up costs that are not affected by the degree of implementation, and recruitment costs that were common to both programs (51). Participants' costs were the costs that participants incurred in order to participate in the treatment modality of their choice.

For the estimation of cost-effectiveness ratios, the $95 \%$ confidence intervals of the quitting rates were taken into account. In order to compare the costeffectiveness ratios of modalities conservatively, the most detrimental ratio for the self-help modality (based on $9 \%$ quit rate) was contrasted with the most advantageous cost-effectiveness ratio for the group program (based on 30\% quit rate). Costs per participant in the self-help condition were about 10 times lower than in the group condition, both from the perspective of the steering group $(\$ 6,33$ versus $\$ 59.18)$ and the participants $(\$ 15.20$ versus $\$ 165.18)$. The costeffectiveness of the self-help modality was over 3 times as high as the costeffectiveness of the group modality for both the steering group ( $\$ 66.47$ versus $\$ 199.53$ ) and the participants ( $\$ 159.60$ versus $\$ 556.89$ ).

Both smoking cessation modalities attracted different types of smokers: selfhelp was selected by 'easier quitters' (they had tried to quit less often, were less addicted to tobacco, and had significantly higher perceptions of self-efficacy, than did group program participants). Even when controlling for these differences, the self-help modality still was more cost-effective than the group program. For the steering group self-help than was at least 2.6 times as cost-effective, while for participants self-help was at least 1.9 times as cost-effective as the group program. The present study suggests that smokers are able to select modalities according to their needs when they are advised by trained counsellors and when a choice of different methods is offered. Moreover, the assertion that cost-effectiveness should not be the only criterion in policy-making and referral of smokers to treatment modalities is supported, since the segment of the potential target group that prefers a group program will probably not benefit from self-help modalities. Selecting the most cost-effective treatment thus would imply that this segment 
may be ignored. The present study suggests that 'easier quitters' can be referred to cost-effective self-help modalities. For this purpose, efficient and practical diagnostic instruments are to be developed.

\section{A NATIONAL MASS MEDIA LED SMOKING CESSATION CAMPAIGN: REACH AND EFFECTIVENESS}

In 1988, the DSHF formulated a strategy including campaigns to stimulate more smokers to quit, to meet the government goal of a smoking prevalence of $20 \%$ in the year 2000 (4). To facilitate large scale diffusion and use of the planned smoking cessation campaigns, the DSHF formed a national steering group. In retrospect, this group is a variation of a linkage group (see page 4). In this steering committee experts in the fields of smoking cessation and mass media, researchers, representatives from the DSHF, and a governmental representative embodied the resource system, while network delegates and health educators of local health services represented the user system.

Based on the results of a pilot study, the DSHF and the steering committee developed a mass-media-led smoking cessation campaign, which was implemented in 1991. A study was set up to evaluate exposure of smokers and non-smokers to the campaign, to determine the impact of exposure on smoking behavior, and to estimate the magnitude of the behavioral effects of the campaign. The campaign included the following elements:

1. 'Come on, Quit' TV shows: a series of 15 informative and entertaining TV shows, in which famous people tried to quit smoking, advised by experts, who also provided feedback about the advantages of quitting.

2. A TV clinic 'Quit Smoking': six weekly television and radio episodes. A matching manual (52), costing about US $\$ 10$, was available in bookstores or by mail. Six 'normal' everyday role-models discussed their quitting experiences on TV, and additional information was provided in the radio episodes.

3. Local group programs: 73 cooperating local and regional organizations (local health services, organizations for home care and regional cancer centers) conducted group programs, which cost about US $\$ 30$ and included 8 meetings in three weeks and a matching manual (53).

4. National Quit-line: every workday and on broadcasting evenings of the TV shows and the TV clinic, a national quit-line, staffed with trained counselors, was available. 
5. Publicity Campaign: Advertisements, posters, and leaflets were disseminated during the campaign to attract attention to the TV elements, the quit-line and the self-help manual (44) that could be ordered by mail. A special brochure was sent to general practitioners to inform them about the campaign and to offer them guide-lines for effective smoking cessation counseling.

The campaign ran during the first three months of 1991. The local group programs and the national quit-line were continued during 1991 and subsequent years.

\section{Effect Evaluation}

Exposure to campaign elements and behavioral impact were evaluated in a random sample of smokers of 15 years of age and older. This sample $(\mathrm{N}=1338)$ was subjected to three computer-assisted telephone interviews: a pretest before the start of the campaign (December 1990), and posttests after the campaign (April 1991 ) and after a 10 month follow-up (February 1992). Conceivable test effects of the pretest on exposure and cessation were examined by incorporating a second random sample of smokers $(N=508)$, who were only subjected to the posttest and follow-up. A random sample of non-smokers $(\mathrm{N}=521)$ was subjected to a pretest and posttest.

The campaign was noticed by most smokers and non-smokers, and correct recall of campaign elements was high: $55 \%$ of the smokers and $38 \%$ of the nonsmokers spontaneously recalled at least one element. Significantly more smokers were aware of the campaign and reported to have watched the TV-clinic broadcasts, than did non-smokers. Participation in the pretest (pre-campaign interview) enhanced awareness and exposure significantly, although the evidence was not consistent over all elements. Therefore, the exposure data obtained from the non-pretested group of smokers were used to estimate unbiased exposure and use of campaign elements.

Campaign elements covered $97 \%$ of the smokers at least once (based on selfreports). It was estimated from network ratings that $27 \%$ of the smokers watched at least one 'Come on, Quit' TV show, and that $7 \%$ watched at least one TV clinic episode. The educational TV-network sold 7,000 manuals (reaching $0.2 \%$ of the Dutch smokers). Furthermore, registrations showed that 1,300 smokers $(0.03 \%)$ participated in a group program and that the quit-line was called about 7,500 times $(0.18 \%)$. Estimates based on these objective measures revealed a $0.4 \%$ active participation among smokers. Self-reported exposure data led to substantial over-estimation of exposure. 
Twenty-nine percent of the pretested smokers and $21 \%$ of the non-pretested smokers tried to quit between pre- and posttest, resulting in $6 \%$ post-campaign abstinence in pretested smokers and $4 \%$ in non-pretested smokers. Follow-up abstinence was $10 \%$ in pretested smokers and $8 \%$ in non-pretested smokers. Exposure may have stimulated quit attempts and enhanced short and long-term abstinence, since significant dose-response relations were found suggesting positive relations between numbers of recalled elements and TV elements viewed at one side and quitting behavior at the other side. Furthermore, participation in the pretest enhanced quit attempts in the short term, especially in non-exposed smokers. However, the pretest did not bias the effectiveness of quit attempts and long term abstinence.

The evaluation of mass media campaigns incorporates unpreventable threats to internal validity (49). History (any other influence that might have caused cessation), secular trends (the percentage of smokers who would have quit anyway), and test-effects (sensitization of smokers by interviewing them), probably were the most important threats in this case. The incorporation of a comparable control group of whom beforehand was known that they would not be exposed, would have controlled these threats. However, in a small country as the Netherlands, national mass media have the potential to reach everyone, thus ruling out the possibility of such a control group. During the campaign no extraneous events were observed that might have caused (part of) the outcomes. Through subtraction of estimates of the secular trend $(2,5 \%)$, and the test-effect over the total study period (1\%), which were probably the most important threats, from the final cessation rate found in non-pretested smokers (the most conservative observation of abstinence), a conclusive campaign effect of $4.5 \%$ abstinence attributable to the campaign is estimated. In contrast with cessation rates in previous years, the results of the campaign are meaningful, especially in the light of the $72 \%$ raise in expenditures on tobacco promotion in 1991 . Compared with the results of the Chicago Televised Smoking Cessation Program (54), reporting a point-prevalence abstinence of $3 \%$ in a population panel after 12 month follow-up (not corrected for test-effects), the results of the present study are impressive. Positive dose-response relations between self-reported exposure and smoking cessation made the effect claim for the campaign more convincing and supported causal relations, although the non-preventable lack of a control group complicates conclusions. The effect of this campaign is also remarkable since no governmental control exists over the media in the Netherlands. Flay (55) suggests that this may be the main reason for the success of media interventions. 
The linkage approach led to the development and implementation of an effective mass media led campaign. Mass media approaches on a national level, completed with an individual feedback system (telephone quit-line) and activities on a local level, and the availability of various smoking cessation modalities incorporating varying degrees of guidance (from informative TV-shows to a group program), succeeded in reaching the majority of the Dutch smokers and probably established a larger coverage than when these channels would have been applied separately. The linkage approach also led to continuation, since the steering group exists until now, in a slightly different form.

\section{CONCLUSIONS}

Several major overall conclusions can be drawn from the studies presented in this dissertation. First, the reported studies covered aspects of the Analysis, Behavior Change and Continuation phases of the $\mathrm{ABC}$-framework (7). This framework helped to place studies into the perspective of planned health education. It has been shown that the quality of the planning process enhances positive outcomes of health education interventions $(56,57)$. The conclusions of the present studies may provide information for the planning process, and thus may contribute to the improvement of the outcomes of future smoking cessation interventions.

Second, the importance of self-efficacy as a predictor in the process of smoking cessation in group participants was ascertained. Major critique on the concept of self-efficacy was opposed (31). However, these results were found in group participants and may not be generalizable to other smokers. Group participants are in the preparation stage before the treatment starts, and in the action or relapse stages at the end of treatment, in terms of the transtheoretical theory (42). In precontemplators, those who do not intend to quit within six months, and contemplators who consider quitting within six months, lower levels of self-efficacy were found than in preparators and actors (58), indicating weaker relations between self-efficacy and cessation in precontemplators and contemplators.

Third, pretesting as a strategy in the development of a self-help manual helped to adjust the manual to smokers in the contemplation stage. It is hypothesized that precontemplating smokers foremost need attitudinal information about the health hazards of smoking and the advantages of quitting (58). Therefore, precontemplators may not benefit from the developed manual, since only limited 
attention in the manual is paid to these attitudinal information, and the focus is on self-efficacy enhancing information. For contemplating smokers in various settings, the efficacy of the manual was demonstrated.

Fourth, the steering committee that was formed in Den Bosch consisted uniquely of professionals. The community approach in Den Bosch did not succeed in activating social organizations or individual citizens to participate in the local steering group. This does not per definition mean that no results can be achieved, since the mass-media-led campaign, described in chapter 6, showed positive results while linkage was managed on a professional level. Because the majority of the Dutch smokers is in the stage of precontemplation (36), and nonsmokers may see smoking cessation as a problem that does not affect them, intersectoral participation of non-professionals may be difficult to obtain in a project that exclusively focusses on smoking cessation. Van Assema (59) reported intersectoral participation in a Dutch cancer prevention project in Bergeyk, aiming at four cancer related behaviors (smoking, excessive alcohol consumption, high fat consumption and use of solaria), suggesting that assessing a broader problem is a factor that may stimulate citizen participation in the planning and implementation of the project. However, citizen participation did not result in behavior changes on a population level in Bergeyk, except for a modest decrease in fat intake, that differed significantly from the decrease in a control community. A second difference between both projects is that Bergeyk is a much smaller community than Den Bosch. In larger communities, the degree of institutionalization probably is higher, as indicated by the results of a community inventory in Den Bosch revealing that citizens perceived planning and implementation of smoking cessation interventions to be tasks of the Municipal Health Service, in which citizens had no role. Furthermore, the 'sense of community' may be weaker among citizens in larger communities. These facts lead to the conclusion that community based interventions preferably do not focus on a single risk behavior that applies only to a part of the community, and that small scale communities, such as villages and neighborhoods, are more appropriate for this approach.

Fifth, principles of community projects, such as community participation and social network approach, are time-consuming (46), and thus cannot be fully developed in the time stretch of short term projects. Intensive mass-media attention is needed to establish an acceptable reach among the target group in a limited period of time. Although active self-reported participation (purchasing books or self-help materials, participating in groups, calling quit-lines) was higher 
in the community-based project (6-11\% versus $1.2 \%$ in the national mass media led campaign), the coverage of the media was substantially greater in the national campaign, with an almost total single coverage of the smoking population. In a small country as the Netherlands, the role of national mass-media may be more important than local or regional media. Moreover, there is a greater variety of national media than of local and regional media, demonstrated by the absence of local television in the Netherlands. Finally, free publicity, as intended in the community project, requires special skills from the implementors to deal with the media. In the national campaign, all intended media attention was either bought or subsidized by the DSHF, and the steering group incorporated media experts. Thus, incorporating the national mass media is essential in short term smoking cessation interventions to establish a broad reach among smokers. However, this requires sufficient resources (money and skills).

Sixth, mass media may reach a greater part of the precontemplators, than can be reached by community-based projects. Results of the national mass media led smoking cessation campaign indicated that in the group of base-line precontemplators $22 \%$ advanced one or more stages (36). In this group $5 \%$ was abstinent after the campaign and $10 \%$ was abstinent 10 months later. Although comparison with cessation rates in previous years within precontemplators cannot be made, because these data are not available, this evidence suggests that substantial progress can be achieved in this group, and that precontemplators can shift via contemplation to action in a relatively short period of time. Consequently, mass media approaches can produce a greater behavioral impact on precontemplators within the period of a campaign, than more intensive interventions that mainly reach contemplators. Relapse prevention strategies included in the intervention and ideally provided on a long term basis, are essential for maintaining the positive results. Since very few smokers actively participated in modalities of the national mass media led campaign, the substantial cessation result was foremost accomplished in individual quitters, who only were exposed to media messages. This underlines the importance of media attention in smoking cessation programs, because media obviously can reach smokers who do not wish to, or are not able to participate in more intensive cessation modalities.

Finally, cost-effectiveness evaluation of self-help versus group treatment (see chapter 5) showed that for participants the costs of interventions obviously are merely one of the criteria in the selection of treatments. The more expensive group treatment attracts more women, addicted smokers, and those with low self- 
efficacy levels. For policymakers and implementors, cost-effectiveness should not be the only criterion. Although self-help is at least twice as cost-effective as group treatment, both modalities attract different segments of the potential target group. Selecting the most cost-effective self-help modality would probably not serve the segment of the potential target group that prefers a group program. In general, cost-effectiveness of smoking cessation interventions is rather low, compared to low-cost policy measures, such as price measures, that can potentially have substantial effects on smoking prevalence $(50,60)$.

\section{METHODOLOGICAL LIMITATIONS}

The various studies presented in this dissertation suffer from collective methodological shortcomings. First, no physical validation measures of smoking behavior, such as cotinine or CO-appraisals, were taken. However, a metaanalysis of studies validating self-reported smoking supports the accuracy of selfreports of abstinence in intervention studies when questionnaires are interviewer administered (61). Moreover, Murray, Connett, Lauger and Voelker found recently only very small error in post 1-year follow-up self-reported smoking status in an intervention trial (62).

Second, the designs of the studies showed deficiencies with respect to controlling for the possible history effects (49). In the community study a larger sample of communities in both conditions, and in the mass media study the incorporation of a matching control group of whom beforehand was known that they would not be exposed, would have greatly improved the validity of the studies. Shared deficits of both designs are the limited amount of measurements and limited study time periods. A time-series design, stretched over a sustained period of time, would have contributed to the validity of the studies. However, financial constraints hindered the realization of more post-tests in the various studies.

Third, the effects of pre-campaign measurement on behavior change, as found in the mass-media study, may also have influenced the assessments of behavior change in the self-efficacy study (chapter 2) and the community-based study (chapter 3), and thus may have enhanced the quitting rates in these studies. At the other hand, measurement induced change may have weakened the strength of relations between predictors (e.g., self-efficacy, exposure to intervention elements) and behavior change, since a part of the change might not be brought on by a 
change in the determinants but by the test. Moreover, on first sight a contradiction can be seen in the sensitization of smokers by participation in a pre-campaign interview and desensitization by massive media attention for a mandatory smoking ban. However, the information that smokers received during the national mass-media-led campaign may have been helpful for quitting, while the smoking ban campaigns did not provide any smoking cessation information. These smoking ban campaigns may even have caused reactance because a favored behavior was prohibited.

Fourth, in the evaluation studies evidence for a dose-response relationship was sought by partioning the experimental sample by level of exposure. The doseresponse relationship as found between exposure and behavior change in the mass media study was supposed to support the hypothesis that behavior change was caused by the intervention. However, it should be kept in mind that such a result does not rule out the rival hypothesis of self-selection, i.e., those who selectively attend to a message could be those who spontaneously change (63).

Fifth, self-reported exposure probably resulted in over-estimation. Checking self-reported viewing rates, book sales and calls on a quit-line, with objectively obtained measures (through network ratings and registrations of actual book sales and calìs̀), reveàed that sèlt-reports were substantially overreported. This misperception may have led to the fact that in the community study, where no objective data were available for comparison (see chapter 4), no relation was found between exposure and behavior change,

Finally, most measures were taken through telephone interviewing. This resulted in samples which were not quite comparable to the Dutch smoking population. More women were interviewed, probably because they spend more time at home in the Netherlands, since a substantial part of the women in the Netherlands are homemakers. Moreover, telephone interviewing may have resulted in more impulsive answering strategies, because in order to advance quickly through the questionnaire, answers had to be provided instantly. Moreover, not having questions in writing may affect subjects' comprehension of the questions.

\section{IMPLICATIONS FOR FUTURE. SMOKING CESSATION PROGRAMS}

Since the community-based intervention was only implemented in one city, and the planning and implementation process were just partially successful, several 
suggestions emerge. The experienced difficulties in the incorporation of citizens, target group members and social organizations in the planning and execution of the local smoking cessation program, may suggest that a community approach is less suitable for interventions that address a single behavior. In future, community-based smoking cessation may be 'wrapped' in a broader context to make programs more acceptable to a larger segment of the target group, and to non-smokers in order to acquire their cooperation in the planning and implementation of community projects. Moreover, larger communities, in which the sense of community may be weak, may be divided in smaller more coherent parts.

Furthermore, a linkage approach in the development and implementation of a national mass media led campaign was found to be successful, and is therefore recommended for future campaigns. For local programs, more skills may be required for health educators, or other members of organizing steering groups, to incorporate local media, since adequate media coverage appeared to be essential to attract a major part of the target group in smoking cessation projects. On a national level, in the presented campaign the networks cooperated because the topic of smoking cessation co-incidently fitted into their programming at that time, and because the DSHF provided additional funding for the development of TV programs. When these prerequisites are not fulfilled, it might be difficult to secure mass media attention. Since the DSHF's resources are limited, and TV networks will only occasionally be interested in broadcasting smoking cessation programs, the type of mass media led campaigns with respect to smoking cessation may only be accomplished now and then. Furthermore, the linkage approach contributed to continuation of smoking cessation projects. The steering group exists until now, and interventions for various target groups were developed and implemented after the reported campaign. Moreover, a network of local health services and cross organizations is established that implements local group programs on a regular basis, and interventions were executed to stimulate the health care workers to quit smoking and to stimulate their patients to quit.

Since different types of interventions reach different groups of smokers, interventions may be more effective when tailored towards specific target groups. A feature for tailoring may be stage of change, e.g., precontemplators may need attitudinal information about the advantages of quitting, while contemplators may benefit more from skills training. Demographic variables, such as education or gender, can also be ground for tailoring, as can be motivational level, e.g., pregnant women may have quite other reasons for quitting smoking than 
workers with toxic agents. Furthermore, interventions can be tailored to the intermediates or implementors that are intended to use the intervention in future, for instance general practitioners can disseminate self-help materials.

The diffusion of effective program modalities deserves more attention. In the context of both described interventions, effective program modalities have been developed, such as the self-help manual and the TV-clinic, that can be applied in different settings. As a start, the self-help manual was adapted to patients of general practitioners and workers. Both versions are currently applied in research projects that focus on the effectiveness of dissemination strategies. A project to adapt self-help materials for pregnant women and their partners, and to distribute these materials through general practitioners and midwives, has been funded.

The presented studies showed that only a very limited part of the potential target population for smoking cessation activities, is interested in participating actively in smoking cessation modalities. Therefore, the intensity of cessation guidance, such as group programs, counseling by health workers and direct mail, should be experimented with. Non-intrusive methods, such as TV shows or a TV clinic, may have larger potentials than clinical approaches.

Although new directions in the development and implementation of smoking cessation strategies were suggested $(17,64)$, others question the potential magnitude of smoking cessation interventions (65). Supporting policies are crucial for their potential impact on smoking prevalence. The role of the Dutch government has been disappointing until now (5), leaving the tobacco industry practically all possibilities to promote and sell their products, hardly regulating the composition of tobacco products, not fully applying the instrument of price measures, and only partially protecting non-smokers for exposure to environmental tobacco smoke at the one hand, while spending only very limited amounts for tobacco control, and not making clear where the substantial tobacco taxes are allocated on the other hand. In developed countries, tobacco is already causing two million death per year while elsewhere the epidemic is generally at an earlier stage (19). The persisting paradox in tobacco control in the Netherlands contributes to the growing worldwide epidemic of premature death from tobacco. 


\section{REFERENCES}

1. Stichting Volksgezondheid en Roken. Jaarverslag 1993. 's-Gravenhage, NL: Stichting Volksgezondheid en Roken, 1994.

2. Rice DP, Hodgson TA, Sinsheimmer P, Browner W, Kopstein AN. The economic costs of the health effects of smoking, 1984. Milbank Q 1986;64:489-547.

3. Oster G, Colditz GA, Kelly NL. The economic costs of smoking and benefits of quitting for individual smokers. Prev Med 1984;13:377-89.

4. Tweede Kamer. Nota 2000, Gezondheid als uitgangspunt. Vergaderjaar 1985-1986, kamerstuk 19 500, nrs 1-2-3. 's-Gravenhage NL, 1986.

5. Dresscher I, Elzinga A, Koldenhof E. Evaluatie tabakswet en zelfregulering tabaksreclame. Leiden, NL: Research voor Beleid BV, 1991.

6. Green LW, Kreuter MW. Health promotion planning, an educational and environmental approach. Mountain View CA: Mayfield Publishing Company: 46.

7. De Vries $\mathrm{H}$. The $\mathrm{ABC}$ of health education and planning; a brief reader for the summer university course. Maastricht, NL: Department of Health Education, University of Limburg, 1993.

8. Ajzen I. Attitudes, personality and behavior. Milton Keynes: Open University Press, 1988.

9. De Vries H, Dijkstra M, Kuhlman P. Self-efficacy: The third factor bedsides attitude and subjective norm as a predictor of behavioral intentions. Health Educ Res, 1988; 3:273-82

10. Janz NK, Becker MH. The health belief model: A decade later. Health Educ Q 1984;11:1-47.

11. Bandura A. Social foundations of thought and action. Englewood Cliff, NJ: Prentice-Hall, 1986.

12. Schwarzer R. Sel-efficacy in the adoption and maintenance of health behaviors: Theoretical approaches and a new model. In: Schwarzer R, editor. Sel-efficacy: Thought control of action. Washington: Hemisphere Publishing Corporation, 1992: 217-63.

13. Kok GJ. Gedragsmodellen in patiëntenvoorlichting. In: Damoiseaux V, Visser APh, editors. Patiëntenvoorlichting, een interdisciplinaire benadering. Assen/Maastricht NL: Van Gorkum, 1988:61-71.

14. McGuire WJ. Persuatio, resistance and attitude change. In: Pool LS, Schramm W, editors. Handbook of Communication. Chicago: Rand McNally, 1973:216-52.

15. Cummings KM, Sciandra R, Carol J, Bergess S, Tye JB, Flewelling R. Approaches directed to the social environment. In: Shopland DR, Burns DM, Samet JM, Gritz ER, editors. Strategies to control tobacco use in the United States: A blueprint for public health action in the 1990's. U.S. Department of Human Services, Public Health Service, National Institutes of Health, National Cancer Institute, NHI Publication No. (NIH) 92-3316, 1991: 203-65.

16. Orlandi MA, Landers C, Weston R, Haley N. Diffusion of health promotion innovations. In: Glanz K, Lewis FM, Rimer B, editors. Health Behavior and Health Education: Theory, Research and Practice. San Fransico CA: Jossey-Bass, 1990: 288-313.

17. U.S.Department of Health an Human Services. Reducing the Health Consequences of Smoking: 25 years of Progress. A report of the Surgeon General. U.S. Department of Health and Human Services; Public Health Service; Centers for Disease Control; Centre for Chronic Disease Prevention and Health Promotion; Office on Smoking and Health. DHHS Publications No. (CDC) 89-8411, 1989.

18. Voorlichtingsbureau Sigaretten en Shag. Jaaroverzicht 1989. Den Ha2g NL: Voorlichtingsbureau Sigaretten en Shag: 4. 
19. Peto R, Lopez AD, Boreham J, Thun M, Heath C. Mortality from tobacco in developed countries: Indirect estimation from international vital statistics. Lancet 1992;339:1268-78.

20. U.S.Department of Health, Education and Welfare. Smoking and Health: A report of the Surgeon General. U.S. Department of Health, Education and Welfare; Public Health Service; Office of the Assistant Secretary for Health; Office on Smoking and Health. DHEW Publication No. (PHS) 79-50066, 1979.

21. U.S.Department of Health an Human Services. The Health Consequences of smoking: Chronic Obstructive Lung Disease. A report of the Surgeon General, 1984. U.S. Department of Health and Human Services. DSSH Publications No. (PHS) 84-50205, 1984.

22. U.S.Department of Health an Human Services. The Health Consequences of Involuntary Smoking: A report of the Surgeon General. U.S. Department of Health and Human Services; Public Health Service; Centers for Disease Control. DHHS Publications No. (CDC) 87-8389, 1986.

23. U.S.Department of Health an Human Services. The Health Consequences of Smoking: Cancer and Chronic Lung Disease in the Workplace. A report of the Surgeon General. U.S. Department of Health and Human Services; Public Health Service; Office on Smoking and Health. DHHS Publications No. (PHS) 85-50207, 1985.

24. Kavanagh DJ, Pierce J, Lo SK, Shelley J. Self-efficacy and social support as predictors of smoking after a quit attempt. Psychol and Health 1993;8:231-42.

25. Breteler MHM, Mertens EHM, Rombouts R. Motivation to change smoking behavior: A revised model. In: Breteler MHM. Smoking cessation: Some determinants of motivation and success [Dissertation]. Nijmegen NL: University of Nijmegen, 1988:93-106.

26. Strecher VJ, DeVellis BM, Becker MH, Rosenstock IM. The role of self-efficacy in achieving health behavior change. Health Educ Res 1986;13:73-91.

27. Carey MP, Snel DL, Carey KB, Richards CS. Self-initiated smoking cessation: A review of the empirical literature from a stress and coping perspective. Cogn Ther Res 1989;13:323-41.

28. Coletti G, Supnick, JA, Payne TJ. The smoking self-efficacy questionnaire (SSEQ): Preliminary scale development and validation. Behav Assess 1985;7:249-60.

29. Strecher VJ, Becker MH, Kirscht JP, Eraker SA, Graham-Tomasi RP. Evaluation of a minimalcontact smoking cessation program in a health care setting. Patient Educ Counselling 1986;7:395407.

30. Schwartz JL. Review and Evaluation of Smoking Cessation Methods:The United States and Canada, 1978-1985. U.S. Department of Health and Human Services; Public Health Service; National Institutes of Health; National Cancer Institute. NIH Publications No. 87-2940, 1987.

31. Biglan A. A Behavior-analytic critique of Bandura's self-efficacy theory. Behav Analyst 1987;10:115.

32. Marlatt GA, Gordon JR. Relapse prevention: Maintenance strategies in the treatment of addictive behaviors. New York, London: Guildford Press, 1985.

33. Försterling F. Attribution theory in clinical psychology. Chichester, UK: Wiley \& Sons, 1988.

34. Kok GJ, Den Boer D-J, De Vries H, Gerards F, Hospers HJ, Mudde AN. Self-efficacy and attribution theory in health education. In: Schwartzer R, editor. Self-efficacy: Thought control of action. Washington: Hemisphere Publishing Corporation, 1992:245-62.

35. Edmundson E, McAllister A, Murray D, Perry C, Lichtenstein E. Approaches directed to the individual. In: Shopland DR, Burns DM, Samet JM, Gritz ER, editors. Strategies to control tobacco use in the United States: A blueprint for public health action in the 1990's. U.S. 
Department of Human Services, Public Health Service, National Institutes of Health, National Cancer Institute, NHI Publication No. (NIH) 92-3316, 1991:147-99.

36. Mudde AN, Dolders MGT, De Vries H. Publieksevaluatie van de Actie: Volwassen bevolking. In: Baan B, Breteler MHM, Van der Rijt GAJ, editors, Evaluatie van de actie 'Samen stoppen met roken', 30 december $1990-7$ april 1991. Den Hazg NL: Stichting Volksgezondheid en Roken, 1994:22-44.

37. Stichting Volksgezondheid en Roken. Jaarverslag 1992. 's-Gravenhage, NL: Stichting Volksgezondheid en Roken, 1993.

38. Schwartz JL, Dubitzky M. Expressed willingness of smokers to try 10 smoking withdrawal methods. Public Health Rep 1967;82:855-61.

39. Owen N, Davies MJ. Smokers' references for assistance with cessation. Prev Med 1990;19:424-31.

40. Epstein LH, Grunber NE, Lichtenstein E, Evans RI. Smoking research: Basic research, interventions, prevention, and new trends. Health Psychol 1989;8:705-22.

41. Strecher VJ, Rimer B. Freedom from smoking for you and your family. American Lung Association, 1987.

42. Prochaska PO, DiClemente CC. Stages and processes of self-change of smoking: Toward an integrative model of change. J Consult Clin Psychol 1983;51:390-5.

43. Strecher VJ, Rimer BK, Monaco KD. Development of a new self-help guide 'Freedom from smoking for you and your family.' Health Educ Q 1989;16:101-12.

44. Mudde AN. Van het roken af. Maastricht NL: Universitaire Pers, 1989.

45. Kok GJ, Mudde AN. The effectiveness of smoking cessation education. In: Liedekerke PC, Jonkers R, De Haes WFM, Kok GJ, Saan JAM, editors. Effectiveness of Health Education: Review and analysis. Assen NL: Van Gorkum, 1990:87-88.

46. Bracht N. Introduction. In: Bracht $\mathrm{N}$, editor. Health promotion at the community level. Newbury Park: Sage, 1990:19-25.

47. Mudde AN, Willemsen MC. Help uw patienten van het roken af. Masstricht NL: University of Limburg, 1989.

48. Orlandi MA, Landers C, Weston R, Haley N. Diffusion of health promotion innovations. In: Glanz K, Lewis FM, Rimer BK, editors. Health behavior and health education: Theory, research, practice. San Francisco: Jossey Bass 1990:288-313.

49. Green LW, Lewis FM. Measurement and evaluation in health education and health promotion. Mountain View CA: Mayfield Publishing Company, 1986.

50. Elixhauser A. The cost of smoking and the cost-effectiveness of smoking-cessation programs. J Public Health Policy 1990;summer:218-37.

51. Drummond MF, Stoddart GL, Torrace GW. Methods for the economic evaluation of health care programs. Oxford UK: Oxford Press, 1987.

52. Mudde AN, Zeeman, G. Stoppen met roken. Utrecht NL: Teleac, 1990.

53. Zeeman G, Aluoch L. Kursusboek voor het stoppen met roken. Bosch en Duin, NL: Stichting Leven en Gezondheid, 1984.

54. Flay BR, Gruser CL, Warnecke RB, Jason LA, Peterson P. One year follow-up of the Chicago Televised Smoking Cessation Program. Am J Public Health;1989;79:1377-80.

55. Flay BR. Mass media and smoking cessation: A critical review. Am J Public Health 1987;77:153. 60.

56. Liedekerke P, Jonkers R, De Haes WFM, Kok GJ, Saan JAM. Effectiveness of health education. Assen NL:Van Gorkum/Uitgeverij voor Gezondheidsbevordering BV, 1990. 
57. Mullen PD, Green LW, Persinger GS. Clinical Trials of patient education for chronic conditions: A comparative meta-analysis of intervention types. Prev Med 1985;14:753-781.

58. De Vries $\mathrm{H}$, Backbier E. Self-efficacy as an important determinant of quitting among pregnant women who smoke: The Ø-pattern. Prev Med 1994;23:167-74.

59. Van Assema P, Steenbakkers M, Kok GJ, Eriksen M, De Vries H. Results of the Dutch community project 'Healthy Bergeyk'. In: Van Assema P. The development, implementation and evaluation of a community health project [Dissertation]. Maastricht NL: University of Limburg, 1993:81-95.

60. Warner KE. Health and economic implications of a tobacco-free society. JAMA 1987; 258:2080-6.

61. Patrick DL, Cheadle A, Thompson DC, Diehr P, Koepsell T, Kinne S. That validity of selfreported smoking: A review and meta-analysis. Am J Public Health, 1994;84:1086-94.

62. Murray RP, Connett JE, Lauger GG, Voelker HT. Error in smoking measures: Effects of intervention on relations of cotinine and carbon monoxide to self-reported smoking. Am J Public Health 1993;83:1251-7.

63. Flay BR, Cook RD. The evaluation of media-based prevention campaigns. In: Rice R, Pailey W, editors. Public communication campaigns. Beverly Hills CA: Sage, 1981:239-64.

64. Lichtenstein E, Wallack L, Pechacek TF. Introduction to the community intervention trail from smoking cessation (COMMIT). Int Q Community Health Educ 1990-91;11:173-85.

65. Lando HA. Toward a comprehensive strategy for reducing the health burden of tobacco. $\mathrm{Br} \mathrm{J}$ Addict 1991;86:649-52. 


\title{
SELF-EFFICACY AS A PREDICTOR \\ FOR THE CESSATION OF SMOKING: \\ METHODOLOGICAL ISSUES AND IMPLICATIONS \\ FOR SMOKING CESSATION.
}

\author{
Aart N. Mudde, Gerjo Kok \& Victor J. Strecher \\ Accepted for publication in Psychology and Health, 1995;10.
}

\section{ABSTRACT}

A prospective study focused on self-efficacy as a predictor for smoking cessation. Subjects were 123 Dutch participants in a 3-week smoking cessation group program. Before and after treatment perceived self-efficacy was measured by questionnaire. Three measures related to self-efficacy were used: a 17-item perceived ability scale (PAS), a 10-item perceived difficulty scale (PDS), and a 1-item perceived ability measure (1-item PAM). Smoking behavior was assessed through self-report at pre-and post-treatment, and after 6-weeks and 1-year follow-up periods.

Pre-treatment perceived difficulty was a predictor for short-term cessation, while post-treatment perceived ability predicted long-term abstinence for post-treatment successes. The 1-item PAM was the strongest predictor, which may indicate that asking respondents to include every possible situation in their answer to a 1-item PAM is an effective conceptualization of the dimension 'generality' of self-efficacy. The results of factor analyses on the items of pre-and post-treatment self-efficacy scales suggested sub-scales of which the 'negativelaffective' subscale of the PAS and the 'negativelmoodstates' sulscale of the PDS were the strongest related with future abstinence. Based on the results, implications for interventions on how to improve smokers' perceptions of self-efficacy will be discussed.

\section{INTRODUCTION}

Smoking cessation is a long-standing issue in health education. Research shows that the effectiveness of health education activities is determined by the quality of the planning process $(1,2)$. An important step in this planning process is the analysis of the determinants of the behavior on which the education will focus $(3,4)$. In this article we will concentrate on self-efficacy as a determinant of short and long-term effectiveness of the cessation of smoking.

According to Bandura (5), a change in belief about one's ability to successfully execute a given action mediates the initiation and maintenance of behavior 
change. Self-efficacy expectations are supposed to be based on the person's experiences with the behavior, observations of others performing the behavior, teaching or persuasion by others, and physiological information (e.g. nervousness). Self-efficacy expectations are to be distinguished from outcome expectations and program-efficacy (6). Outcome expectations consist of beliefs about whether a given behavior will lead to given outcomes, whereas program-efficacy reflects the estimated effectiveness of a program in helping a person to reach the intended behavioral goal.

Studies of self-efficacy in the area of smoking cessation have been numerous (for review see: 7,8), and several studies emphasized the predictive value of selfefficacy for behavior change among treatment participants. The consensus of these studies is as follows: pre-treatment self-efficacy was generally not predictive for smoking status after treatment. Self-efficacy increased during treatment and therapies of different types $(9,10)$. Post-treatment self-efficacy of subjects who were abstinent after treatment was significantly higher than self-efficacy of those who were not successful. Post-treatment self-efficacy expectations were significant predictors for short-term maintenance of smoking cessation (three to six months after treatment) (9,11-13). This relationship held true even when post-treatment smoking status was controlled for and only subjects, who were abstinent after the treatment, were included (14-16). For self-quitters the predictive power of selfefficacy may even be stronger. Gritz, Berman, Bastani and Wu (17) found that self-efficacy predicted long term abstinence (12 and 18 months) as a result of selfinitiated quit attempts in a group of female smokers.

\section{Conceptualizing self-efficacy for smoking cessation}

Bandura (5) argued that self-efficacy expectations vary along dimensions of magnitude, generality and strength. Each of these dimensions implies different measurement procedures. Magnitude refers to the ordering of tasks by difficulty level. In smoking cessation research, problems arise in the application of this dimension, since smoking situations and corresponding coping responses are not easily arranged into a standard hierarchy of related steps of increasing difficulty. Researchers tackled this problem by measuring ratings of perceived difficulty of refraining from smoking $(18,19)$, presuming that the individual rates the perceived difficulty of the individually relevant coping responses.

The second dimension, generality, concerns the extent to which efficacy expectations about a specific situation can be generalized to other situations. To 
evaluate generality researchers include various samples of the multitude of situations in which smoking occurs $(18,20-22)$.

The third dimension, strength, refers to a judgement of how certain one is of one's ability to refrain from smoking. This dimension has been assessed in most studies. Subjects were asked to rate their confidence on a scale from minimum to maximum certainty $(5,10,16,20,22)$.

\section{Subscales of self-efficacy measures}

DiClemente (23) concluded that, although the scales in various studies differed, there were important similarities between them. The internal consistency of these scales was very high (alpha's were .95 or higher). Principal-component analyses of the scales generally yielded a powerful first component that was responsible for most of the variance accounted for by the scales. Thus there appears to be a general self-efficacy for non-smoking, rather than many separate, situation-specific categories (23).

However, Velicer, DiClemente, Rossi and Prochaska (24) found through structural modeling of multi-item confidence and temptation scales, that for subjects in the stages of action and relapse a hierarchical model, consisting of three primary factors and one second order factor, provided a very good fit to their data. The results for both confidence and temptation scales were essentially the same. The primary factors were labeled 'Positive/Social', 'Negative/Affective' and 'Habit/Addictive'. The second order factor was interpreted as a general level of confidence, which may exist across different situations.

\section{Purpose of this study}

The primary purpose of this study is to assess the predictive value of pre- and post-treatment self-efficacy for short and long-term smoking cessation of participants in a group program. A secondary goal is to determine which of three measures, representing combinations of the three dimensions of self-efficacy as proposed by Bandura (5), is the strongest predictor for cessation. The utilized measures were: 1) a perceived difficulty scale (18), representing magnitude and generality; 2) a perceived ability scale (20) exemplifying generality and strength; and 3) a 1-item perceived ability measure incorporating conceivably the generality dimension by means of an instruction to include every possible situation in the confidence rating, that embodied the strength dimension. A third aspiration of the present study is to detect subscales of the applied self-efficacy scales and to assess their predictive powers. 


\section{METHOD}

\section{Sample and design}

Enrollers in five groups of a standard three-week smoking cessation program in different Dutch cities were asked to participate in this study. Group sizes varied between 10 and 39 participants. Six enrollers did not wish to take part in this study. Measures were obtained by questionnaire at pre- and post-treatment and after follow-up periods of six weeks and one year after treatment. The pretreatment questionnaire was handed out and completed by 123 subjects at the beginning of the first meeting. The post-treatment questionnaire was filled in at the end of the last meeting. Follow-up questionnaires were mailed to participants.

\section{Treatment}

Treatment was a standard smoking cessation group program based on the 'Five Day Plan' (25). The Life and Health Foundation of the Dutch Seventh Day Adventists Church constituted a network of trained group counselors who provided this program in a group format (about 25 participants per group) in approximately 15 cities per year in the Netherlands. No religious messages or obligations were part of the program. Smokers were invited through advertisements in local newspapers to visit an introductory meeting, in which they received information about the program and where they could sign up for participation.

The most important standards of the program were:

* quitting in the first meeting;

* concentrating on one's own potential to fight addiction through willpower;

* preparing for the physiological consequences of cessation.

The program consisted of 7 meetings of 90 minutes each in the evenings, spread over 3 weeks: 4 meetings in the first week, 2 meetings in the second week and 1 meeting in the third week. All group meetings had the following components:

* Group discussion assessing participants' experiences in trying to maintain abstinent during the preceding period;

* Information about such themes as 'What smoking does to the body', 'How to minimize physiological consequences of quitting through diet', etc.; 
* Group discussion, addressing participants' attitudes toward non-smoking and expectations for the next period.

A physician provided complementary information about health matiers in the third meeting, and a dietician advised on preventing weight gain in the seventh meeting.

Enhancing self-efficacy was not the focus of this program. Although certain components of the program were likely to enhance self-efficacy, no specific attention was paid to skill-training or obtaining adequate coping responses. The possibility of relapse, and how to handle it when it occurred, received little attention.

Participants received a handbook (26) that contained all the information that was communicated during the meetings. Three weeks after the last meeting, an optional meeting provided the opportunity to exchange experiences. The costs of the program were about $\$ 50$ (U.S. dollars), of which half was refunded if the result of the program was negative, and all meetings were attended.

\section{Measures}

Smoking behavior: assessments of smoking behavior were realized by self-report. A non-smoker was defined as not having smoked even one puff during the last seven days before the measurement. In every questionnaire subjects who were smokers at that time, were asked to rate the average daily consumption of cigarettes. To gain insight in relapse patterns subjects were asked at post-treatment and after 6-weeks follow-up to report on which day(s) they smoked how many cigarettes. After one year follow-up, smoking behavior in the past year was assessed by an open-ended question 'How would you describe your smoking behavior in the past year?' (e.g. in which month did you start smoking, do you smoke regularly, did you try to quit again, etc.).

Self-efficacy: three instruments to assess self-efficacy were applied in pre- and post-treatment questionnaires.

1. A translated and adapted version of the 'Smoking Self-Efficacy Questionnaire' developed and validated by Coletti et al. (20). This measure assesses the perceived ability to resist the urge to smoke in seventeen different situations. In the following the Perceived Ability Scale will be referred to as the PAS. Internal consistency scores $(\alpha)$ of .90 at pre-treatment and .91 after a treatment of 3 weeks were reported by Coletti and colleagues (20). The original scaling procedure was simplified into a five-point scale. Options were 1 'absolutely not', 2 'yes, perhaps', 3 'yes, probably', 4 'yes, almost certainly' and 5 'yes, certainly'. The 
overall mean of scores on the seventeen items was considered as a subjects' PAS score. When six or more items were not answered, the PAS score was missing. 2. A translated version of a ten-item perceived difficulty scale, developed by Strecher et al. (18). In the following this scale will be referred to as PDS (perceived difficulty scale). Subjects were asked to rate the perceived difficulty of refraining from smoking in ten different situations and mood states. Answers were scored on a three-point scale, with options 1 'much difficulty', 2 'some difficulty' and 3 'no difficulty'. The overall mean of scores on the ten items was considered as a subjects' PDS score. When four or more items were not answered, the PDS score was missing. Strecher at al. (18) reported an $\alpha$ of .80 in a pre-treatment assessment.

3. A one-item perceived ability measure, with the same format as the questions in the PAS. Subjects were asked to rate their perceived ability to resist the urge to smoke in every possible situation. This measure will be referred to as 1-item PAM (perceived ability measure) in the following.

An instruction was added to pre-treatment self-efficacy question to minimize the effect of program-efficacy expectations on subjects' designation of pretreatment self-efficacy. This instruction was designed by Condiote \& Lichtenstein (1981). Respondents should imagine that they were trying to quit smoking on their own, without professional assistance.

Demographic variables: data on age and gender were obtained at pre-treatment.

\section{Missing data}

In smoking research various methods of handling missing data are used. In this study a solution derived from survival analysis was applied. Once data from a participant were missing at follow-up, he or she was considered missing and smoking for the remaining of the study. Thus non-respondents were classified as smokers. The use of this method indicates a strict criterion of success.

\section{RESULTS}

\section{Sample characteristics}

Subjects were on average 43.2 years of age $(S D=11.2)$, and $42 \%$ of them were female. The mean daily cigarette consumption was 25.5 cigarettes per day $(S D=14.4)$. When comparing the subjects in this study to the Dutch smoking population (27), female and heavy smokers appeared to be over represented. 
Comparable programs in the Netherlands have been shown to attract similar groups of participants (28).

\section{Response and attrition analysis}

Response rates were $80 \%(n=99)$ at post-treatment, $68 \%(n=84)$ at post 6-weeks and $50 \%(n=62)$ at post 1-year follow-up (see figure 1). There were no significant differences found between pre-treatment measures concerning smoking behavior, self-efficacy or demographic variables of participants who did and who did not complete the second questionnaire.

However, drop-outs from the study during six-weeks follow-up $(n=22$, of whom 10 were post-treatment abstainers and 12 were post-treatment smokers) smoked more cigarettes before treatment $(F(1,97)=5.13, \mathrm{p}<.05)$, had lower posttreatment PAS scores $(\mathrm{F}(1,97)=5.26, \mathrm{p}<.05)$, and lower pre-treatment PDS scores $(F(1,96)=6.01, p<.05)$ than respondents of the post 6-weeks follow-up assessment $(\mathrm{n}=84)$.

Drop-outs during the one-year follow-up ( $n=24,9$ were post 6-weeks followup abstainers and 15 were post 6-weeks follow-up smokers) reported more previous attempts to quit $(F(1,75)=4.25, p<.05)$, and had lower scores on posttreatment 1-item PAM $(F(1,74)=13.98, p<.001)$ than respondents $(n=62)$ who participated in the last measurement.

\section{Smoking bebavior}

After treatment 66 participants (54\%) were abstinent. This number declined to 48 (39\%) after 6-weeks follow-up and to $30(24 \%)$ after 1-year follow-up (see figure 1). During treatment an initial lapse led in all cases to a fullblown relapse. Subjects who lapsed, failed to cease smoking in a later stage.

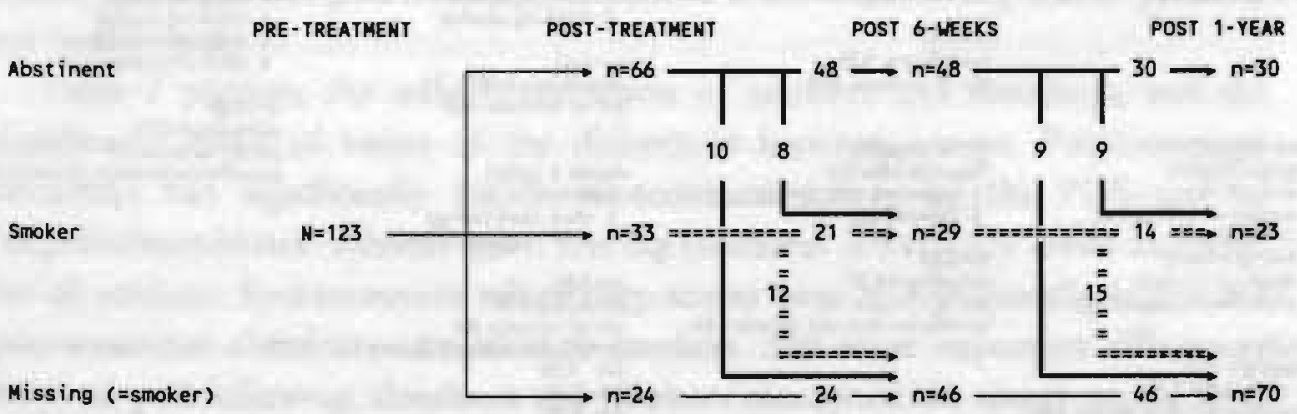

Figure 1. Smoking status of group participants. 


\section{Self-efficacy scales}

- Inter-item reliability

Self-efficacy scales showed high $\alpha$ 's. For the PAS coefficient $\alpha$ was .92 at pretreatment and .96 at post-treatment. The PDS $\alpha$ 's were .75 at pre-treatment and .85 at post-treatment. The high $\alpha$ 's provide support for the internal consistency of these scales. Exclusion of items could not raise $\alpha$ 's.

\section{- Factor analysis}

Tabachnick \& Fidell (29) give as a rule of thumb that 5 cases for each observed variable are required for factor analysis. The 17 items in the PAS thus required at least 85 cases in order to perform factor analysis. The numbers of pre- and posttreatment subjects $(\mathrm{N}=123$ and $\mathrm{n}=99$ respectively) were sufficient to meet this criterion.

Table 1. Factors, extracted by alpha factor extraction with oblique rotation, for pre-treatment and post-treatment self-efficacy scales

(factor loadings smaller than 0.30 not taken into account).

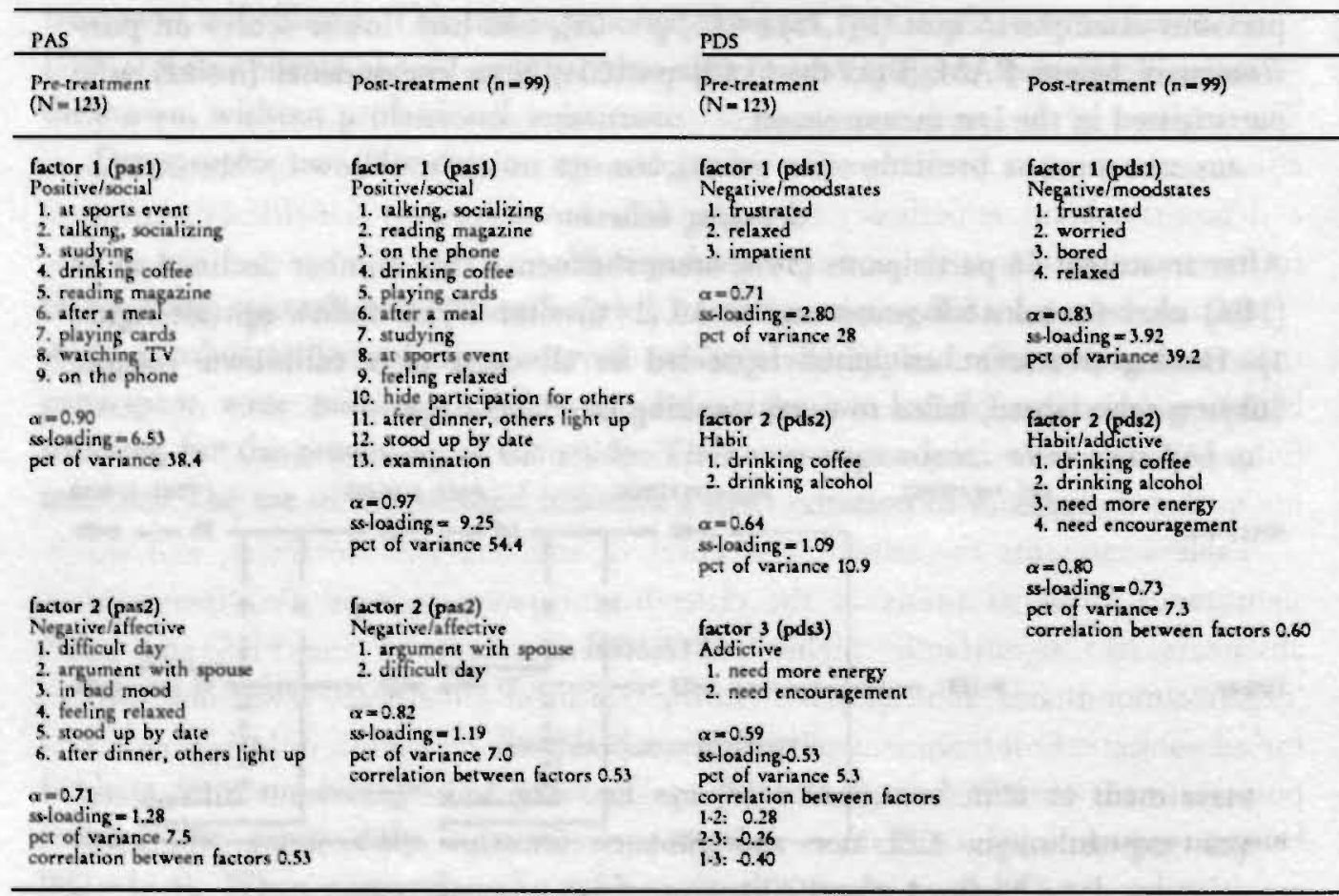


The results of $\alpha$-factor extraction are reported in table 1 . In $\alpha$-factoring, communalities are estimated, using iterative procedures, that maximize $\alpha$ 's for the factors. Because factors were mostly highly correlated, oblique rotation was applied, which allows a wide range of factor intercorrelations (29).

Factoring of the pre- and post-treatment PAS resulted in two factors. Pretreatment factors were pas1, a 'positive/social' factor accounting for a great part of the variance, and pas2, a weaker second factor containing mostly 'negative/affective' items. Although after treatment the strong first 'positive/social' factor pas1 contained some of the 'negative/affective' items, it remained in principle positive. The weaker second factor pas 2 consisted of two 'negative/affective' items.

The extraction of factors of the pre-treatment PDS resulted in three factors: pds1, containing the 'negative/moodstates' items; pds2, consisting of two 'habit' items; and pds3, including two 'addictive' items. After treatment, two factors were extracted: pds1, consisting of 'negative/moodstates' items, and pds2, containing the 'habit/addictive' items. Percentages of variance accounted for by the PDS factors were lower than those of the PAS.

- Predictive utility of pre- and post-treatment self-efficacy measures and subscales The analyses of the predictive value of self-efficacy concerned pre-treatment selfefficacy measures as predictors for post-treatment and post follow-up abstinence, and post-treatment self-efficacy measures and the increase of self-efficacy during treatment as predictors for post-follow-up abstinence.

Because of the inability to turn an initial lapse into a successful quit attempt, the group of post-treatment smokers (see figure 1) was in fact 'lost'. Their future behavior was clear: they continued smoking. Hence, the prediction of postfollow-up success for post-treatment abstainers is most interesting and of practical use in this study.

Table 2 presents the self-efficacy scores of smokers and abstainers, and the significance levels of t-tests of the differences between groups. Post-treatment abstainers had significantly higher pre-treatment scores on the PDS and its 'negative/moodstates' subscale pds1. During treatment self-efficacy levels increased for all subjects. Post-treatment self-efficacy scores were all significantly higher for post-treatment abstainers compared to smokers. The most important differences between post-follow-up abstainers and smokers concerned the scores on the PAS and its subscales, and the 1-item PAM. 
Table 2. Mean pre- and post-treatment self-efficacy scores of abstainers and smokers.

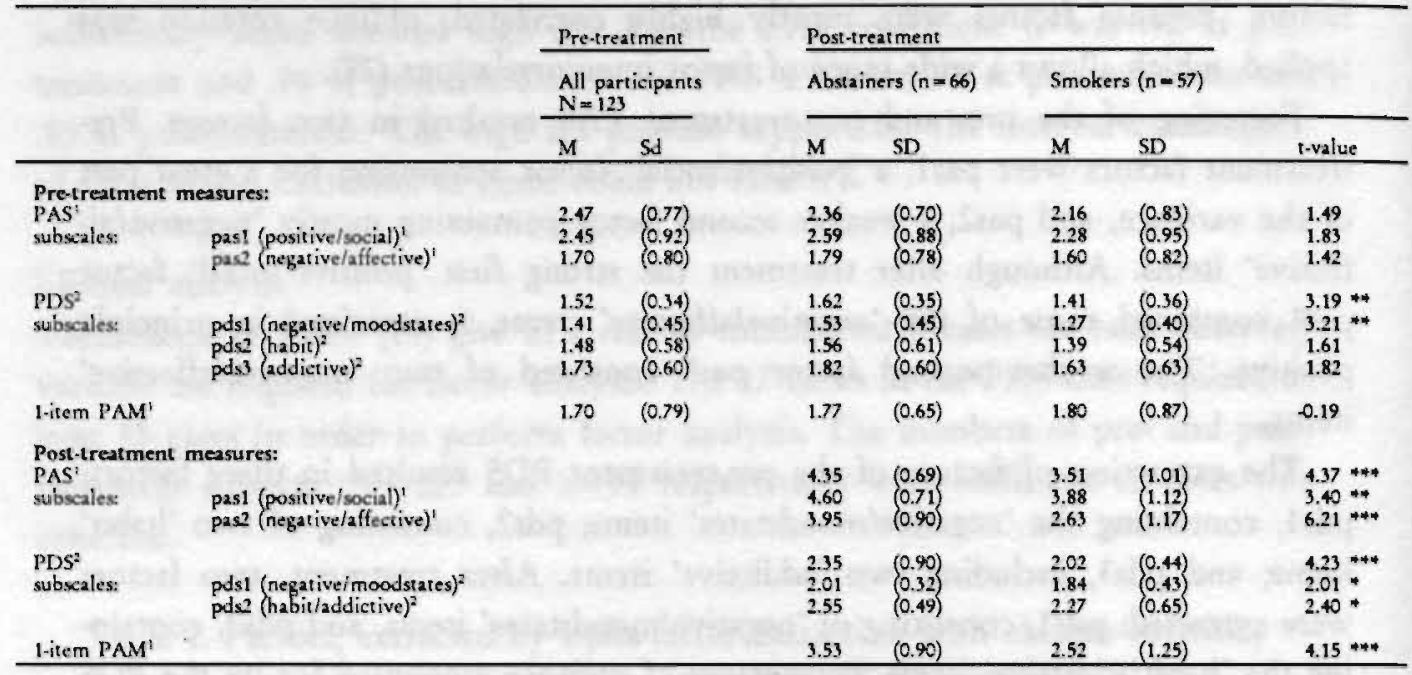

${ }^{1} 1=$ low to $5=$ high perceived ability; ${ }^{2} 1=$ low tot $3=$ high perceived difficulty; Significance levels of $t$-tests: $p<.05 ;{ }^{* *} p<.01 ; *+*<<.001$.

To determine the predictiveness of self-efficacy measures for post-treatment and post-follow-up abstinence, these measures were considered as independent variables in univariate logistic regression analyses. The results of these analyses are presented in table 3. Pre-treatment demographic and smoking characteristics were also proposed as independent variables, but they were not related with short or long-term cessation. Since none of the pre- or post-treatment self-efficacy measures were significant predictors for post 1-year cessation in the total group of participants, odds ratios for post 1-year abstinence are not reported for this group.

Pre-treatment PDS scores proved to be predictive for post-treatment success. The 'negative/moodstates' factor pds1 was also a significant predictor. The pretreatment PDS scores were also predictive for post- 6 weeks abstinence. However, the confidence intervals of the odds ratios of these measures were rather broad, indicating considerable variance in the odds ratios.

Post-treatment self-efficacy measures were all predictive for post 6-weeks abstinence. The most reliable predictors for post 6 -weeks cessation were the posttreatment 'negative/affective' factor, pas2, and the 1-item PAM, since the confidence intervals of the PDS and subscales were again rather broad. The increase during treatment of the 'negative/affective' factor pas2 and the 1-item PAM were almost as strongly predictive as their post-treatment levels. 
Table 3. Univariate logistic regression analyses of post-treatment and post follow-up abstinence (abstinent $=1$, smoking $=0$ ).

\begin{tabular}{|c|c|c|c|c|c|c|c|c|c|}
\hline & & \multicolumn{4}{|c|}{ All participants } & \multicolumn{4}{|c|}{ Abstainers after treatment } \\
\hline & & \multicolumn{2}{|c|}{$\begin{array}{l}\text { post-treatment cesso- } \\
\text { tion }^{1}\end{array}$} & \multicolumn{2}{|c|}{$\begin{array}{l}\text { post: 6-weeks cessa- } \\
\text { ivon }^{2}\end{array}$} & \multicolumn{2}{|c|}{ post 6-weeks cescation } & \multicolumn{2}{|c|}{ past 1.year cessation, } \\
\hline & & odds ratio & $95 \% \mathrm{CI}$ & odds ratio & $95 \% \mathrm{CI}$ & adds ratio & $95 \% \mathrm{CI}$ & odds ratio & $95 \%$ CI \\
\hline $\begin{array}{l}\text { Pre-treatm } \\
\text { PAS } \\
\text { subsiales: }\end{array}$ & $\begin{array}{l}\text { ent } \\
\text { pas1 (positive/social) } \\
\text { pas2 (negative/affective) }\end{array}$ & $\begin{array}{l}1.44 \\
1.34 \\
1.47\end{array}$ & $\begin{array}{l}0.89 \cdot 2.34 \\
0.91-1.97 \\
0.91 \cdot 2.38\end{array}$ & $\begin{array}{l}1.21 \\
1.13 \\
1.21\end{array}$ & $\begin{array}{l}0.75-1.93 \\
0.77-1.65 \\
0.77-1.91\end{array}$ & & & & \\
\hline $\begin{array}{l}\text { PDS } \\
\text { subscales }\end{array}$ & $\begin{array}{l}\text { pdsl (negativelmoodstates) } \\
\text { pded (habit) } \\
\text { pds3 (addictive) }\end{array}$ & $\begin{array}{l}5.25^{+4} \\
4.13 \\
1.69 \\
1.79\end{array}$ & $\begin{array}{r}1.77-15.56 \\
1.63 \cdot 10.43 \\
0.88 \cdot 3.23 \\
0.95 \cdot 3.26\end{array}$ & $\begin{array}{l}3.094 \\
2.19 \\
1.27 \\
1.76\end{array}$ & $\begin{array}{l}1.11-8.59 \\
0.96-5.01 \\
0.68-2.36 \\
0.95 \cdot 3.25\end{array}$ & & & & \\
\hline 1-item PAN & & 0.95 & $0.59 \cdot 1.53$ & 0.91 & $0.56 \cdot 1.47$ & & & & \\
\hline $\begin{array}{l}\text { Post-treatn } \\
\text { PAS } \\
\text { subscales: }\end{array}$ & $\begin{array}{l}\text { nent } \\
\text { pas1 (positive/social) } \\
\text { pas? (negative/affective) }\end{array}$ & & & $\begin{array}{l}2.15^{* *} \\
1.75^{*} \\
2.24^{* * *}\end{array}$ & $\begin{array}{l}1.26-3.69 \\
1.07-2.86 \\
1.50-3.35\end{array}$ & $\begin{array}{l}0.94 \\
0.83 \\
0.38\end{array}$ & $\begin{array}{l}0.42 \cdot 2.09 \\
0.36 \cdot 1.93 \\
0.76-2.49\end{array}$ & $\begin{array}{l}1.88 \\
1.67 \\
1.90^{4}\end{array}$ & $\begin{array}{l}0.83 .4 .26 \\
0.75 \cdot 3.72 \\
1.06-3.40\end{array}$ \\
\hline $\begin{array}{l}\text { PDS2 } \\
\text { subscales: }\end{array}$ & $\begin{array}{l}\text { pds1 (negative/moodstates) } \\
\text { pds2 (habit/addictive) }\end{array}$ & & & $\begin{array}{l}3.84^{4} \\
2.25 * \\
3.00^{4}\end{array}$ & $\begin{array}{r}1.31-11.25 \\
1.10-4.58 \\
1.24-7.26\end{array}$ & $\begin{array}{l}0.79 \\
1.55 \\
1.20\end{array}$ & $\begin{array}{l}0.16-3.94 \\
0.18-1.68 \\
0.33-4.35\end{array}$ & $\begin{array}{l}1.63 \\
1.03 \\
1.71\end{array}$ & $\begin{array}{l}0.39-6.90 \\
0.39-2.67 \\
0.52 \cdot 5.63\end{array}$ \\
\hline 1-item PAA & & & & $2.34^{n * *}$ & $1.50-3.63$ & 1.964 & $1.00-3.81$ & $2.13^{*}$ & $1.16-3.92$ \\
\hline $\begin{array}{l}\text { Increase du } \\
\text { PAS } \\
\text { subscales: }\end{array}$ & $\begin{array}{l}\text { uring treatment" } \\
\text { past (positive/social) } \\
\text { pas2 (negativelaffective) }\end{array}$ & & & $\begin{array}{l}1.72^{\circ} \\
1.23 \\
2.20^{+0 *}\end{array}$ & $\begin{array}{l}1.11-2.68 \\
0.85-1.77 \\
1.46-3.30\end{array}$ & $\begin{array}{l}1.58 \\
1.16 \\
2.01^{*}\end{array}$ & $\begin{array}{l}0.86-2.19 \\
0.70-1.93 \\
1.15-3.51\end{array}$ & $\begin{array}{l}1.70 \\
1.24 \\
1.90^{*}\end{array}$ & $\begin{array}{l}0.94-3.10 \\
0.77-2.00 \\
1.143 .15\end{array}$ \\
\hline $\begin{array}{l}\text { PDS2 } \\
\text { subscales: }\end{array}$ & $\begin{array}{l}\text { pds1 (negative/moodstates) } \\
\text { pds2 (habit/addictive) }\end{array}$ & & & $\begin{array}{l}1.50 \\
0.94 \\
1.32\end{array}$ & $\begin{array}{l}0.58-3.86 \\
0.42-2.08 \\
0.74-2.37\end{array}$ & $\begin{array}{l}1.30 \\
1.54 \\
1.29\end{array}$ & $\begin{array}{l}0.33-5.09 \\
0.51-4.64 \\
0.52-3.20\end{array}$ & $\begin{array}{l}1.89 \\
1.32 \\
1.01\end{array}$ & $\begin{array}{l}0.556 .52 \\
0.49-3.54 \\
0.45-2.28\end{array}$ \\
\hline 1-item PAN & & & & 2.03000 & $1.38-2.97$ & $2.17^{*}$ & $1.17-4.03$ & $2.15^{* *}$ & 1.293 .60 \\
\hline
\end{tabular}

' $N=123 ;{ }^{2}$ for pre-treatment self-efficacy measures $N=123$, for post-treatment selífificacy measures $n=99 ;{ }^{\prime} n=66$;

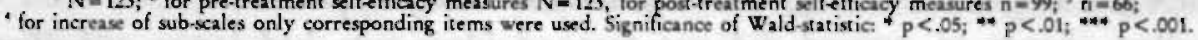

When post-treatment abstainers were considered, fewer predictors for future abstinence emerged. Post 6-weeks follow-up abstinence was predicted by posttreatment scores on the 1-item PAM, while the increases during treatment on the 1-item PAM and the 'negative/affective' factor pas2 were also predictive. Posttreatment scores on the 1-item PAM as well as the increase during treatment on this item during treatment were predictive for post 1-year abstinence. Post 1-year abstinence could also be predicted by the score on the 'negative/affective' subscale pas2 and the increase during treatment on the subscale.

\section{DISCUSSION}

In a prospective study, the predictability of short and long-term success of participants in a smoking cessation group program by means of their perceived self-efficacy was confirmed. Three measures for self-efficacy were used - a 17-item 
perceived ability scale, a 10 -item perceived difficulty scale, and a 1 -item perceived ability measure - that all showed predictive capabilities. Perceived difficulty may predict short-term cessation, in contrast with perceived ability, that was suggested as a predictor for long-term abstinence. By means of factor analyses, various subscales were found in the perceived difficulty scale as well as in the perceived ability scale. Self-efficacy expectations towards negative/affective and negative/moodstates aspects of smoking cessation may be the most important elements in both scales. However, the 1-item perceived ability measure showed the greatest predictive power for post-follow-up abstinence.

\section{External validity}

The limitations of several measurement aspects of this study require some caution in interpreting the results. The measured smoking behavior relied exclusively on self-report. External confirmation or biochemical validation of self-reported abstinence were not included in this study, because of financial and practical limitations. However, self-reported smoking status of adult smokers has been found to be reasonably correct, especially in the long term $(30,31)$.

There was no evidence of selection caused by drop-out from the study during treatment. Drop-outs during follow-up were more often smokers in the last assessment before they dropped out. Furthermore, differences between respondents and drop-outs during follow-up indicate that the 'heaviest cases' with the smallest chance to succeed did not respond (drop-outs had lower self-efficacy scores, they smoked more before treatment and had more previous quit-experiences). Hence the handling of missing data, considering drop-outs as smokers, probably corresponds highly with reality and provides conservative conclusions, assuming that the differences between abstainers and smokers would probably have been even more prominent, had drop-outs remained in the study.

In his extensive review of smoking cessation methods, Schwartz (32) reported median success rates for group programs ranging from $24 \%$ to $36 \%$ after one-year follow-up. The success rate of the treatment, as carried out by the 'Life and Health Foundation', which in this study was found to be $24 \%$, is comparable to the median of group programs in the United States and Canada. Generalization of the conclusions of this study to participants of other smoking cessation group programs seems justified. 


\section{Prediction of success}

The main conclusion emerging from this study is that various conceptualizations of self-efficacy were predictive for post-treatment, post 6-weeks and post 1-year follow-up cessation of smoking in participants in a group program. In the total group of participants, pre-treatment self-efficacy measures showed predictive power for post-treatment and post 6-weeks abstinence, although confidence intervals indicated considerable variance of this power. Post-treatment self-efficacy levels, as well as the increase of self-efficacy during treatment, were predictive for post 6-weeks cessation. However, post-treatment self-efficacy was not predictive for post 1-year cessation in the total group of participants.

Because none of the post-treatment smokers succeeded in quitting again during follow-up, post-treatment abstainers were separately considered for the prediction of long term success, since in this group continued non-smoking or relapse could take place. Post-treatment self-efficacy turned out to be predictive for long-term success (1 year follow-up) within the group of post-treatment abstainers.

\section{Conceptualization of self-efficacy}

A secondary goal of this study was to determine the most fitting conceptualization of self-efficacy. The results of this study suggest that pre-treatment perceived difficulty, incorporating a combination of the dimensions magnitude and generality, may be the most appropriate measure in the prediction of post-treatment cessation.

For the prediction of long-term abstinence both post-treatment perceived ability measures, incorporating the dimensions generality and strength, may be a conceptualization with greater predictive power than perceived difficulty. Since all three measures included the dimension generality, a conclusion might be that magnitude is the dimension that is of importance for the prediction of short term cessation success, while strength may be the dimension that determines long term abstinence.

The fact that the 1-item perceived ability measure performed even better than the 17-item scale may indicate a lack of relevant items in this scale, and supports the effectiveness of the conceptualization of the dimension generality by asking respondents to include every possible situation in their confidence rating.

\section{Subscales}

DiClemente (23) argued that a general self-efficacy for non-smoking exists, rather than many situation-specific categories. The very high internal consistency scores 
of the scales in this study support this statement. Velicer and colleagues (24) suggested that self-efficacy has a dynamic nature that differs for smokers in the various stages of quitting. Because of the limited sample size it was not possible to replicate the Lisrel procedure that Velicer and co-workers performed on their data. However, the number of cases in this study allowed factor analyses of the pre- and post-treatment PAS and PDS items. Where Velicer et al. (24) did not find a difference between the confidence and temptation scales, here perceived ability produced positive/social primary factors, while the negative/moodstates factors of the perceived difficulty scale explained most of the variance.

The factors that emerged were comparable with the factors that Velicer et al. (24) reported. However, no supporting evidence was found for the dynamic nature of self-efficacy, since both before and after treatment practically the same factors were extracted. However, one should be very cautious in drawing conclusions because different scales were used and the groups of subjects were not totally comparable, since subjects in Velicer's study were just interested in quitting or were responding to an advertisement for a self-help manual.

\section{Theoretical implications}

The findings of this study oppose the major critique on the concept of selfefficacy as being merely a reflection of former behavior (33) by showing the predictive power of the concept when former behavior is controlled for. Hence, self-efficacy is a determinant of future behavior. This conclusion corresponds with the theory of planned behavior, that asserts that the performance of a certain behavior is determined by both the intention to perform the behavior and self-efficacy. The intention to perform a behavior is controlled by the person's attitude towards the behavior, social norm and self-efficacy $(34,35)$. Several researchers reported an improvement in the prediction of behavior by combining attitudes, social norm and self-efficacy $(34,36)$. This study supports the direct relation between self-efficacy and smoking cessation. In the case of smoking cessation self-efficacy may be the most important of the determinants (37), and the relation between self-efficacy and intention may be absent (38), but this need not be true for other behaviors. Ajzen (39) showed various correlations between attitudes, social norms, self-efficacy and the intention to lose weight, attend class and to get an 'A' for tests. Ajzen (39) hypothesized that factors as difficulty of the behavior and visibility for others of the behavior may create this variation. Furthermore, factors that are not directly related with the behavior may influence the relative importance of self-efficacy, which is illustrated by the interaction 
effect that Mittag and Schwarzer (40) found between self-efficacy and unemployment with respect to alcohol consumption in migrants from former East Germany. Further research of the influence of such specific conditions and aspects of behaviors that may influence the relations between determinants and behavior change is indicated.

The conclusions with respect to the conceptualizations of self-efficacy that were tested here, indicating that perceived ability might be a more accurate measure for self-efficacy than perceived difficulty, may not be generalizable to other behaviors or even to smokers trying to quit with other methods. Selfefficacy towards other behaviors or in other groups of smokers may be more situation specific, e.g. self-quitters who are more self-confident than group participants may perceive specific difficulties in certain situations, whereas group participants may feel less efficacious in all situations. Moreover, perceived ability may be an accurate conceptualization for self-efficacy towards behaviors that require much skills, e.g. getting an ' $A$ ' for tests or smoking cessation, while perceived difficulty may be more reliable for behaviors that ask very little ability, e.g. attending class. Here also further investigation is required of specific aspects of behaviors in relation with the various conceptualizations of self-efficacy.

\section{Implications for smoking cessation programs}

The results of this study indicate that in order to enhance the efficacy of group programs, participants' self-efficacy towards non-smoking should be enhanced sufficiently during treatment. Various studies have suggested strategies to raise self-efficacy levels in group sessions (for review see: 5,41), and in individual counseling $(42,43)$. The enhancement of the 1-item self-efficacy measure can serve as an indicator for the tailoring of further guidance of the ex-smoker to his or her specific needs, after a first treatment modality. Ex-smokers who do not report a sufficient rise in self-efficacy can be prompted to enroll in more intensive followup treatment, for instance the three-session follow-up skills-training program that Stevens and Hollis (44) used in their study. Quitters who reached a high level of self-efficacy can be helped by more extensive methods, such as booster sessions, written information materials, occasional guidance by phone, etc., or even do without any guidance.

Finally the results of the group program in this study accentuate the importance of relapse prevention. Subjects who experienced a initial lapse were not able to overcome this lapse and went back to. smoking. Marlatt \& Gordon (41) describe a number of useful strategies for relapse prevention. Therefore, instruc- 
tions about how to prevent a lapse, and how to handle a potential lapse, should be part of a smoking cessation program.

\section{REFERENCES}

1. Liedekerken P, Jonkers R, De Haes WFM, Kok GJ, Saan JAM. Effectiveness of Health Education. Assen, the Netherlands: Van Gorkum/Uitgeverij voor Gezondheidsbevordering, 1990

2. Mullen PD, Green LW, Persinger GS. Clinical trials of patient education for chronic conditions: A comparative meta-analysis of intervention types. Prev Med 1985;14:753-81.

3. Kok GJ, Green LW. Research to support health promotion in practice: A plea for increased cooperation. Health Promotion Internl, 1990;5:303-8.

4. Green LW, Kreuter MW. Health promotion planning, an educational and environmental approach. Mountain View, CA: Mayfield Publishing Company, 1991.

5. Bandura A. Social foundations of thought and action. Englewood Cliff, NJ: Prentice-Hall, 1986.

6. Schwarzer R. Self-efficacy in the adoption and maintenance of health behaviors: Theoretical approaches and a new model. In Schwartzer R, editor. Self-efficacy: Thought control of action. Washington: Hemisphere Publishing Corporation, 1992:217-44.

7. Strecher VJ, DeVellis BM, Becker MH, Rosenstock IM. The role of self-efficacy in achieving health behavior change. Health Educ Q, 1986;13:73-91.

8. Carey MP, Snel DL, Carey KB, Richards CS. Self-initiated smoking cessation: A review of the empirical literature from a stress and coping perspective. Cogn Ther Res, 1989;13:323-41.

9. Coelho RJ. Self-efficacy and cessation of smoking. Psychol Rep, 1984;54:309-10.

10. Condiote MM, Lichtenstein E. Self-efficacy and relapse in smoking cessation programs. J Consult Clin Psychol, 1981;49:648-58.

11. Pederson LL, Strickland C, DesLauriers, A. Self-efficacy related to smoking cessation in general practice patients. Int J Addict, 1991;26:467-85.

12. Haaga DA. Articulated thoughts and endorsement procedures for cognitive assessment in the prediction of smoking relapse. Psychol Assessment, 1989;1:112-7.

13. Melntyre K, Lichtenstein E, Mermelstein RJ. Self-efficacy and relapse in smoking cessation: A replication and extension. J Consult Clin Psychol, 1983;51:632-3.

14. Haaga DA, Stewart BL. Self-efficacy for recovery from a lapse after smoking cessation. J Consult Clin Psychol, 1992;60:24-8.

15. Bear JS, Lichtenstein E. Classification and prediction of smoking relapse episodes: An explanation of individual differences. J Consult Clin Psychol, 1988;56:104-10.

16. DiClemente CC. Self-efficacy and smoking cessation maintenance: A preliminary report. Cogn Ther Res, 1981;5:175-87.

17. Gritz ER, Berman BZ, Bastani R, Wu M. A randomized trial of a self-help smoking cessation intervention in a nonvolunteer female population: Testing the limits of the public health model. Health Psychol, 1992;11:280-9.

18. Strecher VJ, Becker MH, Kirscht JP, Eraker SA, Graham-Tomasi RP. Evaluation of a minimalcontact smoking cessation program in a health care setting. Patient Educ Counsel, 1985;7:395-407.

19. Ajzen I, Timko C. Correspondence between health attitudes and behavior. Basic Appl Soc Psychol, 1986:7:259-76. 
20. Coletri G, Supnick JA, Payne TJ. The smoking self-efficacy questionnaire (SSEQ): Preliminary scale development and validation. Behav Assessment, 1985;7:249-60.

21. DiClemente CC, Prochaska JO, Gibertini M. Self-efficacy and the stages of self-change of smoking. Cogn Ther Res, 1985;9:181-200.

22. Nicki RM, Remington RE, MacDonald GA. Self-efficacy, nicotine-fading/self-monitoring and cigarette-smoking behavior. Behav Res Ther, 1984;22:447-85.

23. DiClemente CC. Self-efficacy and the addictive behaviors. J Soc Clin Psychol, 1986;4:302-15.

24. Velicer WF, DiClemente CC, Rossi JS, Prochaska JO. Relapse situations and self-efficacy: An integrative model. Addict Behav, 1990;15:271-83.

25. McFarland JW, Folkenberg EJ. How to stop smoking in five days. Englewood Cliffs, NJ: Prentice-Hall Inc., 1965.

26. Zeeman G, Aluoch L. Kursusboek voor het stoppen met roken. Bosch en Duin, The Netherlands: Stichting Leven en Gezondheid, 1984.

27. Stichting Volksgezondheid en Roken. Jaarverslag 1987. 's-Gravenhage NL: Stichting Volksgezondheid en Roken, 1988.

28. Breteler MHM, Nieuwenhuizen J van den. Stoppen met roken in de regio: Effect- en procesevaluatie van SMR-cursussen bij de GGD's en de Kruisverenigingen. In: Bijdragen aan de Studiedag Landelijke en Regionale Stoppen-met-Roken Activiteiten. Den Haag: Stichting Volksgezondheid en Roken, 19882:8-9.

29. Tabachnick BG, Fidell LS. Using multivariate statistics. New York: Harper \& Row, 1989.

30. Velicer WF, Prochaska JO, Rossi JS, Snow, M. Assessing outcome in smoking cessation studies. Psychological Bulletin, 1992;111:23-41.

31. Glasgow RE, Mullooly JP, Vogt TM, Stevens VJ, Lichtenstein E, Hollis JF, Lando HA, Severson $\mathrm{HH}$, Pearson KA, Vogt MR. (in press) Biochemical validation of smoking status: Pros, cons, and data from four low-intensity intervention trials. Addict Behav.

32. Schwartz JL. Smoking cessation methods: The United States and Canada, 1978-1985. Bethesda, Maryland: Department of Health and Human Services, 1987.

33 Biglan A. A behavior-analytic critique of Bandura's self-efficacy theory. Behav Analyst, 1987;10:115

34. Ajzen I. Attitudes, traits and actions: Dispositional prediction of behavior in personality and social psychology. In Berkowitz L, editor. Advances in Experimental Social Psychology. Academic Press, NY, vol 20, 1987: 1-63.

35. Kok GJ, De Vries H, Mudde AN, Strecher VJ. Planned health education and the role of selfefficacy: Dutch research. Health Educ Res, 1991;6:231-8.

36. De Vries H, Dijkstra M, Kuhlman P. Self-efficacy: The third factor besides attitude and subjective norm as a predictor of behavioral intentions. Health Educ Res, 1988;1:85-94.

37. Kavanagh DJ, Pierce J, Lo SK, Shelley J. Self-efficacy and social support as predictors of smoking after a quit attempt. Psychol Health, 1993;8:231-42.

38. Breteler MHM, Mertens EHM, Rombouts R. Motivation to change smoking behavior: A revised model. In Breteler, M.H.M. Smoking cessation: Some determinants of motivation and success. Doctoral Dissertation, University of Nijmegen NL, 1988:93-106.

39. Ajzen I. Atritudes, personality, and behavior. Milton Keynes: Open University Press, 1988.

40. Mittag W, Schwartzer R. Interaction of employment status and self-efficacy on alcohol consumption: A two-wave study on stressful life transitions. Psychol Health, 1993;8:77-87. 
41. Marlatt GA, Gordon JR. Relapse prevention: Maintenance strategies in the treatment of addictive behaviors. New York, London: The Guildford Press, 1985.

42. Försterling F. Attribution theory in clinical psychology. Chichester: Wiley \& Sons, 1988.

43. Kok GJ, Den Boer D-J, De Vries H, Gerards F, Hospers HJ, Mudde AN. Self-efficacy and attribution theory in health education. In Schwartzer $R$, editor. Self-efficacy: Thought control of action. Washington: Hemisphere Publishing Corporation, 1992:245-62.

44. Stevens VJ, Hollis JF. Preventing smoking relapse, using an individually tailored skills-training technique. J Consult Clin Psychol, 1989;57:420-4. 


\title{
DEVELOPMENT AND UTILIZATION \\ OF A SELF-HELP MANUAL FOR
}

\section{COMMUNITY SMOKING CESSATION INTERVENTIONS.}

\author{
Aart N. Mudde, Hein de Vries, Marc C. Willemsen \& Patricia van Assema
} In: Richmond R, editor. Interventions for smokers: an international perspective. New York: Williams \& Williams, 1994:293-322.

\section{ABSTRACT}

We describe the processes involved in developing a self-help manual for smoking cessation in the Nether. lands. The principal method we used was a comprehensive process of pre-testing, whereby health education and communication experts and members of the target group (i.e., smokers who wished to quit) were asked whether the manual contributed towards the realization of the intervention goals and about the ways in which the future effectiveness of the manual could be enhanced.

Target group members for the assessment of the effectiveness of the manual were recruited from three separate communities, and these were: a) a smoking cessation project in Den Bosch (where 1412 manuals were distributed among 115,000 inhabitants); 2) a district of the PTT-Telecom company (130 manuals disseminated among 1,700 employees); and c) a local health project that dealt with four risk factors including smoking, in the district of Bergeyk (10,000 inhabitants, 37 manuals disseminated).

All three projects reported positive success rates at quitting: $13 \%$ of the Den Bosch subjects claimed to be abstinent at the 6 month follow-up, $8 \%$ of the PTT-project were abstinent after 3 months, and $18 \%$ after 6 weeks in Bergeyk. The positive evaluations given by the readers of the self.help manual confirmed the usefulness of the pre-test process.

According to Rogers' theory (1) of adoption and diffusion of innovations, implications are given for future diffusion and research with respect to tailoring the manual according to the five attributes of innovations to future intermediaries (whose job it will be to distribute the manual) and to different segments of the target group, such as health care consumers and pregnant women.

\section{INTRODUCTION}

Smoking rates in the Netherlands have decreased considerably during the last few decades. Many of the initiatives to reduce tobacco use have involved mass media approaches and group interventions, and there have been only a limited number of activities implemented to enhance individual quitting rates. Thus the need to develop and evaluate self-help quit manuals was recognized. 


\section{Smoking Prevalence}

In the Netherlands, $34 \%$ of the adult population aged 15 years and above (i.e., approximately 4 million people) smoke (2). The percentage of smokers in the male population has decreased from $90 \%$ in 1958 to $38 \%$ in 1991 . However, the smoking prevalence in women has increased from 29 to $30 \%$ in the same period. Female smoking prevalence peaked in 1967 at $42 \%$ but has been declining gradually since 1970 . Smoking prevalence in teenagers aged 10 to 14 years has also declined during the last few decades, from $27 \%$ in 1978 to $7 \%$ in 1991 ( $7 \%$ for boys and $6 \%$ for girls). However, by the age of 24 , about $40 \%$ of the population is smoking (2).

Despite the decrease in smoking prevalence rates, the mean daily cigarette consumption has increased from 13 cigarettes per day in 1967 to 24 per day in 1992 (2). Two separate factors are thought to be partly responsible for this. First, the introduction of cigarettes with lower nicotine content may mean that nicotine dependent smokers need to smoke more cigarettes to reach their desired nicotine level. Second, it is possible that light smokers may have been successful in quitting, thus leaving the heavy tobacco consumers as the smoking population.

As in the United States, smoking in the Netherlands is regarded as a social problem. There is evidence that Dutch smokers have a lower socio-economic status (SES) than do nonsmokers (3). A survey using a four category division of SES, conducted in 1989 , found that $33 \%$ of the adults in the highest SES category were smokers, compared with $46 \%$ in the lowest SES category (3). Furthermore, $69 \%$ of smokers in the lower SES category rolled their own cigarettes from tobacco thus putting them at greater risk of developing cigarette-related diseases, as hand-rolled cigarettes contain higher levels of nicotine and tar than do manufactured cigarettes. By comparison, only $38 \%$ of smokers in the highest SES category rolled their own cigarettes.

\section{Sinoking Cessation Interventions In The Netherlands}

Until the 1990s, few regular anti-smoking activities were provided in the Netherlands, and those actions which were implemented were rarely evaluated in terms of behavior change. Most smoking cessation initiatives in the Netherlands were confined to mass media campaigns, originating from the SHF, and group programs, carried out by the Foundation for Life and Health (FLH). It was not until 1990 that the smoking cessation activities of the FLH were incorporated in the SHF. In the past, the SHIF occasionally approached workplaces to stimulate policies to protect the nonsmoker, and local health organizations sometimes 
initiated smoking cessation group programs. In an attempt to facilitate these activities, the SHF provides a training for group counselors.

Unfortunately, these activities do not cover the whole target group of smokers who wish to quit. This problem is exacerbated by the fact that the information often is disseminated through the mass media and thus may not be accurate enough to help smokers quit. Mass media messages provide few opportunities for skills training or role modelling which act to enhance the smoker's perceived level of his or her ability to quit (self-efficacy). Although group programs provide these skills and strategies, few smokers attend, as the vast majority of smokers prefer quitting on their own or with minimal assistance $(4,5)$.

A national sample surveying 1,100 adult smokers in the Netherlands found that $29 \%$ of the sample intended to quit within the next 6 months (6). With a national population of 4 million smokers, it can be estimated that there are about $1,160,000$ smokers wanting to quit. However, every year only 600 smokers participate in group programs (2). Therefore, there is a large group of Dutch smokers (around $1,159,000$ ) wishing to quit, for whom smoking cessation selfhelp materials may be helpful.

\section{Review Of Self-help Materials}

To enhance the effectiveness of unaided or minimally assisted quit attempts, a number of self-help methods are developed and assessed, including printed materials received through the mail (7), community-wide quitting contests (8), the idea of encouraging quitting as a New Year's resolution $(9,10)$, individual self-help manuals $(11,12)$ and computer-assisted self-help programs (13). These methods teach smokers skills and strategies to assist them stop smoking and result in a slightly lower success rate than is found in clinical interventions such as group programs. Point-prevalence quit rates at 1-year follow-up tend to range between 10 and $20 \%(12,14,15)$. A less frequent but more conservative criterion is used to assess continuous abstinence rates, which tend to be in the range of 3 to $5 \%$ at 1 year follow-up $(12,14)$. Although the success rates of individual quit attempts using self-help materials are lower than those for more intensive interventions, their cost-effectiveness is probably higher since there is little or no professional time involved (16).

Self-help materials have a number of advantages which make them a critical element in any comprehensive smoking cessation intervention. Because self-help materials are acceptable to many smokers, are relatively inexpensive, and can be 
distributed in settings where smokers are found (medical offices, worksites, stores), they have the potential to reach far more smokers than do clinical interventions. They are easy to distribute and are applicable in many situations (e.g., for use on one's own or provided by a health care worker, group program or self-help group). Another advantage is that self-help materials can be distributed widely in community-based interventions, where the community decides which interventions will be implemented end the method of providing supporting materials. They also offer the opportunity to tailor messages to particular subgroups of smokers in a cost-effective way. For example, self-help materials can be focussed on various demographic groups or on smokers at different stages of readiness to change (17). In many countries there are a wide variety of self-help materials available for smokers who wish to quit; however, until the development of the self-help manual described in this chapter, there were no comprehensive self-help materials accessible in the Netherlands.

\section{DEVELOPMENT OF THE SELF-HELP MANUAL}

\section{Pre-test Route}

The development process of the self-help manual consisted of a number of phases in which concepts were produced, pre-tested and revised (see figure 1). Target group participation was facilitated by involving two separate samples of the Dutch smoking population ( $n=177$, and $n=178$ ) so that the content and presentation of the manual could be adjusted to suit their particular characteristics. To account for cultural differences, smokers were recruited in the northern, middle and southern Netherlands. Advertisements in local newspapers asked smokers who were interested in quitting to call a local phone number. Two thirds of the smokers recruited had low to average education levels. Their mean age was 44 years and there was a fairly equal distribution of male (48\%) and female (52\%) participants.

Eight experts in the field of health education and communication were consulted to evaluate the conceptualizations of theoretical principles applied in the manual. 


\section{The First Draft Version}

The manual distributed by the American Lung Association (ALA), "Freedom from smoking, for you and your family" (18) was chosen as a model (with permission from the ALA) for the following reasons: it applied the most recent

\section{CONTENT}

LAY-OUT
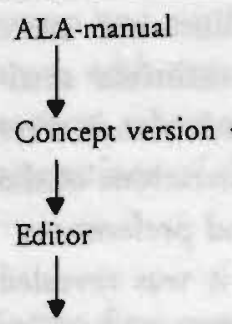

FIRST DRAFT VERSION

\section{Content-analysis} of magazines

Editor

Designer, photographer

panel of experts

LAY-OUT PROPOSALS,

MODELS

\section{Pre-test 1}

text,

conceptualizations

text, titles, lay-out,

Text revision covers, models, typefaces
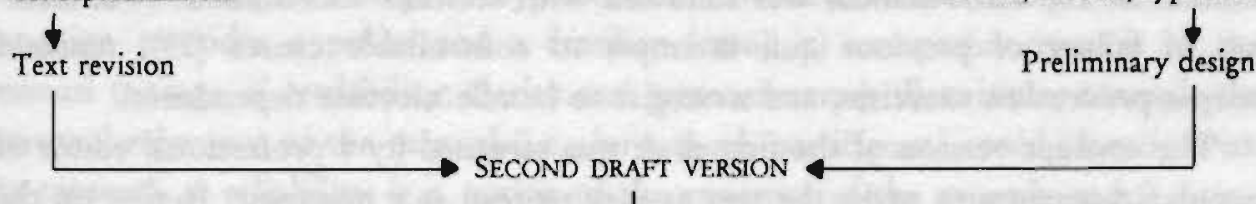

\section{Pre-test 2}

panel of experts

178 other smokers

text,

conceptualizations

Text revision

text, lay-out

Final design

PRESENT VERSION OF

SEIF-HIEIP MANUAL.

Figure 1. Pre-test route for self-help manual. 
insights in smoking cessation, such as the stages of change theory (19), and principles of relapse prevention (20), and it had been pre-tested among target group members and experts in the U.S. (21).

Based on the characteristics of the recruited pretest group of smokers, the target group was assumed to consist of male and female smokers, aged 35 years or older, with low to average levels of education. Because people with a lower level of education have been shown to rely more on social comparisons (22), an important part of the message was presented as 'testimonials' (illustrated statements from ex-smokers about how they managed to quit and maintain abstinence). Cultural differences between the United States and the Netherlands were considered and it was decided to intensively pretest layout and illustrations of the Dutch self-help manual in order to comply with Dutch customs and preferences.

The reading behavior of the pretest group was analyzed, and it was revealed that this group mostly read magazines. A content analysis of the 15 most popular Dutch magazines provided guidelines for structuring the text and illustrations. It was assumed that the target group would read the manual as a magazine, which implies that they would only read those sections of interest to them. Thus, special attention was given to the comprehensiveness of separate sections. The content of the ALA-manual was followed with sections added about re-attribution of failure of previous quit attempts to controllable causes (23), repeated relapse prevention exercises, and strategies to handle nicotine dependence.

The concept version of the first draft was screened by a professional editor of popular magazines to make the text as easy to read as a magazine. Acting on the recommendations from the content analysis, a designer created three layout proposals and three cover suggestions and chose a number of possible print typefaces. Ten male and ten female models were selected to serve as one of four possible role models for the testimonials. Based on advertising principles (24), the models were chosen from the youngest age category of the target group (35-40 years old) and were neither overly attractive or unattractive.

\section{Pretest Criteria}

A panel of eight education and communication experts and the target group population were used for the pretests. Following Vroom's (25) suggestions we listed the comments of the target group into five categories; 1) positive conviction; 2) neutral opinion; 3) unspecific negative judgement (e.g., "I don't like this section"); 4) specific negative judgement (e.g., "I would not use this word, but I cannot give an alternative"); and 5) specific negative judgement with an alterna- 
tive (e.g., "This testimonial makes it seem too easy. I would prefer to hear what was the most difficult thing in quitting").

Vroom (25) recommends alterations be made when at least $15 \%$ of the pretest group has a specific negative judgement of an element, with or without an alternative, when there is an absence of positive judgments of the same element (as positive judgments of the same element compensate for negative judgments). The suggested alternatives were used to improve the text. Occasionally the target group and experts disagreed over alterations to be made. When such a situation arose with regards to conceptual matters we followed the advice of the panel of experts, whereas if the discrepancy arose over presentation or textual matters the suggestions of the target group were followed.

\section{Pretests 1 and 2}

In the first pretest, 177 smokers were randomly assigned to six groups of about 30 smokers, and each group received a different combination of two chapters. Apart from limiting the amount of text to be read, this procedure assessed the comprehensiveness of chapters. Semistructured telephone interviews provided data on: a) opinion about lay-out proposals, proposed role models, title suggestions, cover designs and print typefaces; b) manner of addressing (the Dutch language provides a polite and a familiar form); c) comprehensiveness of the manual (ratings of readability, clarity and persuasiveness); d) attitudes towards the personal relevance of the manual (i.e., how much participants could identify with its content); e) reliability (e.g., rating of the expertise of the source); and f) rating of approval of the manual (e.g., acceptability of behavioral alternatives) (26). The interviewers were trained to elicit suggestions for improvements and information on the preferred idiom of the target group. The health education and communication experts received the whole text and were asked to give their opinion in writing.

The major results of the first pre-test indicated that:

* The style of the manual was appreciated by the target group (although the experts thought that the language was too prosaic);

* Some parts of the text needed shortening, some words were too difficult for the target group, the polite form of address was preferred, more arguments and counter-arguments were required in order to present advice as options, instead of orders, from which the reader can choose; 
* The calendar that was intended to help quitters count the days of abstinence Should be replaced by table cards to inform people around the smoker his/her intention to quit, and thus make the environment as conductive to quitting as possible;

* The self-monitoring exercise was perceived as too time-consuming;

* The testimonials were specifically appreciated, and thus more should be added;

The revised text and the preferred layout design, cover, and models were now integrated in a second draft version so that it would be comparable to the presentation of the final version. This included the use of colour printing. Although this was a costly procedure, it was used to prevent distraction (by minor black and white layout defects), which the interviewers noted frequently in pretest 1.

In pretest 2 the complete manual was tested by the second group of 178 smokers. Because of the size of the manual to be judged in pretest 2 the target group was questioned by printed questionnaire. Questions were asked about each chapter and the impression of the manual as a whole was assessed. The concepts investigated were the same as in pretest 1 , and most of the questions were open ended. The experts were asked to give their opinions in writing on the changes in conceptualizations and the coherence of the manual.

The results of the second pre-test indicated additional changes:

* Altering the sequence of parts within chapters, indicated by both the target group and the experts;

* Adapting some of the testimonials, because they were judged to be too positive and unrealistic;

* Shortening some sections (for instance the part about weight control which was regarded as too long); and

* Changing the colors of the manual.

\section{Summary}

Pretesting the manual facilitated the assessment of opinions of the target group and experts about planned and unplanned effects of the message (26). Although time-consuming, it was an effective strategy in the development of the Dutch selfhelp manual. Many elements of the American manual were not suitable for use in the Netherlands, and translation alone would have been insufficient. Thus, 
thorough adaptation of elements or even replacement of sections was needed to make the manual acceptable to Dutch smokers. Pretesting resulted in changes in the strategy of the manual as well as in the manner of addressing smokers and in lay-out matters. By checking whether the message contributed to the realization of the intervention goals, it was hoped that pretesting would enhance the future effectiveness of the final version of the manual (27).

\section{APPLICATIONS OF THE MANUAL IN COMMUNITY INTERVENTIONS}

The primary purpose of the research projects discussed here was to determine the feasibility and impact of a community approach to smoking cessation. The principal aims of an effective community-based smoking cessation program are to coordinate existing resources in the community and generate a multi-facetted intervention. By doing this the program has the potential to reach a greater number of smokers for a longer period of time. "Saturating" a community with messages from multiple sources may produce synergistic effects greater than the individual influences of each resource (28).

The smoking cessation self-help manual was tested in three research projects: The Dutch Community-based Smoking Cessation Project, Smoking Cessation at the Workplace "PTT-Telecom" and Local Health Project "Healthy Bergeyk". The interventions in these project all included the dissemination of the self-help manual and the implementation of a group program for smoking cessation.

Measurement procedures were comparable in the three studies, although there were minor differences in the assessments of awareness and use. Furthermore, in study of the Dutch Communitybased Smoking Cessation Project a bogus pipeline procedure was applied to validate the self-reported smoking status (29). In all three studies the interviews collected data on demographic characteristics (age, sex, education), smoking status, determinants of quitting (attitude, social influence, self-efficacy, and intention to quit), and awareness, use and evaluation of the treatment modalities. The intervals between measurements, however, varied from three weeks to six months. This variation in follow-up time limits the comparability of the results of these three projects. Therefore, we focused on the evidence concerning use and evaluation of the self-help manual in different community settings. 


\section{STudy 1: The Dutch COMmunity-BASEd SMOKIng Cessation PROJECT}

\section{Research Design}

To evaluate the impact of a community approach to smoking cessation, a study funded by the Dutch Cancer Foundation was set up which applied a quasi-experimental design with one experimental and one control city. Cities with a population of $100,000-150,000$ were screened on demographic characteristics (such as age and sex distribution, income, educational level, and degree of urbanization) to select cities with a size and population that was comparable to the average Dutch city. Two cities that had not planned smoking cessation activities were chosen and assigned to the intervention condition (Den Bosch) and the control condition (Apeldoorn).

Three computer assisted telephone interviews at 6 monthly intervals were conducted among a cohort of smokers in both cities ( $n=$ approximately 550 smokers in each city). Smokers for the study were selected via telephone screening from a random sample of private telephone numbers. The pretest was conducted in November 1989.

A study was set up to determine the effectiveness of the different treatment modalities. Applicants who requested a self-help manual, group participants, and smokers who were referred by their general practitioner, were subjected to a computer assisted telephone interview before they received the manual or before the group started. After a follow-up period of 6 months these groups were interviewed again.

\section{Program And Procedure}

A community inventory showed that the inhabitants of Den Bosch saw smoking cessation activities as a part of the tasks of the official organizations, such as the local health service (GGD), the consultancy for alcohol and other drugs (CAD) and the community-based health organization Green Cross (GC). Representatives of these organizations, and of other social organizations in Den Bosch had similar opinions. As a result, a project group of health educators employed by the GGD, $\mathrm{CAD}$ and $\mathrm{GC}$ was formed. This group was responsible for developing the intervention in co-operation with the research team, and implementing it in the community.

The resulting intervention consisted of activities to attract the attention of smokers and offer them the choice of the most appropriate modality (see figure 2). 


\section{Attention Requests and Modalities} referral

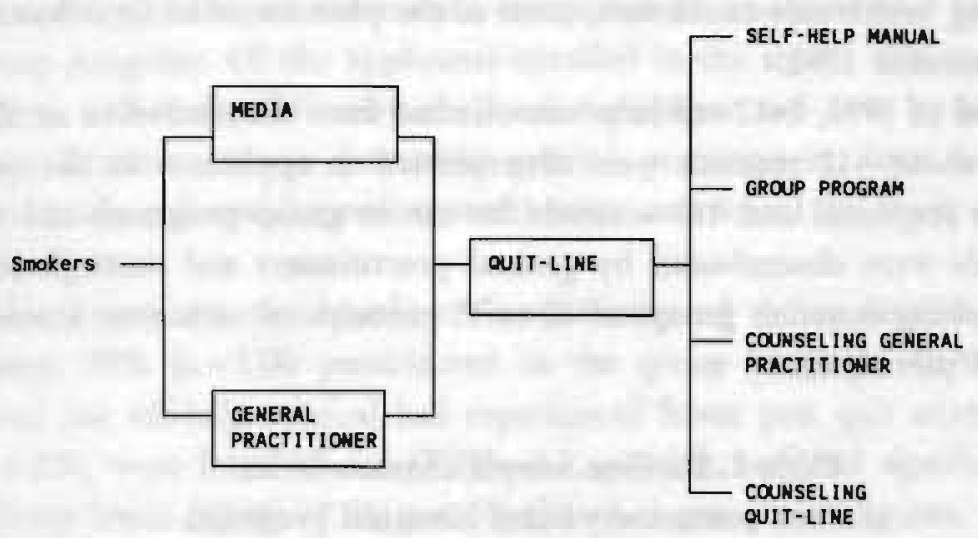

Figure 2. Community-based Smoking Cessation Intervention

Local media resources (i.e., newspapers, advertising papers, posters, radio stations and television news programs) were used to recruit smokers for the study. In addition, general practitioners were used to provide information about the health hazards of smoking and the advantages of quitting, and to refer smokers to a telephone quit-line.

The quit-line was staffed by trained counselors who advised the smoker how ot choose between the offered modalities: a free self-help manual; a three-week group program, costing participants about $\$ 15$ (U.S. dollars); guidance and counseling by the general practitioner or telephone counselors, or a combination of these modalities.

The group program was carried out by trained employees of the GGD, the CAD and the GC. The group counselors decided to use the self-help manual as the written material for the group program.

The intervention started in March 1990. A protocol and flow chart were developed (30) in order to guide general practitioners in the most effective ways to disseminate the manual and to encourage their smoking patients to quit. Instructions for general practitioners on how to apply the protocol could not be fitted into their already overloaded regional educational program. However, half of the 40 general practitioners in Den Bosch signalled their interest in the protocol and were sent written instructions on how to use it. They were also 
offered oral instructions on the use of the protocol, and 13 GP's took up the offer. The 20 interested general practitioners actively approached approximately 540 smokers during the intervention period. To enhance the diffusion of the manual among health care consumers, most of the pharmacies in Den Bosch were included in autumn 1990.

By the end of 1990, 1412 self-help manuals had been distributed to smokers in Den Bosch: about 412 manuals were disseminated to applicants at the quit-line (294 manuals requested and 118 manuals for use in group program) and around 1,000 manuals were disseminated by general practitioners and through pharmacies. Ten smoking cessation groups of 10 to 15 participants each were attended by a total of 118 participants.

Table 1. Baseline sample characteristics of three community-based cessation programs

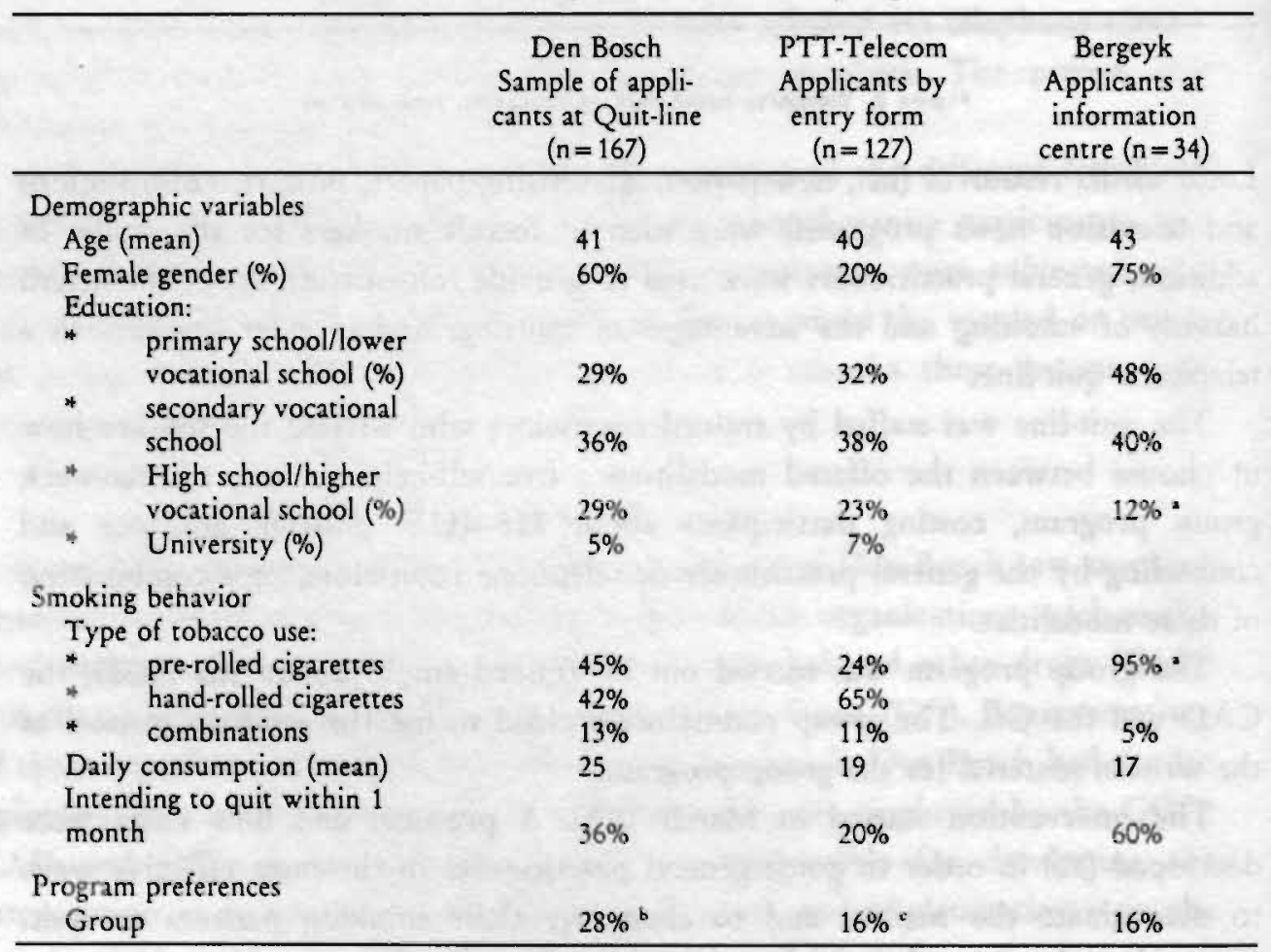

- categories not differentiated in questionnaire

b 118 group participants in 417 applicants

- 25 group participants in 155 applicants 


\section{Participants In The Modalities}

Two separate samples were taken from applicants who responded to the quit-line. The first of these samples consisted of 84 smokers who had requested the selfhelp manual, and the second sample comprised 83 smokers who participated in the group program. Of the applicants enrolled in the study, $47 \%$ reported being induced to call the quit-line by the local newspaper and $11 \%$ by advertisement papers. All other sources (including general practitioners, local television and radio stations, and social environments) were mentioned by fewer than $10 \%$ of the participants.

Table 1 presents the base-line characteristics of the applicants. Of the 417 applicants, $28 \%(n=118)$ participated in the group program. Participants who requested the self-help manual had experienced fewer past quit attempts $\left(X^{2}(1)=\right.$ $5.4, p<.05)$, were less addicted $\left(X^{2}(1)=4.7, p<.05\right)$, and had significantly higher self-efficacy levels $(t(165)=2.91, p<.01)$ than had group participants.

Sixty-seven percent $(n=56)$ of the applicants who preferred to quit individually knew of the group program before calling the quit-line. An additional 12 applicants were informed by the counselor during the first contact. This resulted in $85 \%$ of the individual quitters knowing of the possibility of participating in a group program but who preferred to quit on their own.

In the post-test, $80 \%(n=134)$ of the base-line respondents were contacted (see table 3).

\section{Use And Evaluation Of Program Modalities}

About 417 calls were received by the quit line. Almost all calls concerned the request for a manual $(n=294,71 \%)$ or participation in a group program $(n=118$, $28 \%$ ). Only five calls were received from smokers asking for advice or counseling.

Sixty-seven percent of participants read the manual completely, $20 \%$ read at least half, $4 \%$ less than half, and $9 \%$ did not read it at all. The most popular parts of the manual dealt with nicotine fading, incorporation of the social environment and a self-test for type of smoking behavior (see table 2). The table cards and the tips on weight reduction were less frequently used. The group participants used the sections referring to the breathing exercise, rewarding oneself, nicotine fading, recording personal reasons for quitting, listing difficult situations, telling others, and the self-test for smoking behavior significantly more than did self-help participants. Both the self-help manual and the group program were evaluated positively ( 7.4 on a scale from 1 to 10$)$. 
Table 2. Utilization of the self-help manual

\begin{tabular}{lccc}
\hline & $\begin{array}{c}\text { Self-help } \\
(\mathrm{n}=70)\end{array}$ & $\begin{array}{c}\text { Group } \\
\text { participants } \\
(\mathrm{n}=64)\end{array}$ & $\begin{array}{c}\mathrm{X}^{2} \\
(\mathrm{df}=1)\end{array}$ \\
\hline Read (parts of) manual & $94 \%(\mathrm{n}=66)$ & $88 \%(\mathrm{n}=56)$ & $\mathrm{ns}^{*}$ \\
Used part about: & & & \\
* breathing exercise & $36 \%$ & $59 \%$ & $5.32, \mathrm{p}<.05$ \\
* rewarding oneself & $30 \%$ & $59 \%$ & $8.97, \mathrm{p}<.01$ \\
* nicotine chewing gum & $35 \%$ & $45 \%$ & $\mathrm{~ns}$ \\
* nicotine fading & $35 \%$ & $77 \%$ & $12.19, \mathrm{p}<.001$ \\
* recording personal reasons & $38 \%$ & $71 \%$ & $12.38, \mathrm{p}<.001$ \\
* listing difficult situations & $20 \%$ & $52 \%$ & $12.43, \mathrm{p}<.001$ \\
* telling others & $47 \%$ & $73 \%$ & $7.58, \mathrm{p}<.01$ \\
* weight reduction & $27 \%$ & $38 \%$ & $\mathrm{~ns}$ \\
* self-test smoking typology & $55 \%$ & $84 \%$ & $10.71, \mathrm{p}<.01$ \\
* table cards & $17 \%$ & $23 \%$ & $\mathrm{~ns}$ \\
* section to be read by others & $44 \%$ & $39 \%$ & $\mathrm{~ns}$ \\
\hline
\end{tabular}

ns= not significant

\section{Behavioral Changes}

The overall result of the intervention in the Den Bosch (experimental town) and Apeldoorn (control town) population of smokers shows that the quit rates in both cities did not differ significantly at the end of 1990 (7.3\% in Den Bosch and $8.9 \%$ in Apeldoorn). However, only $5 \%(n=30)$ of the smokers in the cohort in Den Bosch actively participated in the program. A major reason for finding no significant differences is that the intervention lacked power to attract smokers, due to the partial failure of the media strategy.

The modalities, however, showed encouraging results (see table 3), and $22 \%$ of the group participants (18 quitters in a group of 83 baseline participants) were abstinent 6 months after starting the group. Among the smokers who requested the self-help manual, 13\% (11 quitters in a group of 84 smokers) were abstinent 6 months after receiving the manual. To compare the effectiveness of the two modalities (the group program and the self-help manual), we considered only those respondents who made an attempt to quit. It is known that $77 \%(n=64)$ of the group participants tried to quit, and $28 \%(n=18)$ of them were successfully abstinent after 6 months. Of those who requested the self-help manual, 33\% $(n=28)$ attempted to quit, of whom $39 \%(n=11)$ were abstinent after 6 months. To determine statistical significance of the difference between modalities, the research groups were to small. 
Table 3. Sample size, drop-out and abstinence rates in three community-based smoking cessation programs

\begin{tabular}{|c|c|c|c|}
\hline & Den Bosch & PTT-Telecom & Bergeyk \\
\hline Base-line sample & 167 & 127 & 34 \\
\hline Period between base-line and post-test & 6 months & 3 months & 6 weeks \\
\hline Response rate in post-test & $80 \%$ & $90 \%$ & $91 \%$ \\
\hline $\begin{array}{l}\text { Self-help: } \\
\text { base-line participants } \\
\text { post-test abstinence } \\
\text { abstinence rate (public health approach) } \\
\text { tried to quit } \\
\text { abstinence rate (clinical approach) }\end{array}$ & $\begin{array}{c}84,50 \% \\
11 \\
13 \% \\
28,33 \% \\
39 \%\end{array}$ & $\begin{array}{c}104,82 \% \\
8 \\
8 \% \\
47,45 \% \\
17 \%\end{array}$ & $\begin{array}{c}28,82 \% \\
5 \\
18 \% \\
17,64 \% \\
29 \%\end{array}$ \\
\hline $\begin{array}{l}\text { Group program: } \\
\text { base-line participants } \\
\text { post-test abstinence } \\
\text { abstinence rate (public health approach) } \\
\text { tried to quit } \\
\text { abstinence rate (clinical approach) }\end{array}$ & $\begin{array}{c}83,50 \% \\
18 \\
22 \% \\
64,77 \% \\
28 \%\end{array}$ & $\begin{array}{c}23,18 \% \\
6 \\
26 \% \\
23,100 \% \\
26 \%\end{array}$ & $\begin{array}{l}6,18 \% \\
2 \\
33 \% \\
4,67 \% \\
50 \%\end{array}$ \\
\hline
\end{tabular}

- percentages of initial sample

${ }^{b}$ percentage of smokers who tries to quit

\section{Summary}

The communitybased smoking cessation intervention in Den Bosch was not successful in altering the smoking behavior of the general population. Process analyses suggested that this was due to the relatively small proportion of active participants who were attracted to the program.

Separate modalities using the self-help manual attracted specific segments of the target group and were effective in bringing about behavior change. Smokers who had stronger perceptions of self-efficacy, fewer previous quit attempts, and who were less addicted were more likely to prefer quitting on their own, even though the majority were aware of the group program.

The manual was used intensively and evaluated positively, with $87 \%$ of the participants reading at least half of it. Although it was offered as an option to all smokers who requested a manual, the combination of self-help manual and telephone counseling did not prove popular. It is conceivable that the Dutch are not yet accustomed to personalized telephone services. This may also explain in part the low number of smokers who acted on their general practitioners' advice to call the quit-line. 


\section{STUDY 2. SMOKING CESSATION AT THE WORKPLACE: PTT-TELECOM}

\section{Research Design}

A quasi-experimental design was used to study the impact of a smoking cessation program in PTT-Telecom, a large company employing approximately 30,000 workers which is responsible for the management and implementation of Dutch telecommunications infrastructure. The smoking cessation program was carried out in the PTT-Telecom district of Arnhem, consisting of 1,700 employees working in nine sites. The comparable district Utrecht of PTT-Telecom with 2,800 employees served as the a control.

All employees in both the intervention and the control district were send entry forms on which they could report their preference for a self-help or a group modality smoking cessation program. The smokers who returned the form in the control district were informed that the PTT-Telecom was considering future action but that no immediate activities were planned, thus creating a waiting-list control group. All smokers in the intervention district who returned the entry form were submitted to a base-line computer assisted telephone interview, carried out by trained interviewers, before the program and again after 3 months.

\section{Program And Procedure}

After introducing non-smoking policies, PTT-Telecom decided to offer support for employees who wanted to stop smoking. Smoking cessation programs conducted in the workplace have the potential to reach a large proportion of smokers who are difficult to recruit in to programs through other community channels (e.g., smokers with a lower socio-economic status) (31).

The smoking cessation program was announced in the districts weekly newsletter in April 1990, and through posters in the workplace. Participation in the program was voluntary and free.

A short questionnaire was included in the entry form which assessed smoking status and expected barriers to quit. This information was used to provide written advice, tailored to the individual's concerns, as part of the intervention. The idea of the advice letter was to make the information in the manual more personally relevant. Standard advice for five common barriers (gaining weight, stress, withdrawal symptoms, social pressure, and maintenance problems) was included as part of the tailored letter. 
One hundred and fifty-five smokers from the Arnhem district returned their entry forms. In a population where $40 \%$ of all employees smoke (32), this is a response rate of $24 \%$ of smokers who enrolled for the program. In the control district Utrecht 239 smokers returned their entry form (about 22\% of all smokers in the control district). In the intervention district $34 \%(n=52)$ of the applicants wanted to participate in the group program and were sent the self-help manual together with the tailored letter and an invitation to sign up for a quit-smoking program. This resulted in 25 smokers who enrolled in the group program. Twenty-seven smokers indicated that they were interested in the group program but could not sign up because of practical reasons. The 103 applicants who preferred self-help, and the 27 applicants who could not attend the group program, received a manual and a personalized letter.

\section{Participants}

The interviewers contacted $23(92 \%)$ smokers of the group participants in the base-line interview and 104 of the remaining applicants (80\% of 130 applicants). In the control district $187(78 \%)$ of the applicants were interviewed at base-line.

The base-line characteristics of the respondents in the intervention district are given in table 1. Compared to the group of applicants in the community-based study and the pretest group described before, this group contained more male respondents and more smokers of hand-rolled cigarettes. The percentage of female respondents $(30 \%)$ was consistent with the percentage of female employees in the company. The worksite respondents in this sample population seemed less motivated to quit within 30 days than did those in the Den Bosch study. The difference in daily consumption between the Den Bosch participants and the PTT-Telecom respondents may have been caused by the bogus pipeline procedure that was applied in the Den Bosch study.

Compared to respondents who were interested in the group program, applicants for the self-help manual were significantly lighter smokers $(F(1,91)=$ $13.18 ; p<.001)$ and were less motivated to quit $(F(1,91)=7.49 ; p<.01)$. Self-efficacy levels of smokers who tried to quit on their own were significantly higher than reported by participants of the group program $(F(1,54)=4.54 ; p<.05)$.

The response rate at the post-test was $90 \%$ in the intervention district and $82 \%$ in the control district. 


\section{Awareness, Use And Evaluation Of Program Modalities}

Table 4 presents the awareness, utilization and evaluation measures of respondents in Arnhem for the different program components. The poster, manual and group course were well recalled. Respondents were less familiar with the telephone line and the personalized letter, which the majority could not recall. An explanation is that smokers confused the letter with the formal introduction letter that went with the package. Those respondents who remembered the letter evaluated it positively.

Over half $(54 \%)$ of the respondents read the manual completely, $18 \%$ read at least half, $18 \%$ read less than half, and $10 \%$ did not read it at all. The readers evaluated the manual highest of all program components ( 7.7 on a scale from 1 to 10). Among those respondents who had tried to quit, $55 \%$ said that the manual was supportive. Furthermore, $32 \%$ of respondents who were still smoking at post-test indicated that they intended to reuse the manual for future quit attempts. Twenty-five percent of respondents still smoking said that they would probably use the manual in the future, and $13 \%$ were uncertain.

Table 4. Program evaluation of respondents

in the PTT-Telecom workplace $(\mathrm{N}=114)$

\begin{tabular}{lccc}
\hline Program component & Awareness (\%) & Utilization (\%) & Evaluation $^{2}$ \\
\hline Poster & $83 \%$ & - & 7.3 \\
Self-help manual & $98 \%$ & $90 \%$ & 7.7 \\
Tailored letter & $36 \%$ & $14 \%$ & 7.1 \\
Group program & $97 \%$ & $18 \%$ & 7.5 \\
Telephone quit-line & $49 \%$ & $2 \%$ & - \\
\hline
\end{tabular}

$$
\therefore 1=\text { bad; } 10=\text { good. }
$$

\section{Behavioral Changes}

Self-reported quit rates at the 3-month follow-up were significantly higher in the intervention district; 14 of $127(11 \%)$ respondents had quit successfully as result of the program compared with 3 of $187(2 \%)$ in the control district $\left(X^{2}(1)=11,13\right.$, $\mathrm{p}<.001)$. Furthermore, in the experimental condition, smokers who continued to smoke reduced their daily tobacco consumption by four cigarettes per day. This is a significant difference when compared with the control condition, where 
smokers reduced their daily consumption on average by one cigarette per day $(\mathrm{F}(1,239)=16,81 ; \mathrm{p}<.001)$.

The two modalities showed quit rates of $8 \%$ in the self-help group ( 8 quitters in a group of 104 baseline participants), and $26 \%$ in the group program (6 quitters in a group of 23 baseline participants) (see table 3). For the second measure of success, based on the clinical approach, only those subjects who actually tried to quit were considered. All group participants tried to quit, but only $45 \%(\mathrm{~N}=47)$ of those who requested the self-help manual did so. This view results in quit rates of $26 \%$ in the group and $17 \%$ in the self-help condition. The statistical significance of the abstinence differences between the two conditions could not be confirmed, since the numbers of participants were to small.

\section{Summary}

The PTT-Telecom smoking cessation program involved health education strategies to support quit attempts in the workplace. We found that offering a choice between a self-help method (manual and tailored advice) and a group method (group support, self-help manual and tailored advice) resulted in $24 \%$ of smokers returning an entry form, and $82 \%$ of these smokers participating in the project. Because of its relative cost-effectiveness, a self-help method is essential to a worksite smoking cessation program (33).

At least half of the manual was read by $74 \%$ of the applicants, who evaluated it positively. The majority of the applicants (66\%) preferred quitting on their own with the help of the manual, although all participants were offered participation in a group program. The group participants were more motivated to quit and were heavier smokers than the individual quitters, however they had a lower level of self-efficacy. This may indicate that a specific segment of the target group of motivated smokers is attracted by the self-help modality.

\section{Study 3. The Local Health PROJECt Healthy BergeyK}

\section{Research Design}

This study was funded by the Dutch Cancer Foundation to determine the overall behavioral effects of a local project aimed at reducing the incidence of cancer and coronary heart diseases. The intervention was carried out in Bergeyk, a small Dutch municipality with 10,000 inhabitants, while the comparable community of Swalmen served as control. Random samples of 1,000 inhabitants were taken 
from the automatized population registers in both communities. Computer assisted telephone interviews were conducted in February 1990, and in February and September 1991.

To evaluate the self-help manual a registration form and an evaluation form were developed. The registration form was completed by one of the volunteers at the information centre where smokers could get a manual. About 6 weeks later, a post-test was conducted in which applicants were interviewed by telephone by one of the volunteers who filled in the evaluation form.

\section{Program And Procedures}

The Project Healthy Bergeyk was a local health program which stimulated healthy lifestyles among the inhabitants of Bergeyk. A project group was formed representing 11 different interest groups (for example, neighborhood associations, women's associations, industry, health sector). The project group was supervised by a part-time professional social worker, and the group prepared community activities from February 1990 to August 1990, using a workbook developed by the Department of Health Education of the University of Limburg (34). Thirty possible health activities were described in the workbook, covering four risky behaviors: smoking, high fat intake, high alcohol consumption and use of solaria. The proposed health activities were divided over five program components:

1. Mass media messages;

2. Self-help materials and group activities;

3. Information centre;

4. Activities involving key community figures (for example, organizing meetings for opinion leaders to enhance their influence on health matters);

5. Structural activities (for example, stimulating smoking restrictions in workplaces).

The program implementation took place from September 1990 to February 1991. The health information centre was staffed with 16 trained volunteers. Participants could visit or call the centre to ask questions concerning the project or specific activities, to enrol in modalities or to request materials.

Implementing the self-help manual was one of the activities proposed in the workbook as an instrument to reduce the number of smokers in the community and was adopted by the project group as part of their health program. Other stop smoking activities in the community included a group program and mass media 
messages (for instance, interviews with participants of the group program in the local newspaper). In addition to this, the projectgroup stimulated smoking policies in workplaces. Smokers in Bergeyk could order a free self-help manual at the health information centre.

Information about the availability of the self-help manual and other activities was spread via mass media channels (such as newspaper interviews with participants in the group program and exhibitions). Information about health activities was also disseminated by the project group members to interest groups.

\section{Participants}

From September 1990 until February 1991, 37 inhabitants of Bergeyk requested the manual. Three applicants did not smoke, but two requested the manual for someone else and the other requested the manual in order to maintain abstinence. Six of the applicants participated simultaneously in a group course. The evaluation form was filled out by 31 people. Base-line characteristics of the applicants are presented in table 1. Compared with the applicants in the two studies describe above and the pretest group for the manual, more women and smokers with a lower educational level requested the manual in Bergeyk. Almost $77 \%$ of applicants stated the intention to stop smoking within the next year, and $60 \%$ indicated that they intended to stop smoking within a month.

Most respondents said they were induced to request the manual by an advertisement in the local newspaper $(27 \%)$ or because they had heard about it from an acquaintance (27\%). Almost $20 \%$ had heard about the manual while participating in one of the other activities of the project. Some people had heard. about the manual in a meeting of their association (15\%) or because they had visited an information stand of the project group (12\%). Almost all the applicants (96\%) knew about the possibility of participating in a group course, but $82 \%$ preferred to use the self-help manual without attending the group program.

\section{Use And Evaluation}

With the exception of one person, all the respondents who requested the manual for themselves read parts of it, and about $82 \%$ read the manual completely. Almost half $(46 \%)$ of all readers indicated that the manual was also read by other people in their environment. All the readers saved the manual for possible future use. 
On average, the respondents rated the manual 8 on a scale of 1 to 10 . Those aspects of the manual which were evaluated most favorably were its clarity, its motivational power and the suggestions for quitting and maintaining abstinence.

After reading the manual, almost $75 \%$ said that they thought smoking was more risky than they had previously believed. About $60 \%$ said they had found quitting to be more difficult than they had anticipated. Motivation to quit increased in $71 \%$ of the readers. Of all respondents who indicated that they had tried to quit, $64 \%$ said that the manual was a supportive aid to their quit attempt.

The most common reasons given for why the manual did not help people stop smoking or maintaining abstinence were insufficient will power or motivation, inadequate motivation, and fear of weight gain. Of those who were still smoking at posttest $69 \%$ thought they would reuse the manual, $19 \%$ thought they would probably use it again, and one respondent did not know.

\section{Behavioral Changes}

In both the experimental and the control communities about 600 respondents of the cohort completed all three tests. In Bergeyk the percentage of smokers decreased from $36 \%$ in February 1990 to $32 \%$ in February 1991. In September 1991 the percentage of smokers had increased marginally to $33 \%$. In the control community the percentage of smokers was more stable: $33 \%$ in February 1990, $32 \%$ in February 1991 and 32\% in September 1991. However, the decrease in the percentage of smokers in Bergeyk during the preparation, intervention and follow-up periods did not differ significantly from the decreases in the control community. This was probably due to the relatively small percentages of smokers in the overall samples.

The modalities also showed positive results in Bergeyk (see table 3). Of the smokers who requested the manual with the intention to quit individually, $18 \%$ $(n=5)$ were abstinent after 6 weeks follow-up, and one third $(n=2)$ of the group participants $(n=6)$ were not smoking after about 6 weeks. When considering only those subject who attempted to quit, there was a $29 \%$ success rate in self-help quitters who tried to quit $(n=17)$, and a $50 \%$ success rate for quitters in the group modality (where four out of the six participants attempted to quit, and only two succeeded).

\section{Summary}

No significant differences between experimental and control condition concerning quitting could be determined. This was probably due to the relatively small 
percentages of smokers in both samples. However, the behavioral results in the two modalities were positive. Because of the small numbers of group program participants, no comparison of self-help participants and group participants could be made. Still, the characteristics of the self-help participants lead to the conclusion that a specific segment of the target group benefits from the manual. Overall, the manual was very well received and was successful in the short term for $18 \%$ of the applicants. Although the motivation of people who read the manual increased, self-help manual users indicated that weight gain and lack of motivation and willpower were the main reasons for relapse.

The self-help manual proved to be effective in getting people to stop smoking; few people ordered the manual $(n=37)$. Process evaluation of the project showed that although the project group worked extremely hard and established many effective health activities in their community during the 6-month implementation period, it may take more time in order to find significant behavioral effects at the community level.

An additional explanation may be that smoking cessation activities had to compete with the other topics in the "Healthy Bergeyk" project (for example, nutritional education), which may have caused a lower or delayed interest in smoking cessation in the project group as well as in potential participants.

\section{CONCLUSIONS AND DISCUSSION}

In this chapter the development and evaluation of a Dutch self-help smoking cessation manual has been described. This section summarizes and discusses the main conclusions, focusses on the utility of the manual and suggests directions for further research.

\section{Conclusions}

A process of pretesting was used to develop a Dutch self-help manual for smoking cessation. Two pretests, using target group samples and eight experts, were conducted. The opinions of the target group were used for issues concerning general impression, attention, understanding, personal relevance, confidence, acceptance and unplanned effects. The experts gave judgments on the conceptualization of theoretical principles. Pretesting facilitated the assessment of opinions of the target group and experts in the development process of the manual. It became clear that merely translating a foreign manual would have been insuffi- 
cient. By checking out whether the message contributed to the realization of the intervention goals, it was hoped that pre-testing would enhance future utilization and effectiveness of the manual.

Three community-based applications of the manual were presented: a community-based smoking cessation project in Den Bosch, a workplace smoking cessation project in one of the districts of the PTT-Telecom company, and a local health project "Healthy Bergeyk" in a small municipality, which covered four risk behaviors including smoking. In all three applications, participants chose between quitting on their own or participating in a group program. The smokers who preferred to quit on their own received a free self-help manual. In Den Bosch, 1,412 manuals were distributed in a population of approximately 33,000 smokers, thus creating a coverage of over $4 \%$ of smokers. In the workplace project (PTT-Telecom) the coverage was $24 \%$ (155 manuals distributed in a population of 645 smoker) and in Bergeyk, manuals were distributed to $1 \%$ of the smoking population ( 37 manuals among approximately 3,000 smokers). Hence, the workplace project was the most effective means of disseminating the manual.

In the two local community interventions (i.e., the Den Bosch project and "Healthy Bergeyk" project) the overall results of the experimental conditions did not differ significantly from the control conditions. However, the PTT-Telecom workplace project showed positive effects, possibly caused by the wider dissemination of the manual. Other community-based projects have shown that changes at a local level take time (35), a factor that was limited in these two projects, since the project in Den Bosch had an implementation period of 9 months and the project of Healthy Bergeyk, only 6 months. Abrams et al. (36) states that it can take 2.5 years before a change is noticed in the workplace, so it would take at least this length of time in a large community.

Another reason for the absence of positive overall results may have been a national publicity campaign on the introduction of a smoking ban for public buildings, which immediately preceded the interventions. This previous media campaign may have demotivated a part of the target population and disturbed the media campaign in Den Bosch. This may have been a causal factor for the relatively small number of participants in the project.

The utilization rate among people who requested the manual varied from project to project and limits the interpretation of the results. We computed quit rates in two ways, by accounting for: a) all those who entered the studies with the intention of quitting; and b) only those smokers who attempted to stop 
smoking (see table 3). This procedure resulted in a $13 \%$ quit rate among smokers who requested the manual in Den Bosch ( 6 months follow-up), $8 \%$ in the PTT_Telecom workplace ( 3 months follow-up), and 18\% in Bergeyk (6 weeks follow-up). Among smoker who tried to quit with the manual, abstinence rates of $39 \%$ in Den Bosch ( 6 month follow-up), $17 \%$ in the workplace ( 3 months follow-up), and 29\% in Bergeyk (6 weeks follow-up) were recorded.

Quit rates of participants in the group programs were higher than those obtained by smokers who attempted to quit by themselves; $22 \%$ of group participants in Den Bosch were abstinent at 6 months follow-up, and $26 \%$ at 3 months follow-up in the PTT-Telecom workplace project. In Bergeyk there were two abstinent smokers out of a group of six. When considering only those group participants who tried to quit, quit rates were $28 \%$ in Den Bosch and $26 \%$ in the workplace. In Bergeyk four smokers tried to quit.

The differences between the quit rates of the three projects may be caused by the variation in follow-up periods and also by the differences in efforts required to receive self-help manual. In the workplace project the effort required was minimal, as all smokers who indicated some interest in quitting were sent a manual. This may have resulted in a larger number of manuals reaching less motivated applicants who did not use it, while in Den Bosch and Bergeyk, the smokers who wished to have a manual had to call or visit the referral point. Employees may also have had reservations about participating in a workplace group program because of the risk of failing in front of colleagues. On the other hand the free and readily available nature of the group program may have attracted a segment of the smoking population that otherwise would have selected an inexpensive self-help method. This may have resulted in a somewhat different sample composition, as those in the workplace have better access to a group program. It is quite possible that these people may have chosen to quit on their own if they were in the other community trials. This suggestion is supported by the fact that in the workplace project, individual quitters were less motivated than were group participants.

Schwartz (15) concluded in his review of U.S. and Canadian smoking cessation interventions that median quit-rates after 6 months follow-up were $17 \%$ among those in self-help conditions and $24 \%$ among those who participated in group programs. Hence, the results of the two modalities in Den Bosch are comparable to similar interventions conducted outside the Netherlands. The results of the PTT-Telecom workplace project were in line with a number of reviewed workplace projects, that had a similar follow-up period, although the 
results of the group program tended to be lower than the average. The quit rates in the projects that were reviewed by Schwartz (15) varied from 8 to $18 \%$ for individual quitters (five studies reviewed), and from 23 to $40 \%$ in group participants (four studies reviewed). Because of the short follow-up period of the project in Bergeyk, no comparisons can be made with the results of other projects.

\section{Evaluation And Use of The Manual}

The quality and effectiveness of the pretest process was confirmed by positive evaluations. The Dutch self-help manual was evaluated by all participants. At least half of the manual was read by the majority of applicants. The manual was evaluated on a scale form 1 (bad) to 10 (good) with a 7.4 in Den Bosch, a 7.7 in the PTT-Telecom project, and 8 in Bergeyk. In the three studies different measures for the use of the manual were obtained, all of which indicated intensive use. The manual was used differently in the group program, where the exchange of experiences may have stimulated smokers to use the manual in greater depth.

The majority of the smokers in Bergeyk and in the PTT-Telecom workplace project who did not succeed in quitting stated that they would certainly or probably reuse the manual. In Bergeyk all applicants saved the manual, and $46 \%$ of the applicants indicated that others in their environment had read the manual too.

\section{The Target Group}

The results of the three studies indicate that there is a specific segment of the smoking population who will benefit from a self-help manual. During the development of the manual, the hypothesized target group for the manual consisted of heavy smokers with a lower to average level of education, aged 35 years or older, and divided equally between the sexes. In the workplace project the percentage of female applicants was consistent with the percentage of female employees, but in Den Bosch and Bergeyk relatively more female applicants were listed (60\% in Den Bosch and $75 \%$ in Bergeyk). This is consistent with other evidence that women are more attracted by health-related messages (P.Vierkant, unpublished doctoral dissertation, University of Groningen, 1987). To attract more men, different strategies from mass media approaches, such as workplace projects, may have to be applied. 
An indicator for the existence of a specific target group for self-help manuals is that the vast majority of the applicants knew of the availability of a group program but still preferred the self-help method. Finally, the existence of this specific target group is illustrated further by the fact that individual quitters in Den Bosch and in the workplace project differed from group participants.

\section{Implications For Future Diffusion And Research}

To enhance the probability of adoption and diffusion of an innovation Rogers (1) identifies five attributes: relative advantage, compatibility, complexity, trialability, and observability. The process of pre-testing the self-help manual conforms to some of these attributes, and the results of the community applications indicates that other conditions for diffusion were also met.

\section{- Relative Advantage}

The relative advantage of an innovation refers to its superiority (perceived or actual) compared to the current practice. The main relative advantage of the manual is that it appeared to be effective and was positively evaluated in different community settings (average sized city, workplace and small town), and in the various methods (self-help and group program). The perceived flexibility of the manual was supported by the results of two projects based on the self-help manual in other settings. In Twente, a region of the Netherlands, the manual was used in the evaluation of the effectiveness of a protocol for general practitioners which was very similar to the protocol developed for Den Bosch. In the described project the manual was also positively evaluated by both practitioners and patients. The long-term quit rates that resulted from this study were promising: after one year follow-up $11 \%$ of all smokers in the experimental group $(n=269)$ and $6 \%$ in the control group $(n=264)$ were abstinent. From a clinical perspective (including only those respondents who complied, $n=177$ ), the quit rate in the experimental group was $16 \%$ (37).

Another application of the self-help manual was a TV-clinic, broadcast by the Dutch educational television station Teleac. Testimonials of smokers in the process of quitting were the main component of the six TV programs. A psychologist linked these testimonials with information given in a book that was part of the TV clinic. This book (38) provided basically the same information as the self-help manual. This method was evaluated very positively by its users and the behavioral changes were considerable after one year follow up: $19 \%$ of all participants who bought the book were abstinent (38). 
A further advantage of the self-help manual is cost effectiveness. The manual described in this chapter cost about $\$ 3$ (all costs in U.S. dollars). If the unused manuals and the manuals that did not lead to successful quitting were considered (about seven manuals needed for one successful quitter after 6 months), the average cost of each successful manual was about $\$ 21$. The charge for the group program was about $\$ 15$ in Den Bosch and $\$ 40$ in Bergeyk. Taking the failures into account (one success in four participants), and using the cheaper fee, a quitter in the group program cost the project about $\$ 60$. This computation is incomplete because the time required to participate and the additional costs for recruiting are not taken into account.

\section{- Compatibility}

The compatibility of the manual refers to its congruence with the current norms and values. In the process of pretesting, the manual was adjusted to the needs and preferences of the hypothesized target group. The studies in community and other settings showed that the manual can be used in different ways: on an individual basis with the optional prompt of the general practitioner, in a group program. or as a support to a TV clinic.

\section{- Trialability}

Trialability is the degree to which an innovation may be experimented with or implemented on a limited scale. Trialability of proposed changes in the manual was relatively easy to accomplish. Individual quitting can be experimented with easily, without great investment of money or time. many smokers who had failed to quit using the manual stated that they were prepared to read it again. In other words, the manual could be read whenever the person wanted to, and he or she was not locked into something that could not be put down (this was seen as a distinct advantage of the manual).

\section{- Observability}

Observability refers to the visibility of the results of the innovation. However, as the positive results were relatively modest (about two thirds of the users of the manual relapse within six months), the observability of the innovation (quitting) was rather small. To change this aspect, the effectiveness of quit attempts should be enhanced significantly by using a multipronged approach over time. However, this was not feasible in the time constraints for these studies. 


\section{Future directions}

Tailoring the manual with respect to future intermediaries who are to distribute the manual, and to the segments of the target group, may enhance its compatibility. To enhance adoption of the manual by intermediaries, it is necessary that all relevant structures (for instance, the Organization of Dutch General Practitioners) to embrace the idea of implementing the manual. Effective dissemination strategies using intermediaries should be developed. The possibility of segmentation of the target group is another factor that needs further investigation. The manual was written with the characteristics of the average smoking population in mind. However, any population has many subpopulations which have their own specific characteristics and their own compelling arguments for change. Tailoring the manual to the individual characteristics of different target groups can be accomplished by accounting for three main aspects: motivational level (for example, pre-contemplator versus contemplators), arguments for quitting (for example, pregnant women, men with cardiac diseases), and strategies of distribution (such as distribution by doctors which results in reaching more health care consumers).

A number of these prerequisites is already accomplished or will be in the near future (funding permitted). The research team of the University of Limburg and the SHF have agreed to cooperate for the future development of materials, such as self-help methods, and evaluation of these materials and their strategies for dissemination. Moreover, a project including the national diffusion of an adapted version of the protocol for general practitioners, which includes the distribution of a self-help manual aimed specifically at patients of general practitioners, has started. The strategy, to be disseminated by the existing training structures for general practitioners, will be subject to pre-testing.

At the University of Limburg there is a project underway to examine the development and evaluation of a procedure for smoking cessation in workplaces, including cessation strategies and smoking policies. For this project the self-help manual is adapted to the characteristics of the employees in different divisions. Strategies for diffusion will be developed.

A planned project is the development of a manual for pregnant women to be distributed by midwives and general practitioners. This manual will also be pretested.

Recently a grant was awarded for research in which hypotheses concerning the relation between motivational level and need for information will be tested (40). It is hypothesized that precontemplators benefit most from attitudinal 
information about the health hazards of smoking, while contemplators need information that enhanced self-efficacy on order to quit. The conclusions may have important implications for future segmentation of the target group concerning motivational level and will result in different manuals for these groups.

To facilitate the development of these different versions of the manual, we will investigate whether there is an essential basic body of information and interchangeable parts in the manual which can be used for different segments of the Dutch population.

In conclusion, the assertion that the incorporation of pretesting in the development process of a self-help manual enhanced the probability of adoption and diffusion seems justified.

\section{REFERENCES}

1. Rogers EM. Diffusion of innovations. New York: Free Press, 1983.

2. Smoking and health Foundation (Stichting Volksgezondheid en Roken). Annual report 1991 (Jaarverslag 1991). Den Haag: Stichting Volksgezondheid en Roken, 1992:28-33.

3. Information Service Cigarettes and Tobacco (Voorlichtingsbureau Sigaretten en Shag). Anual report 1989 (Jaroverzicht 1989). Den Haag: Voorlichtingsbureau Sigaretten en Shag, 1990:4.

4. Schwartz JL, Dubitzky M. Expressed willingness of smokers to try 10 smoking withdrawal methods. Public Health Rep 1967;82:855-61.

5. Owen N, Davies, M]. Smokers' preferences for assistance with cessation. Prev Med 1990;19:42431.

6. Mudde AN, Dolders MGT, De Vries H. Rapportage publieks evaluatie Landelijke Actie Stoppen Met Roken, 1991. Den Haag NL: Stichting Volksgezondheid en Roken, 1993.

7. Jeffrey RW, Danaher BG, Killen J, Farquhar JW, Kinnier R. Self-administered programs for health behavior change: Smoking cessation and weight reduction. Addictive Behav 1982;7:57-63.

8. Glasgow RE, Klesges RC, Mizes SM, Pechacek TF. Quitting smoking: Strategies used and variables associated with success in a stop-smoking contest. J Consult Clin Psychol 1985;53:90512.

9. Gritz ER, Carr CR, Marcus AC. Unaided smoking cessation: Great American Smokeout and New Year's Day quitters. Psychosoc Oncology 1988;6:217-34.

10. Marlatt GA, Curry $S$, Gordon JR. A longitudinal analysis of unaided smoking cessation. J Consult Clin Psychol 1988;56:715-20.

11. Cummings KM, Emont SL, Jean C, Sciandra R. Format and quitting instructions as factors influencing the impact of a self-administered quit smoking program. Health Educ Q 1988;15:199. 216.

12. Davis AL, Foust R, Ordenlich $M$. Self-help smoking cessation and maintenance programs: A comparative study with 12-month follow-up by the American Lung Association. Am J Public Health $1984 ; 74: 1212-7$. 
13. Prue DM, Riley AW, Orlandi MA, Jerome A. Development of a computer-assisted smoking cessation program: A preliminary report. J Adv Med 1990;3:131-9.

14. Cohen S, Lichtenstein E, Prochaska JO, Rossi JS, Gritz ER, Carr CR, Orleans CT, Schoenbach VJ, Biener L, Abrams D, DiClemente C, Curry S, Marlatt GA, Cummings KM, Emont SL, Giovino G, Ossip-Klein D. Debunking myths about self-quitting: Evidence from 10 prospective studies of persons quitting smoking by themselves. Am Psychol 1989;44:1355-65.

15. Schwartz JL. Review and evaluation of smoking cessation methods: The United States and Canada, 1978-1985. U.S. Department of Health and Human Service, Public Health Service, National Institutes of Health, National Cancer Institute, NHI Publications No. 87-2940, 1987.

16. Epstein LH, Grumber NE, Lichtenstein E, Evans RI. Smoking research: Basic research, interventions, prevention, and new trends. Health Psychol 1989;8:705-22.

17. Prochaska JO, Velicer WF, DiClemente CC, Fava J. Measuring process of change: Applications to the cessation of smoking. J Consult Clin Psychol 1988;56:520-8.

18. Strecher VJ, Rimer B. Freedom from smoking for you and your family. American Lung Association, 1987.

19. Prochaska JO, DiClemente CC. Stages and processes of self-change of smoking: Toward an integrative model of change. J Consult Clin Psychol 1983;51: 390-5.

20. Marlatt GA, Gordon JR. Relapse prevention: Maintenance strategies in the treatment of addictive behaviors. New York, Guildford, 1985.

21. Strecher VJ, Rimer BK, Monaco KD. Development of a new self-help guide "Freedom from smoking for you and your family". Health Educ Q 1989;16:101-12.

22. Taylor SE, Thompson SC. Stalking the elusive "vividness" effect. Psychol Rev 1982;89:155-81.

23. Försterling F. Attribution theory in clinical psychology. Chicester UK: Wiley, 1989.

24. Roomer J. De praktijk van marketing-communicatie: Achtergronden, van concepten, teksten en ontwerpen. Deventer/Antwerpen: Kluwer, 1987.

25. Vroom B. Publieksonderzoek met behulp van de plus-en-min methode. Tijdschrift voor Taalbeheersing 1987;9:256-72.

26. Damoiseaux V. Listen, lusten en lasten van massamediale voorlichting. Assen NL: van Gorkum, 1988.

27. Mudde AN. Van het roken af. Maastricht NL: Universitaire Pers, 1989.

28. Roberts DF, Maccoby N. Effects of mass communication. In: Lindzey G, Aronson E, editors. Handbook of Social Psychology, vol.2. New York, Random House, 1985:539-98.

29. Evans RI, Rozelle RM, Mittelmark MB, Hansen WB, Bane AL, Havis J. Deterring the onset of smoking in children: Knowledge of immediate physiological effects and coping with peer pressure, media pressure and parent modelling. J Appl Soc Psychol 1978;8:126-35.

30. Mudde AN, Willemsen MC, Gerards F, Dubois VE. Stoppen met roken, een patiëntgerichte benadering. Medisch Contact 1989;44:1456-8.

31. Green LW, Kreuter MW. Health promotion planning: An educational and environmental approach. Mountain View, CA, Mayfield Publishing Company, 1991.

32. De Vries H, Willemsen MC. Een stoppen-met-roken programma bij PTT-Telecom, eindrapport. Maastricht, Rijkuniversiteit Limburg, Vakgroep Gezondheidsvoorlichting en -opvoeding, 1991.

33. Altman DG, Flora JA, Fortmann SP, Farquhar JW. The cost-effectiveness of three smoking cessation programs. Am J Public Health 1987;77:162-5.

34. Assema P, Steenbakkers M. Werkboek gezondheidsproject voor de gemeente Bergeyk. Mazstricht, Rijkuniversiteit Limburg, vakgroep GVO, interne publicatie, 1990. 
35. Preston MA, Baranowski T, Higginbotham JC. Orchestrating the points of community intervention: Enhancing the diffusion process. Int Q Community Health Educ 1988-89;9:11-34.

36. Abrams DB, Emmons KM, Linnan L, Biener L. Smoking cessation at the workplace: Conceptual and practical considerations. In: Richmond R, editor. Interventions for smokers: An international perspective. New York: Williams \& Wilkins; 1994:137-170.

37. Pieterse ME, Boekema AG, Seydel ER. Long-term effectiveness of a minimal smoking cessation program for general practitioners. Poster presented at the 2nd European Conference on Effectiveness of Health Promotion and Health Education, May 14-16 1992, Athens, Greece.

38. Mudde AN, Zeeman G. Stoppen met roken. Utrecht, Teleac, 1990.

39. Niewijk A. Effects of the multi-media course "Stop Smoking". Poster presented at the 2nd European Conference on Effectiveness of Health Promotion and Health Education, May 14-16 1992, Athens, Greece.

40. De Vries H, Bakbier E, Mudde A, Willemsen M, van Assema P. Differences between precontemplators, contemplators, actors and relapsers. Paper presented at the 8 th World Conference on Tobacco or Health, March 30 to April 3 1992, Buenos Aires, Argentina. Abstract Book 212. 


\title{
EVALUATION OF A DUTCH COMMUNITY-BASED SMOKING CESSATION INTERVENTION.
}

\author{
Aart N. Mudde, Hein de Vries \& Maria G.T. Dolders \\ Accepted for publication in Preventive Medicine, 1995;1.
}

ABSTRACT

Background: Until 1990, smoking cessation interventions in the Netherlands were limited. The utility and effectiveness of community-based smoking cessation programs bave not been examined.

Methods: In a treatment city (Den Bosch) a multi-component community-based smoking cessation intervention was implemented in which local mass media and general practitioners draw smokers' attention to a local Quit-Line. Telephone counselors advised applicants on their choice between self-help and group treatment and optional telephone counseling. Another Dutch city (Apeldoorn) served as a control. Population samples of smokers $(n=547$ and $n=546)$ were interviewed three times at approx. seven months intervals. Self-help manual requesters $(n=84)$ and group participants $(n=83)$ were interviewed before and 6 months after treatment.

Results: Treatment modalities were successful: $13 \%$ of self-help manual requesters and $22 \%$ of group participants were abstinent after 8 months. On a population level the intervention resulted in significantly bigher recall of self-help manual and group program in the treatment city. A modest intervention effect on prevalence of abstinence was found at the community level.

Conclusions: Treatment modalities were effective within their participants, but the intervention effectiveness on a community level was limited. No significant difference was found between quit-rates afier 14 months (7\% in treatment city and $9 \%$ in control city). Several system failures could be identified. However, probably the intervention effect was seriously confounded by two national governmental publicity campaigns introducing and reinforcing a mandatory smoking ban, and a series of national campaigns initiated by the united Dutch tobacco producers opposing the ban.

\section{INTRODUCTION}

Cigarette smoking is the number one preventable single risk factor in the Netherlands. In 1991 approximately 18,000 Dutchmen died of smoking related diseases. In 1991 still $38 \%$ of the men and $30 \%$ of the women of 15 years and older were smokers (1). Until 1990, Dutch smoking cessation activities were mostly limited to group programmes and mass media approaches (2). Although the group programmes have been shown to be effective $(3,4)$, their impact on smoking prevalence was limited, since annually only about 600 of the four 
million Dutch smokers participared (4). The mass media approaches focused mainly on the health risks of smoking and provided hardly any information about how to stop smoking and maintain abstinence. Only in leaflets that were published and disseminated by the Dutch Smoking and Health Foundation (DSHF) brief tips for cessation were incorporated. Their impact on smoking behaviour was, except for an incidental TV-clinic, not evaluated. This TV-clinic was broadcast in 1976, and accomplished $22 \%$ abstinence after 9 month follow-up in participants who ordered a $\$ 2$ (US-dollars) manual (5).

A strategy that has a great potential to reach larger segments of the smoking population for sustained periods is the community approach (6). In such an approach, existing community resources, such as mass media, general practitioners and local health services, are coordinated to generate a multi-faceted program. Interventions are not only aimed at individuals, but also at the social system that surrounds them. Some of the best known community-based interventions have been aimed at the prevention of cardiovascular disease and involved smoking prevention and cessation as major targets. Although treatment modalities in these projects have proved to be effective, the studies either did not report data gathered on a population level, or were unable to demonstrate changes in population-wide smoking prevalence (7). Furthermore, the attribution of changes in smoking behaviour on a population level to the intervention requires evidence pertaining to reach, especially in studies employing small samples of communities (8). More recent interventions have shown more confident cessation results, due to stronger evaluation methodology (9).

The utility and effectiveness of a community-based approach in smoking cessation have not been examined in the Netherlands. The goal of this study is to analyze the results of a multi-media Dutch community-based smoking cessation intervention by describing the process of implementation, evaluating separate treatment modalities, and determining the effectiveness in the general smoking population.

\section{METHOD}

\section{Selection of cities}

The present study used a treatment city (Den Bosch) and a control city (Apeldoorn), that were randomly assigned. Through screening of Dutch cities $(\mathrm{N}=23)$ with populations between $80,000-160,000$ on distribution of age, gender, 
income, educational level, and degree of urbanization, ten cities were selected, that were comparable to the average Dutch city with respect to these criteria and size. Only two of the selected cities met the criteria of not having planned or executed in the past any comparable interventions and of having the approval of the Municipal Health Service to implement the intervention and to carry out a study among citizens.

\section{Development of the intervention}

After initial agreement of the Municipal Health Service in August 1989 and approval of the city alderman for public health, the research team conducted a community inventory in the treatment city in autumn 1989. Initially, the establishment of a broad steering committee was intended. However, in January 1990 only three local health care organizations agreed to participate in a local steering committee: the Municipal Health Service (MHS) whose tasks lie in primary prevention for the total population, the Consultancy for Alcohol and other Drugs (CAD) which provides mostly individual counselling for clients with alcohol or drug problems in the community, and the Community Association for Home Care (CAHC), which provides home care but also health education group programmes for specific risk groups. The committee was responsible for development and implementation of the intervention in cooperation with the research team. A community inventory showed low involvement with health matters within formal and voluntary community organizations. Therefore, the initial plan to complete the steering group with representatives of these organizations was blocked. Moreover, during the implementation phase of the project, the steering group vainly tried to interest these organizations for participation on several occasions.

The dissemination strategy incorporated local media, posters and the involvement of general practitioners in order to attract the attention of smokers and to motivate them to call a telephone quit-line (see table 1 , second column). The quitline was staffed with trained counsellors who advised smokers about the choice between modalities: a free self-help manual (10), or a three-week group programme at $\$ 15$ (US-dollars) in which the self-help manual was used as a guideline. The group programme was carried out by trained employees of the MHS, the CAD and the CAHC. Telephone counselling by quit-line staff was optional for all applicants, and general practitioners were intended to counsel patients whom they advised to quit in follow-up consultations. A brief protocol and a half hour 
training were developed to facilitate general practitioners to advise and counsel their smoking patients more effectively (11).

\section{Design and samples}

The behavioral impact of the intervention at a population level was investigated through a population study, applying a random panel of smokers in the treatment city and a similar panel in the control city. The panel in the control city was potentially exposed to all national smoking cessation messages and activities, such as a tobacco promotion, a national quit-line and leaflets, while the panel in the treatment city was potentially exposed to the intervention messages and modalities as well. Through telephone screening from random samples of private telephone numbers, in both cities a panel of cigarette smokers between 25 and 65 years of age was selected. This age group was selected because pretests of the selfhelp manual among Dutch smokers showed that this was the potential target group for smoking cessation interventions, in which behavior change was to be expected (12). The population panels were subjected to computer-assisted telephone interviews at base-line (October 1989), midway through the study period (June 1990) and at the end of the study period (December 1990). In the following the two periods between interviews will be referred to as the first 8-months period and the second 6-months period of the study. The base-line interview was conducted before the start of the development of the intervention to avoid the influence of conceivable media-coverage.

To obtain an indication of the quality of the intervention, the effectiveness of two treatment modalities in the treatment city was examined in groups of participants. The first 84 applicants on the quit-line who requested a self-help manual and the first 83 applicants who joined the group program, were subjected to a computer-assisted telephone interview before they received the manual or before the group started, and after a follow-up period of six months. Because applicants could enter the program throughout the implementation phase and because the follow-up had to be conducted before the end of the project, random sampling and incorporation of more participants were not possible. Overlap between the group of interviewed participants and the population panel in the treatment city was avoided by checking names of subjects. 


\section{Data collection and analyses}

\section{- Dissemination measures}

Records were kept of numbers of group participants, distributed manuals, calls at the quit-line and media messages. At the end of the intervention telephone interviews with a sample of general practitioners $(N=11)$ were conducted to estimate the number of patients that they advised to quit.

\section{- Questionnaires}

The questionnaires for both the population and the participant panels were structured according to the theory of planned behaviour $(13,14,15)$, and assessed the following self-reported variables:

Demographic variables: age, gender and level of education.

Smoking behaviour: a) average daily cigarette consumption; b) quit-attempts (abstained for at least 24 hours) in the past and between assessments; c) addiction, defined by: 1) smoking at least 25 cigarettes per day, or 2) smoking 16 to 24 cigarettes per day and smoking within 30 minutes after awakening, or smoking when sick and in bed, or finding it hard to refrain from smoking for 24 hours $(16,17)$; d) abstinence: not having smoked during the last 7 days before measurement. As a bogus pipe-line procedure, subjects were informed about conceivable validation of self-reported smoking behaviour through a voluntary saliva-test among $50 \%$ of the subjects. No actual assessments were made, since this procedure has been reported to be sufficient to enhance the validity of self-reports $(18,19)$.

Cognitive factors: a) beliefs concerning positive and negative outcomes of smoking cessation (pro's: reducing cancer risk, improving the health of others, improving physical condition, reducing the inconvenience for others; cons: gaining weight, losing an opportunity for relaxation, getting nervous) were scored on 4-point one-sided scales.

b) social support, conceptualized as the summation of ratings of perceived positive social stimulus from important others (partner, children, other family members, friends, colleagues and general practitioner, scored on 7-point two-sided scales, with a neutral middle category);

c) self-efficacy, conceptualized as the summation of confidence ratings (5-point two-sided scale, with a neutral middle category) of the ability to refrain from smoking when feeling stressed, after dinner, when seeing others smoke, when drinking alcoholic beverages, and when drinking coffee or tea. 
Important others and situations that did not apply to a subject were assigned to the neutral middle of the item scale.

Magnitude of the intervention. a) awareness of local smoking cessation activities, and recall of the content of messages; b) use of self-help manual, quit-line, physician counselling, or group programme; c) opinions about messages pertaining to perceived clarity and influence on the decision to quit; d) awareness of the smoking ban.

\section{- Analyses}

Analyses of the data incorporated panel and participant analyses. In panel analyses population panels were compared in logistic regression analyses to determine differences between panels in both cities concerning drop-out, base-line characteristics, awareness, and use and opinions pertaining to the intervention. In these analyses, condition (treatment versus control city) was the dependent variable, and demographic, smoking behavior, and cognitive factors and variables concerning the magnitude of the intervention were the independent variables. To determine the behavioral outcomes of the program on a population level, cessation behavior (abstinent versus not abstinent) was used as the dependent variable in logistic regression analyses, in which condition (treatment versus control city), time of the quit attempt and variables with respect to the magnitude of the program (awareness and use). In these analyses base-line differences between panels were controlled for by entering them in the first step.

Through participant analyses the behavioral impact of the treatment modalities were examined in groups of participants. Reach of the intervention was estimated from self-reported and objectively recorded exposure and participation rates.

\section{RESULTS}

\section{Completeness of the implementation}

The intervention started in March 1990, with press attention, dissemination of posters and self-help manuals, installation of the quit-line, the start of the group programmes and instruction of the interested general practitioners. In the third column of table 1 the completeness of the implementation is described. About two-third of intervention activities were conducted in the second period of the study, after the second assessment. 
Table 1. Community-based smoking cessation intervention: Planned elements and completeness of the intervention

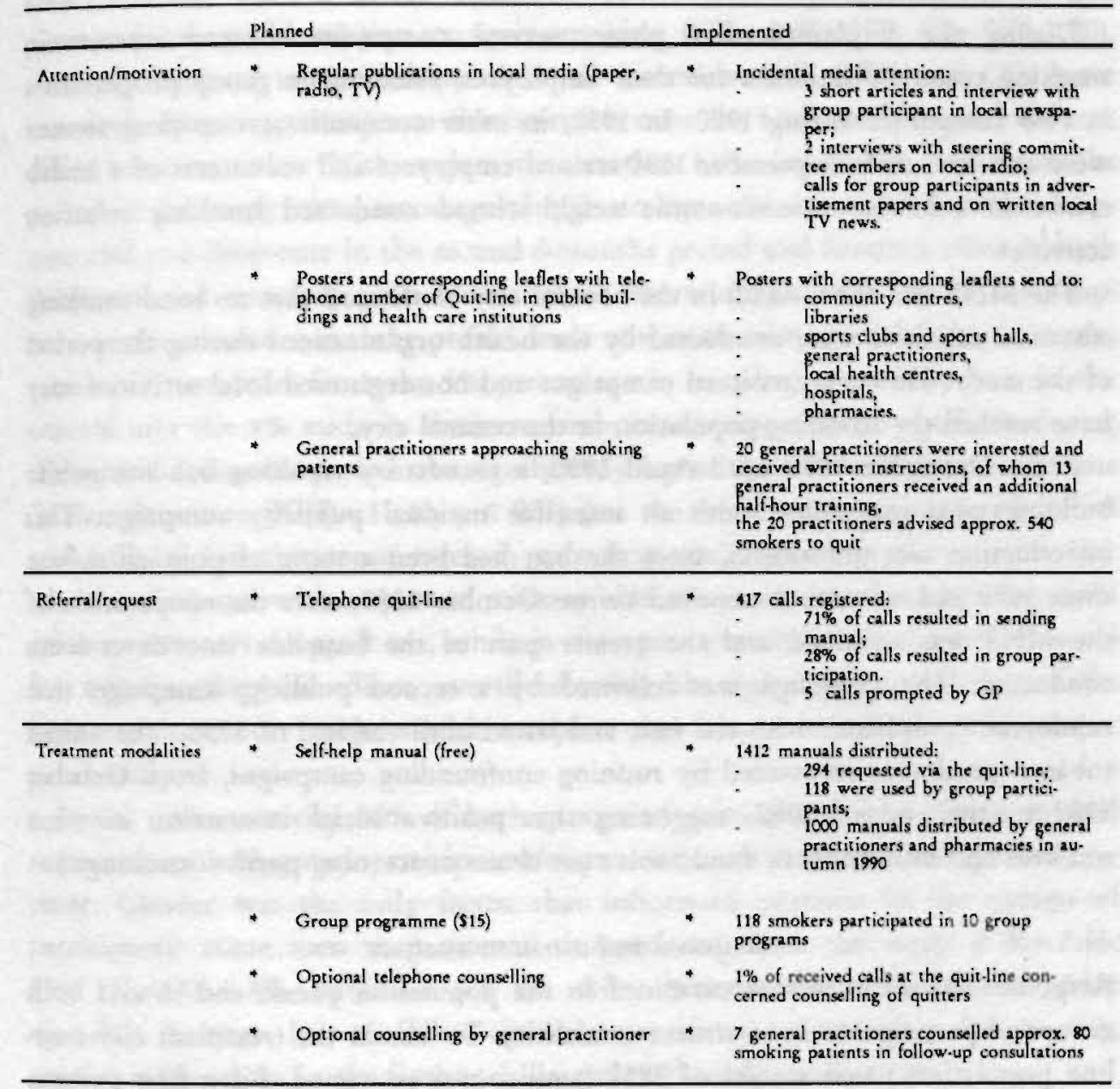

Local media were not willing to cooperate on a regular basis, resulting in incidental media coverage. Posters and corresponding leaflets were sent to the intended institutions. Although half of the 40 general practitioners in the treatment city signalled their interest in the protocol and received written instruction or optional training, very few of the smokers who were prompted by their physician called the quit-line, and few physicians conducted follow-up consultations. To enhance dissemination of the self-help manual in health care consumers, the steering committee distributed self-help manuals among all cooperating general practitioners $(n=20)$ and the majority of the local pharmacies 
$(n=20)$. Almost all calls on the quit-line resulted in either the sending of a selfhelp manual or participation in a group. Very few smokers addressed the quitline for counselling.

During the implementation phase, several companies showed interest in smoking cessation activities for their employees, resulting in group programmes in two companies during 1990. In 1991, in other companies group programmes were carried out. In September 1990 trained employees and volunteers of a health centre in a lower socio-economic neighborhood conducted smoking cessation activities.

The MHS and the CAHC in the control city confirmed that no local smoking cessation activities were conducted by the health organizations during the period of the study. However, national campaigns and non-registered local activities may have reached the smoking population in the control city.

From December 1989 until April 1990, a mandatory smoking ban for public buildings was introduced with an intensive national publicity campaign. This introduction was unforeseen, since the ban had been a topic of political debate since 1979 and was not announced before October 1989, after the cooperation of the MHS was obtained and the greater part of the base-line interviews were conducted. The campaign was followed by a second publicity campaign that reinforced compliance with the ban, and lasted until the end of 1990 . The united tobacco producers responded by running confounding campaigns, from October 1989 to the end of 1990 , suggesting that positive social interaction between smokers and non-smokers would solve problems concerning passive smoking.

\section{Response and attrition analyses}

Response and attrition was examined in the population panels and in and both groups of participants in treatment modalities. To obtain the treatment city baseline population panel a total of 2812 families was contacted. Fifty four percent $(n=1506)$ included a smoker of the required age group, of whom $61 \%(n=924)$ were willing to cooperate. In the control city more contacts $(N=3506)$ were required to obtain the base-line population panel, because significantly fewer families contained a suitable smoker: $47 \%(n=1637)\left(X^{2}(1)=29.14, p<.001\right)$, of whom $55 \%(n=906)$ were interviewed. This indicates a higher smoking prevalence in the treatment city. In the subsequent follow-up measurements $74 \%$ $(\mathrm{n}=686)$ and $59 \%(\mathrm{n}=547)$ of base-line respondents $(\mathrm{N}=924)$ in the treatment city population panel were reached against $74 \%(n=666)$ and $60 \%(n=546)$ of baseline respondents $(\mathrm{N}=906)$ in the control city population panel. 
Drop-outs from the population panels were slightly older (Odds Ratio $(O R)=-$ $1.01,95 \%$ Confidence Interval $(C I)=1.01-1.02)$, more often male $(O R=1.23,95 \%$ $\mathrm{CI}=1.01-1.48$ ), with a lower education ( $\mathrm{OR}=0.89,95 \% \mathrm{CI}=0.82-0.96$ ), and perceived less social support to quit smoking ( $O R=0.98,95 \% \mathrm{CI}=0.96-1.00$ ), than did subjects who participated in all interviews (all OR's and CI's were rounded). Most important was that attrition over the total study period did not differ between cities. With respect to cessation behavior in the first 8-months period of the study, the percentage of quit attempts did not differ between dropouts and non-drop-outs in the second 6-months period and between cities in both drop-outs and non-drop-outs. Moreover, in the treatment city $3 \%$ of the dropouts in the second 6-months period were abstinent midway through the study, which did not differ from the $5 \%$ percentage in non-drop-outs. However, in the control city the $4 \%$ midway abstinence rate in subjects who dropped out during the second 6-months period was significantly lower than the $10 \%$ abstinence rate in non-drop-outs $\left(\mathrm{X}^{2}(1)=11.40 ; \mathrm{p}<.001\right)$ (see the section about behavioral results and table 3 for abstinence rates in non-drop-outs). Thus, in the control city selective drop-out with respect to midway abstinence was observed because more midway relapsers dropped out, while in the treatment city no evidence was found for selective drop-out. Since overall selection through drop-out did not differ between cities, only subjects with complete data sets were considered in further panel analyses.

In the treatment city $80 \%$ of both groups of participants ( 84 self-help manual requesters and 83 group participants) were contacted in the follow-up measurement. Gender was the only factor that influenced attrition in the groups of participants: more men than women dropped out from the study $(O R=2.46$, $95 \% \mathrm{CI}=1.03-5.85)$. Attrition did not differ between the self-help and group modality. Subjects lost to follow-up were considered as treatment failures, i.e., continuing smokers in the final analysis, rather than discounted (20).

\section{Characteristics of subjects}

In 1989 the Dutch smoking population consisted of $45 \%$ women, had a mean age of 37.2 years (of Dutch smokers between 25 and 65 years of age) (1), and smoked on average 23 cigarettes per day (computed from sales) (1). In the present study, women were somewhat over-represented in the population panels, probably due to attrition (see table 2). Furthermore, self-reported daily consumption may be underestimated and smokers who did not agree to participate in the study may have been heavier smokers. In comparison with the control city, the panel in the 
treatment city contained significantly more women, more smokers with the lowest or highest education level, more heavy smokers, who experienced less social support to quit (see table 2).

Details about the characteristics of the groups of participants and differences between participants and the population panel in the treatment city have been reported elsewhere in detail (21). The main findings indicated that applicants to the Quit Line were more 'hard core smokers' than non-applicants: more women and addicted smokers perceiving less social stimulus to quit, responded. Smokers who selected the self-help method probably were easier quitters: they had tried to quit less often, were less addicted, and had significantly higher perceptions of selfefficacy, than did group participants.

\section{Awareness, use and opinions}

Awareness of local smoking cessation activities over the total study period (not including smoking ban publicity) did not differ between cities (see table 2). In the treatment city significantly more subjects recalled messages indicating the existence of the self-help manual and the group programme, and more subjects reported owning a manual than in the control city, where subjects may have obtained another self-help kit from other sources, that also fitted the description of the manual disseminated in the treatment city. Fewer subjects in the treatment city indicated that they had called a telephone quit-line (control subject had access to a national help-line). No differences between the cities were found concerning acquiring written materials other than the self-help manual, participation in a group programme, and receiving general practitioners' advice to quit. Of those subjects in the treatment city who saw, heard or read about any smoking cessation activities, a majority found the messages clear (86\%). A minority (27\%), however, reported that the messages influenced their decision to quit.

In both cities the awareness of the smoking ban was high (99\%). In the treatment city significantly more subjects were aware of the smoking ban publicity than of the intervention messages $\left(X^{2}(1)=69.51, p<.001\right)$.

\section{Reach of the intervention}

The potential target group under study was estimated to contain 16,800 smokers between 25 and 65 years of age $(1,22)$. Of this potential target group $3 \%(n=412)$ to $8 \%(n=1412)$ received a self-help manual. The lower estimate included the manuals requested via the quit-line and distributed in the group programme, while the upper estimate also took into account manuals distributed by pharma- 
Table 2. Base-line characteristics of population panels, and self-reported awareness, use and evaluation of smoking cessation modalities.

\begin{tabular}{|c|c|c|c|}
\hline$t$ & $\begin{array}{c}\text { Treatment city (1) } \\
\qquad(n=5+7)\end{array}$ & $\begin{array}{c}\text { Control city }(0) \\
(n=546)\end{array}$ & $\begin{array}{l}\text { Odds Ratio } \\
(95 \% \mathrm{Cl})\end{array}$ \\
\hline \multicolumn{4}{|l|}{ Baseline characteristics } \\
\hline \multicolumn{4}{|l|}{ Demographic zariablex: } \\
\hline Age (mean, sd) & $38.8(\mathrm{sud} 10.8)$ & $39.0($ sd 10.7 ) & ns \\
\hline Female gender $(0)$ & $58 \%$ & $51 \%$ & \\
\hline Male gender (1) & $42 \%$ & $49 \%$ & $0.67(0.520 .85)$ \\
\hline \multicolumn{4}{|l|}{ Educarion : } \\
\hline * primary/lower voc. school & $29 \%$ & $25 \%$ & 1.00 \\
\hline - secondary voc. school & $38 \%$ & $46 \%$ & $0.73(0.55 .1 . \infty)$ \\
\hline - high school & $6 \%$ & $6 \%$ & $0.92(0.53-1.62)$ \\
\hline - higher voc. school, university & $27 \%$ & $24 \%$ & $1.15(0.82-1.63)$ \\
\hline \multicolumn{4}{|l|}{ Smaking behariour: } \\
\hline Daily consumption (mean, sd) & $17.5(\mathrm{sd} 11.1)$ & $15.9(\mathrm{sd} 10.5)$ & $30.39: 1.87(1.08-3.24)$ \\
\hline Previous quit attempi & $75 \%$ & $78 \%$ & ns \\
\hline $\mathrm{N}$ of previous attempis (mean, sd) & $2.8(\mathrm{sd} 2.7)$ & $3.0(\mathrm{sd} 2.7)$ & ns \\
\hline Addicted & $54 \%$ & $48 \%$ & ns \\
\hline \multicolumn{4}{|l|}{ Determinants (mean, sd) } \\
\hline $\begin{array}{l}\text { Pro's of cessation } \\
\text { (0= no pros, } 12=\text { many pros) }\end{array}$ & $5.4(\operatorname{sd~2.8)}$ & $5.7(\mathrm{sd} 3.0)$ & ns \\
\hline \multicolumn{4}{|l|}{ Con's of cessation } \\
\hline \multicolumn{4}{|l|}{$(0=$ no cons, $-9=$ many cons $)$} \\
\hline \multicolumn{4}{|l|}{$\begin{array}{l}\text { Selfefficacy } \\
\qquad(-12=\text { low, } 12=\text { high })\end{array}$} \\
\hline \multicolumn{4}{|l|}{$\begin{array}{l}\text { Social stimulus } \\
\qquad(-24=\text { low, } 24=h \text { igh })\end{array}$} \\
\hline \multicolumn{4}{|l|}{ Awareness, use and evaluation } \\
\hline \multicolumn{4}{|l|}{ Awareness: } \\
\hline Knew of cessation activities & $85 \%$ & $84 \%$ & ns \\
\hline Heard of ban & $99 \%$ & $99 \%$ & ns \\
\hline Recalled one or more messages & $70 \%$ & $61 \%$ & ns \\
\hline \multicolumn{4}{|l|}{ Recalled content of messages: } \\
\hline I telephone quit-line & $5 \%$ & $2 \%$ & ns \\
\hline 2 selfhelp material & $4 \%$ & $i \%$ & $2.85(1.21-6.71)$ \\
\hline 3 group programme & $14 \%$ & $2 \%$ & $6.12(3.29 .11 .38)$ \\
\hline 4 prompted by GP & $5 \%$ & $3 \%$ & ns \\
\hline 5 heaith hazard & $62 \%$ & $60 \%$ & ns \\
\hline \multicolumn{4}{|l|}{ Reported use of modalifiex: } \\
\hline 1 ielephone quit-line & $1 \%(n=5)$ & $2 \%(n=13)$ & $0.20(0.06-0.68)$ \\
\hline 2 self-help manual/written material & $4 \% / 18 \%$ & $1 \%(n=4) / 18 \%$ & $7.74(2.10-26.10) / \mathrm{ns}$ \\
\hline 3 group programme & $0.2 \%(n=1)$ & $0.7 \%(n-4)$ & ns \\
\hline 4 GP talked about quitting (of visits) & $9 \%$ & $8 \%$ & ns \\
\hline \multicolumn{4}{|c|}{$\begin{array}{l}\text { Evaluation: } \\
\text { (\% of smokers who were aware in Den Bosch }\end{array}$} \\
\hline \multicolumn{4}{|c|}{$n=467$ ) } \\
\hline Mesages were dear & $86 \%$ & & \\
\hline Messages influenced decision to quit & $27 \%$ & & \\
\hline
\end{tabular}

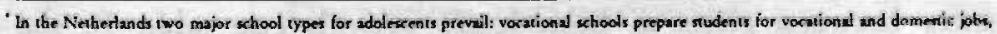

while high schools prepare sudents for continued educ ation and university

'Analysis of differences berween eities zonerming wwareness use and evaluation of smokiong ceinguion modaliuies were controlled for tascline difierences between cities. 
cies and general practitioners. The quit-line was called by $3 \%(n=417)$, the group programme attracted $1 \%(\mathrm{n}=118)$, and the general practitioners advised $3 \%$ $(n=540)$ of the potential target group. All together, about $6 \%(n=957)$ to $11 \%$ $(n=1950)$ of the potential target population in the treatment city may actually have been reached by intervention elements. No significant differences were found between this more objective dissemination evidence and self-reported use of modalities (quit-line, self-help manual, group programme and general practitioner's advice).

Table 3. Quit attempts and abstinence in population panels and groups of self-help manual users and group participants.

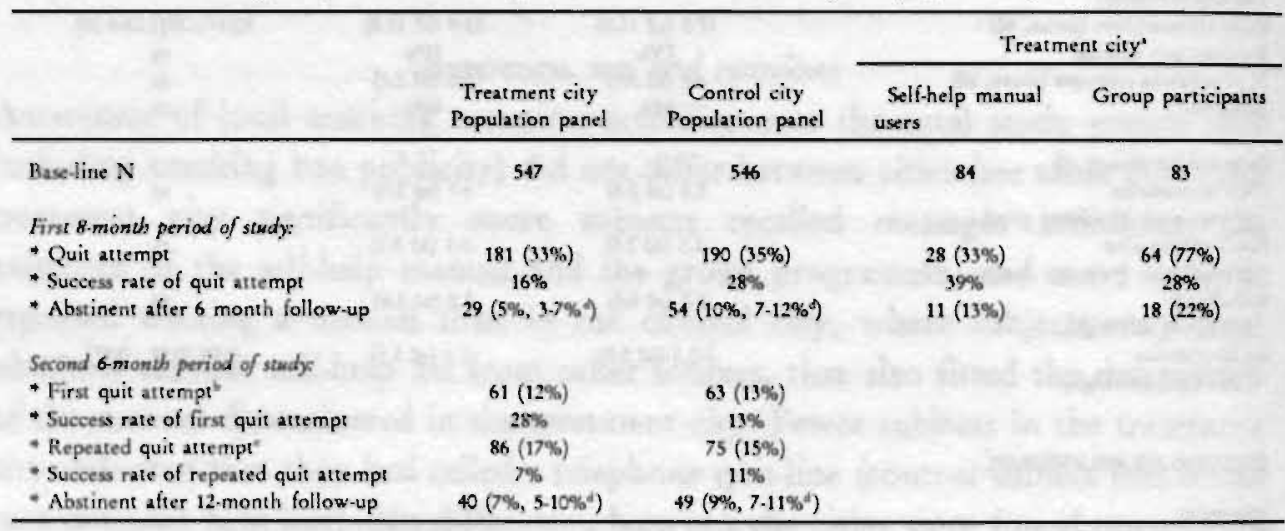

"results after 6-month follow-up

"quit attempts of smokers who did not try to quit in the first 6 months of the study, percentage of smoking subjects after the first period of 6 months;

"quit attempts of smokers who also tried to quit in the first 6-month period, percenrage of smoking subjects after the first period of 6 months:

$495 \%$ confidence interval.

\section{Behavioral effects}

Panel analyses indicated that during the total study period in the treatment city $44 \%(n=242)$ of the smokers in the population panel tried to quit smoking, against $46 \%(n=253)$ in the control city. This resulted in 40 abstinent smokers $(7 \%)$ in the treatment city panel and 49 abstinent smokers $(9 \%)$ in the control city panel at the end of the study period. Although the number of quit attempts did not differ between cities in both study periods (see table 3), the differing success rates of first quit attempts between cities in the two study periods seem to be responsible for the elimination of the preliminary abstinence advantage of the control city in the second 6-month period. Logistic regression confirmed the 
significance of this phenomenon. The main effects of condition (treatment versus control) $(\mathrm{OR}=0.57,95 \% \mathrm{CI}=0.32-1.00)$ and time of the first attempt $(\mathrm{OR}=0.52$, $95 \% \mathrm{CI}=0.23-1.19)$ on abstinence at the end of the study period were not significant. However, a significant interaction effect between condition and time of the first attempt (2nd period versus 1st period) on abstinence at the end of the study period was found ( $\mathrm{OR}=5.32,95 \% \mathrm{CI}=1.76-16.11)$.

Reported awareness and use of modalities, and opinions concerning smoking cessation messages were not related with success of quit attempts and abstinence. Furthermore, no significant interactions were found between condition (treatment versus control) and demographic variables, smoking behaviour variables and cognitive factors, suggesting the absence of different relations between cessation success and self-reported determinants in both cities.

Figure 1 presents the prevalence of abstinence midway and at the end of the study period in the treatment city (line ACE, 38\% increase in the number of abstinent subjects in the second period) and the control city (line ABD, $9 \%$ decrease of abstinent subjects in the second period). If in the second 6-months period of the study smokers in the treatment city behaved as smokers in the control study and a $9 \%$ decrease would have occurred, 26 smokers would be abstinent in the treatment city at the end of the study period (indicated by line CF). A significant difference was found between observed abstinence $E(n=40)$ and $F(n=26)\left(X^{2}(1)=2.73, p<.05\right.$ one-sided test). However, this difference was not confirmed in logistic regression analysis, when controlling for smoking status at the end of the first period.

Participant analysis revealed that in the treatment city $33 \%$ of the applicants who requested a self-help manual tried to quit during the 6-months follow-up, while a majority of the group participants made a quit attempt (see table 3). These attempts resulted in $13 \%$ abstinent smokers among the self-help manual requesters and $22 \%$ abstainers among the group participants, after 6-months follow-up. The differences in success rates of quit attempts and abstinence were not significant. This may be due to lack of power. Controlling for differences between groups did not affect this conclusion.

\section{DISCUSSION AND DISCUSSION}

A community-based smoking cessation intervention was developed and implemented in Den Bosch, an average Dutch city (treatment city). Three local health 
organizations implemented the intervention consisting of media interventions, a local quit-line, self-help and group modalities, and counselling facilities. In an evaluation study a quasi-experimental design was applied, incorporating three subsequent telephone interviews at respectively eight and six months intervals among random population panels of smokers in the treatment city and in the control city (Apeldoorn). The intervention caused modest but significant differences in awareness of modalities in favour of the treatment city, compared to the control city. However, confounding media campaigns introducing and reinforcing a mandatory smoking ban in public buildings, which ran during the intervention, were significantly better known. In the treatment city $6-11 \%$ of the potential target population were actively reached by intervention modalities. Two treatment modalities, a group programme and a self-help manual, were evaluated separately, and showed post-six months results that are comparable to other studies (22).

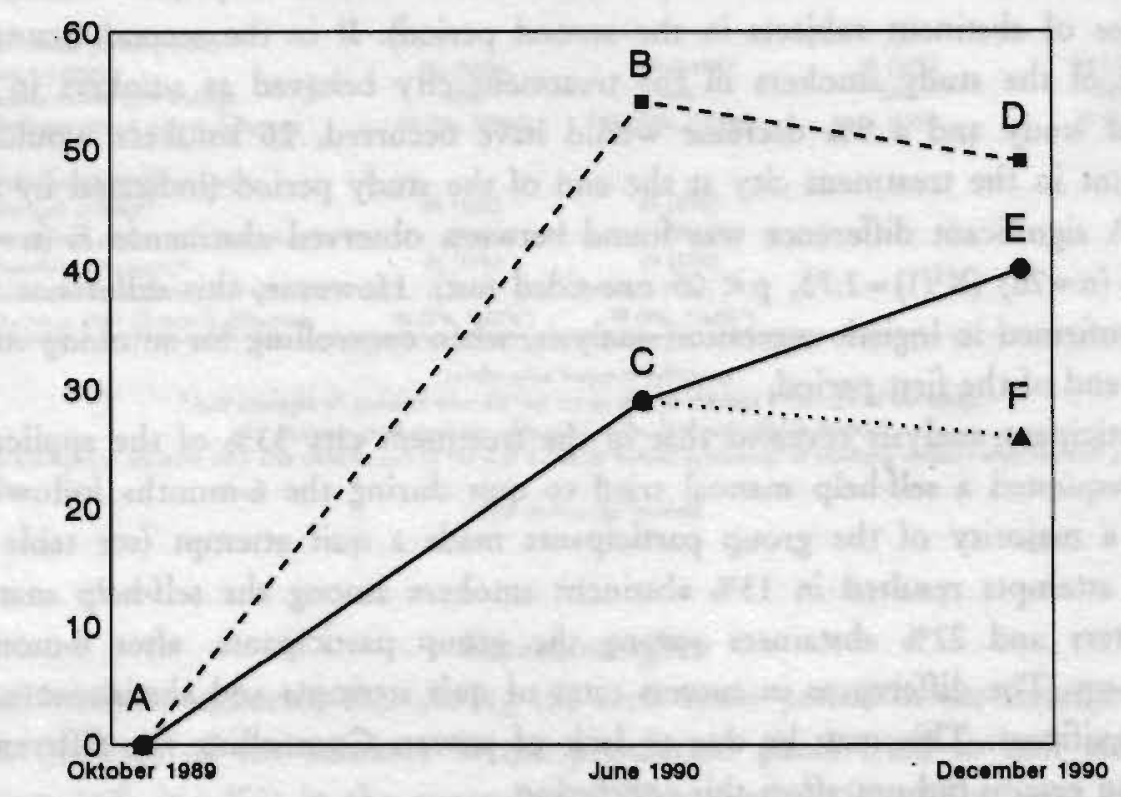

Smoking ban campaigns

Program

Figure 1. Observed numbers of quitters in treatment city (n-547, ACE), and control city $(n=546, A B D)$, and hypothetical numbers of quitters in treatment city when the intervention had no effect in second 6-month period (CF). 
No differences were found between treatment and control city concerning numbers of quit attempts during the study and abstinence on a population level at the end of the study. However, success rates of first quit attempts differed between cities in two periods of the study: in the first eight months of the study quit attempts in the control city were more successful, while in the second six months smokers in the treatment city were more successful. The starting position of the smoking population in the treatment city may have been less favorable than in the control city, since the treatment city panel perceived less social support to quit and contained more women and heavier smokers than did the control city panel. These factors have been shown to be negatively related with smoking cessation success (23), although when controlling for them, quit attempts in the control city still were significantly more successful in the first period of the study.

Other non-measured factors may have contributed to the differing success rates, e.g. the probably higher smoking prevalence in the treatment city. There was no evidence for differing power of the smoking ban campaigns between cities, since these campaigns used one media-mix for the whole of the Netherlands. The slight decrease in abstinence in the second period in the control city may point at a 'borrowing from the future' effect (24), as a result of the smoking ban publicity, while in the treatment city the increase of abstinence continued in the second period (see figure 1). Since two-thirds of the intervention activities were conducted in the second period of the study, the differing success rates suggest an intervention effect in the treatment city. There are, however, two flaws in this argumentation. Firstly, comparison of prevalence measures at subsequent moments does not account for the relation between abstinence at these moments. Because large proportions of smokers do not try or try and fail to quit, the association between smoking behaviour after the first 8-months period and smoking behaviour after the second 6-months period is very strong. Logistic regression analysis, in which abstinence after the first period is controlled for, therefore, did not confirm the presence of a significant intervention effect. Secondly, the absence of a relation between quitting behaviour and exposure to intervention elements weakens the effect claim for the intervention. The conclusion emerges that there is a feasible but modest intervention effect, although this study is not able to fully validate this effect.

The complexity of the process and evaluation of community-based interventions is recognized (23). When community-based interventions were found to be effective, it was not totally clear what caused their effectiveness, but when no 
results were found, it was also not clear why there were no effects (6). Finding no or only modest results may be caused by methodological failure points (25), but also by intervention and implementation deficits. In the following we will discuss both issues. From a methodological viewpoint, history is the most prominent and unavoidable threat to internal validity in this study (24). The confounding smoking ban campaigns may have seriously interfered with the intervention and the assessment of exposure to the intervention. These campaigns also changed the conditions in this study from treatment versus no treatment to treatment plus campaigns versus campaigns only. The study design, however, was based on the former conditions. Moreover, the timing of follow-up tests may have been too early. Development and implementation of community-based interventions take considerable time (6). However, the system of externally supported research projects hinders the execution of long term research projects. A time-series design stretched over a longer period may have detected effects in subsequent years, when the impact of the smoking ban publicity had declined, given that the intervention could be prolonged. The quasi-experimental design of the study, involving randomly sampled panels in a treatment and a control city, is supposed to account for the exclusion of other threats to internal validity (24). However, only two cities were included, obstructing use of cities as unit of analysis. Larger samples of cities would have been preferable to account for incomparability of cities. Moreover, comparability of cities might have been improved by pre-treatment screening of independent local samples of smokers in order to match cities according to determinants of cessation. Furthermore, selection caused by drop-out (mortality), may also have affected internal validity in this study. In the population samples in both cities, smokers with less chance to succeed in quitting (smokers perceiving less social support and having a lower level of education) tended to drop out more during the 12 months of the study. Although selection through drop-out differed between cities in the second 6 months period of the study, this probably did not affect the overall conclusions, since the main outcome measure of this study was abstinence at the end of the study. Internal validity may have also suffered from invalidity of measurement procedures. Because all measures were based on self-reports, over- or underestimation may have had its impact. However, a bogus pipe-line procedure was applied to substitute for costly biochemical validation of self-reported smoking behaviour. A number of studies justify this procedure (18).

Interventions may fail to reach their intended goals due to an inadequate diffusion, caused by intervention and implementation deficits. The theory of 
diffusion of innovations suggests five types of failures (26), of which innovation failure (ineffective materials and strategies) is the least likely to have occurred, since the results of treatment modalities were comparable to other studies (23). The intensive media coverage of the mandatory smoking ban may have caused a communication failure through desensitization of smokers for a local intervention. On the other hand, lack of experience of the steering group to communicate with the press, and the limited magnitude of local media in the Netherlands (27) may have contributed to communication failure. To examine the degree of an adoption failure on a participant level, the reach of present intervention (percentage of participants among estimated potential target group) was compared with the approximated reach of four recent examples of community-based smoking cessation programmes: the CHIP-programme in Lycoming County reached less than $1 \%$ over two years (28), a media-lead community-wide programme in St. Louis lead to 6\% participation (29), the Minnesota Heart Health Program resulted in 4 to $5 \%$ reach $(30)$, while the Pawtucket Heart Health Program reported $8 \%$ reach over four years (31). Thus, reach in the present study was comparable with other projects, but the limited reach of community-based smoking cessation interventions may indicate adoption failure on a participant level, possibly caused by incompatibility of the modalities offered in the intervention and the needs of the majority of smokers. On the other hand, signs were found for an adoption failure on an intermediate level: cooperation of only a part of the general practitioners, indifference of the local press and non-participation of social organizations in the steering group. Lack of adequate skills of the steering group, but also incompatibility of intervention demands to the needs and possibilities of intermediates may have caused this adoption failure. Monitoring of the implementation and the behavioral results of the modalities showed that the implementation of most of the elements and modalities was satisfactory, since all applicants were on their request incorporated in group programmes or received self-help manuals. However, the partly failing media strategy and incorporation of physicians contributed to a partial implementation failure. The last failure, maintenance failure, is not relevant in this study, since intervention elements were provided on a regular basis within the implementation period of 10 months.

A final conclusion emerges that present community-based intervention was comparable to other programmes with respect to reach and modality outcomes, but that definite interpretation of the suggested intervention effect on a population level was muddled by the occurrence of several possible implementation and methodological inadequacies. 


\section{REFERENCES}

1. Stichting Volksgezondheid en Roken [Dutch Smoking and Health Foundation]. Jaarverslag 1991 [Annual report 1991]. Den Haag NL: Stichting Volksgezondheid en Roken, 1992.

2. Kok GJ, Mudde AN. The effectiveness of smoking cessation education. In: Liedekerke PC, Jonkers R, De Haes WFM, Kok GJ, Saan JAM, Eds. Effectiveness of Health Education: Review and analysis. Assen NL: Van Gorkum, 1990:87-88.

3. Mudde AN. Stoppen met roken, de rol van persoonlijke effectiviteit, succesverwachting en oorzakelijke attributies [Smoking cessation, the role of self-efficacy, success expectancies and causal attributions]. Maastricht NL: University of Limburg, 1987; GVO-Cahier 31.

4. Zeeman G. Verslag stoppen met roken cursussen 1982 [Report of group programs 1982]. Bosch en Duin NL: Stichting Leven en Gezondheid, 1984.

5. Marsman G, Peeters GJ. Stoppen met roken [Smoking cessation]. Nijmegen NL: Instituut voor Toegepaste Sociologie, 1979.

6. Bracht N. Introduction. In: Bracht N, Ed. Health promotion at the community level. Newbury Park: Sage, 1990:19-25.

7. Schofield MJ, Redman S, Sanson-Fisher RW. A community approach to smoking prevention: A review. Behav Change, 1991; 8:17-25

8. Flay BR. Mass media and smoking cessation: A critical review. Am J Public Health, 1987; 77:153160.

9. Lichtenstein E, W/alack L, Pechacek TF. Introduction to the community intervention trial for smoking cessation (COMMIT). Int Q Community Health Educ, 1990-91; 11:173-185

10. Mudde AN. Van het roken af [Quit smoking] Maastricht NL: University of Limburg, 1989.

11. Mudde AN, Willemsen MC. Help uw patienten van het roken af [Help your patients to quit smoking] Masstricht NL: University of Limburg, 1989.

12. Mudde AN, De Vries H, Willemsen MC, Van Assema P. Development and utilization of a selfhelp manual for community smoking cessation interventions. In: Richmond R, editor. Interventions for smokers: An international perspective. Baltimore, ML: Williams \& Wilkins, 1994:293322.

13. Ajzen I. Atritudes, personality and behavior. Milton Keynes: Open University Press, 1988.

14. DeVries H, Dijkstra M, Kuhlman P. Self-efficacy: The third factor besides attitude and subjective norm as a predictor of behavioral intentions. Health Educ Res, 1988; 3:273-282.

15. DeVries, H. \& Backbier, M.P.H. Self-efficacy as an important determinant for smoking cessation among pregnant women: the $\varnothing$-phenomenon. Prev Med, 1994;23:167-74.

16. Henningfield JE. Improving the diagnosis and treatment of nicotine dependence (editorial). JAMA, 1988; 260:1631.

17. Killen JD, Fortmann SP, Telch MJ, Newman B. Are heavy smokers different from light smokers? A comparison after 48 hours without cigarettes. JAMA, 1988; 260:1581-1585.

18. Velicer WF, Prochaska JO, Rossi JS, Snow M. Assessing outcome in smoking cessation studies. Psychol Bul, 1992; 111:23-41.

19. Murray RP, Connett JE, Lauger GG, Voelker HT. Error in smoking measures: Effects of intervention on relations of cotinine and carbon monoxide to self-reported smoking. Am J Public Health, 1993; 83:1251-1257.

20. Lichtenstein E, Glasgow, RE. Smoking cessation: What have we learned over the past decade? J Consult Clin Psychol, 1992, 60:518-27. 
21. Mudde AN, DeVries H, Dolders MGT. Can smokers choose the right smoking cessation program? Poster presented at the 7th Conference of the European Health Psychology Society, Brussels 1-3 September 1993. Abstract book:140.

22. CBS [Central Bureau for Statistics]. Statistisch Bulletin [Statistical Bulletin], 1987; 16: 6.

23. Schwartz JL. Review and evaluation of smoking cessation methods of smoking cessation methods: The United States and Canada. 1978-1985. Bethesda MD: Narional Institutes of Health, 1987.

24. Green, LW, Lewis, FM. Measurement and evaluation in health education and health promotion. Mountain View, CA.: Mayfieid Publishing Company, 1986.

25. Rossi PH, Freeman, HE. Evaluation, a systematic approach. Newbury Park: Sage, 1993.

26. Orlandi MA, Landers C, Weston R, Haley N. Diffusion of health promotion innovations. In: Glanz K, Lewis FM, Rimer BK Eds. Health behavior and health education: theory, research, practice. San Francisco: Jossey Bass, 1990:288-313.

27. Bardoel J, Bierhoff J. De aarzelende opkomst van een universeel communicatie patroon [The hesitating development of a universal communication pattern]. In: Bardoel J, Bierhoff J Eds. Media in Nederland [Media in the Netherlands]. Groningen NL: Wolters-Noordhof, 1987:7-21.

28. Norman SA, Greenberg R, Marconi K, Novelli W, Felix M, Schechter C, Stolley P, Stunkard A. A process evaluation of a two-year community cardiovascular risk reduction program: what was done and who knew about it? Health Educ Res 1990; 5:87-97.

29. Wheeler RJ. Effects of a community-wide smoking cessation program. Soc Sci Med, 1988; 27:1387-1392.

30. Lando HA, Hellerstedt WL, Pirie PL, Fruetel J, Huttner P. Results of a long term community smoking cessation contest. Am J Health Promotion, 1991; 5: 420-425.

31. Lefebvre RC, Lasater TM, Assaf AR, Carleton RA. Pawtucket heart health program: The process of stimulating community change. Scand J Health Care, 1988; suppl 1:31-37. 


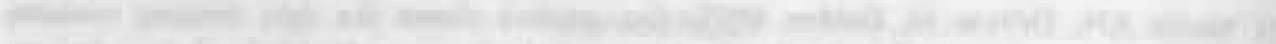

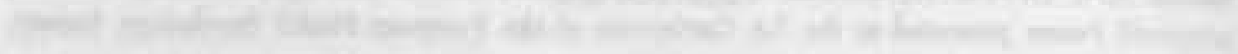

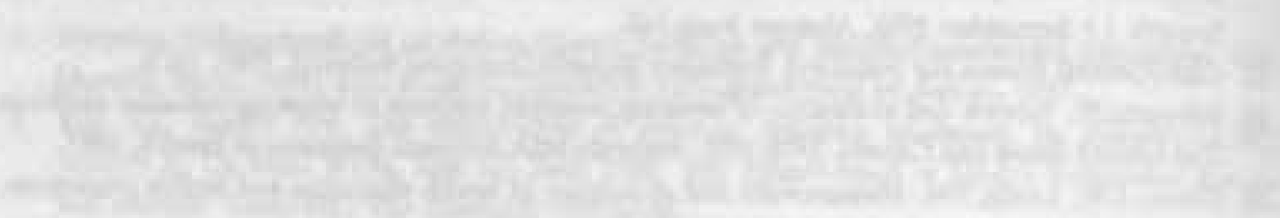
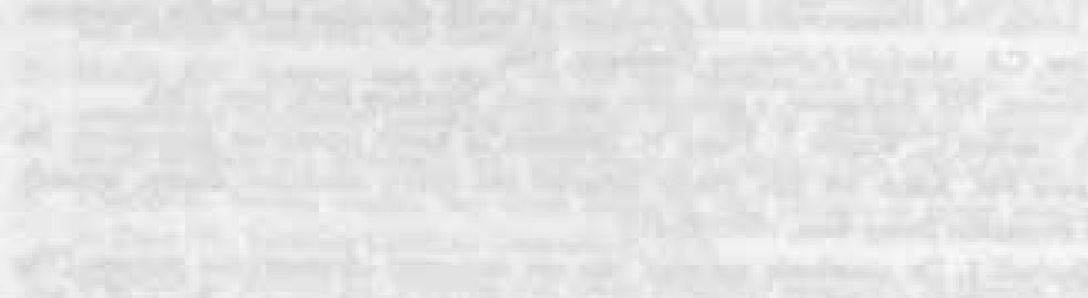

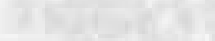




\title{
COST-EFFICIENCY AND COST-EFFECTIVENESS \\ OF SMOKING CESSATION MODALITIES: COMPARING APPLES WITH ORANGES?
}

\author{
Aart N. Mudde, Hein de Vries \& Victor J. Strecher \\ Submitted for publication.
}

\section{ABSTRACT}

Objectives: To compare the cost-efficiency, cost-effectiveness and participants' characteristics of self-help and group treatment in a local community-based smoking cessation program.

Methods: Consecutive samples of 84 self-help manual requesters and 83 group participants were subjected to telephone interviews before treatment and after a six month follow-up. Participants' basse-line characteristics were compared and contrasted with a random sample non-participating smokers $(N=924)$. Cost-efficiency and cost-effectiveness were computed from the perspectives of the steering group and participants.

Results: Participants appeared to be more "hard core smokers" than non-participants. Self-help manual requesters seemed easier quitters than group participants. Self-help was at least 10 times as cost-efficient and over 3 times as cost-effective as group treatment, both from the perspective of the steering group and the participants. When controlling for differences between participants in both modalities, self-help was still 2.6 times as cost-effective as group treatment for the steering group and 1,9 times for the participants.

Conclusions: Since both modalities attracted different groups of smokers, cost-efficiency and costeffectiveness comparisons may be comparing apples with oranges, and referral to either one modality should also be based on smokers characteristics.

\section{INTRODUCTION}

Smoking is the leading cause of preventable morbidity and mortality in the Netherlands (1). Approximately $34 \%$ of the people in the Netherlands older than 15 years of age smoke. Cigarette smoking is linked to a wide array of diseases. In 1992, in the Netherlands over 18,000 deaths caused by chronic obstructive pulmonary disease, lung cancer, and coronary heart disease were ascribed to smoking (1). The morbidity and mortality associated with smoking have serious implications for society's expenditures and economic productivity. Therefore, evaluation of cost and benefits of interventions with respect to smoking prevention and cessation may provide important cues for policy-making and program 
development. From a health professional's viewpoint, costs and benefits of smoking cessation treatment options may influence their advice to smokers wanting to quit. Since professionals' time is limited, the emphasis in smoking cessation counselling is often placed on providing written materials or referring patients to other treatments (2).

Cost-benefit analysis explores the health and societal benefits resulting from a program expressed in monetary terms in relation with the financial costs of the program. The fact that the evaluation of health and societal outcomes of smoking prevention programs requires long term cohort studies, complicates the analysis of benefits of these programs. Cost-efficiency and cost-effectiveness analyses are used for the comparative analysis of two or more programs or interventions, when outcomes cannot be valued in economic terms but in units, such as lives saved or abstinent smokers. In the case of smoking prevention, cost-efficiency ratios are often presented in terms of dollars per participant (3) and cost-effectiveness ratios in terms of dollars per quitter. In her detailed review of cost-effectiveness studies of smoking cessation programs, Elixhauser (4) concludes that the methods that are most cost-effective are smoking cessation methods which are specifically aimed at a particular population subgroup, as well as combined multiple interventions and methods that provide information on maintaining abstinence rather than simply providing information on how to quit. However, Elixhauser states that cost-effectiveness should not be the sole criterion for choosing a cessation method, since different types of programs attract different types of individuals who wish to stop smoking, and that equity considerations demand that attention be paid to those individuals with the greatest need.

This study examined in detail whether a self-help modality was more costefficient and cost-effective than a group program, since the evaluation of health end societal outcomes that is needed for cost-benefit analysis was not feasible in the present study of 6 months. Both program modalities were components of a Dutch community-based smoking cessation intervention. Costs were analyzed from two perspectives: the perspective of the local steering group that developed and implemented the program, and the perspective of participants in both modalities. Furthermore, characteristics of both groups of participants were compared and contrasted with a population sample of smokers in order to explore the suggested differential attraction of different types of programs. 


\section{METHOD}

\section{Program}

In March 1990, a community-based smoking cessation intervention started in Den Bosch, a Dutch city with about 100,000 inhabitants. Three local health care organizations participated in a steering group that was responsible for the development and implementation of the intervention: the Municipal Health Service (MHS), whose tasks lie in primary prevention for the total population; the Consultancy for Alcohol and other Drugs (CAD), which generally provides individual counselling for clients with alcohol or drug problems in the community; and the Community Association for Home Care (CAHC), which provides home care but also group programs for specific risk groups. The dissemination strategy incorporated free publicity in local media and the involvement of general practitioners to attract the attention of smokers and to motivate them to call a local telephone quit-line. The quit-line was staffed with trained employees of the Municipal Health Service who advised smokers about their autonomous choice between two modalities: a free self-help manual (5), or a nine session group program at about US\$16 in which the self-help manual was used as a guidebook. During 1990, 417 calls to the quit-line were registered, of which $71 \%$ resulted in sending a self-help manual and $28 \%$ in enlisting a participant in the group program.

The self-help manual was developed for this intervention, through a comprehensive process of pretesting, whereby health education, communication experts and members of the target group (i.e., smokers who wished to quit) were asked to comment on whether the manual addressed the intervention goals and to propose ways in which the future effectiveness of the manual could be improved (6). The manual contained sections about the assessment of personal reasons for quitting, re-attribution of former failures, nicotine dependency and substitution strategies, relaxation and exercise, the setting of a quitting date, preparation by means of self-monitoring and the consideration of imaginary relapse situations, negative social influences, withdrawal symptoms, reduction of weight gain, relapse, and long term advantages of non-smoking. During 1990, 1412 manuals were distributed in Den Bosch: 118 were used in the group program, 294 were requested on the quit-line for individual use, and 1000 were distributed via general practices and pharmacies. Since the behavioral outcomes of the latter dissemination strategy were not evaluated, cost-efficiency and cost-effectiveness 
analyses will be limited to the group program and self-help manuals requested on the quit-line.

The group program was carried out by employees of the MHS, the CAD and the CAHC who had attended the standard training for group counsellors of the Dutch Smoking and Health Foundation. Nine sessions were spread over 6 weeks: in the first weeks three sessions were offered, in the second week two sessions and in consecutive weeks four sessions; 118 smokers attended 10 groups. Quitting techniques included self-monitoring, assessing reasons for quitting, preparing for high risk situations, nicotine fading, replacing smoking by alternative actions, rewarding abstinence, enhancing social support and preventing relapse.

\section{Cost estimation}

Elixhauser (4) concludes that no consensus exists about the cost-categories that should be included in the analysis. Therefore, we have chosen Green and Lewis' standpoints as a guideline for our estimations (3). They identify program costs as consisting of start-up costs, made during development and planning, and operating costs, which are the costs of running the program minus income (e.g. charge for participants). Drummond, Stoddart and Torrance (7) advise, in the case of a comparison of two programs, not to consider the costs that are common to both, as they will not affect the choice between the given programs.

Program costs were seen as the extra costs that had to be made by the organizations participating in the steering group for the execution of the programs. According to Green and Lewis (3), overhead costs, such as the organizational costs of these organizations, and the costs of the evaluation study were not taken into account, since this study was financed externally by the Dutch Cancer Foundation. Moreover, the costs of evaluation are not essential for the realization of the programs. Participants' costs were the costs that participants incurred in order to participate in the treatment modality of their choice. Furthermore, for the comparison of both program modalities, we considered operating costs per modality, leaving out recruitment costs that were common to both programs.

Five major cost categories were distinguished: 1) staff (telephone and group counsellors), 2) supplies and equipment (printing, telephone, postage, answering machine, refreshments for group participants), 3) development costs (pretesting and design of self-help manual, design of posters and leaflets, counsellor training), 4) rent (rooms for group program) and 5) costs incurred by smokers (charge for call, time involved in attendance or reading and transportation, charge for group). Moreover, three stages in the execution of the programs were differentiated: 1) 
preparation, 2) recruitment and 3) operation. During preparation, posters and leaflets were designed and the group counsellors were trained. For the manual, which was developed during preparation, a price was computed per capita, since the 1412 disseminated manuals were part of a larger edition of 20,000 manuals that were used in other research projects as well. The development and production costs of this edition were $\$ 64,715$ of which $\$ 41,693$ were attributable to printing and the remainder to pretesting, editing and illustrating the manual. This resulted in a price of $\$ 3.24$ per capita. Recruitment incorporated the costs of the telephone quit-line and printing of posters and leaflets. Operation included the costs of mailing manuals to individual users and the costs of the execution of the group program (e.g., rent, staff). Hour-wages were estimated to be $\$ 25$, including taxes and social security contributions, based on government standards for trained health educators (8). Charges for participants were subtracted from execution costs.

All estimations of costs were based on the financial records of either the research project or the MHS, which kept the records for the implementation of the project. Time investment was estimated to be 1.5 hour for individual users to read the self-help manual (6), and 13.5 hours for attendance of group meetings for group participants. The value placed on each hour of participation was assumed to be $\$ 10$, as was assumed by Altman et al. (9). Transportation costs for group participants were estimated to be $\$ 1.50$ per meeting. Costs were computed in 1990 US-dollars (exchange rate 1 dollar $=1.82$ Dutch guilders) (10).

\section{Design and samples}

In a prospective study, consecutive samples of the first 84 applicants to the quitline who requested a self-help manual and the first 83 applicants who joined the group program were subjected to a computer-assisted telephone interview before they received the manual or before the group started, and after a follow-up period of six months. Drop-outs were considered not to have tried to quit. On a population level, the effectiveness of the intervention was investigated in random samples of smokers in the treatment city and a comparable control city. Results are reported elsewhere (11). In both cities, a sample of cigarette smokers between 25 and 65 years of age was selected through telephone screening from random samples of private telephone numbers. Data from the base-line interviews were used to compare participants with the smoking population in Den Bosch. Overlap between the group of interviewed participants and the population sample was avoided by checking the names of subjects. 


\section{Questionnaires}

The questionnaires for both the population sample and the groups of participants were structured according to the Model of Planned Behavior $(12,13)$ and assessed the following self-reported variables:

1. Demographic variables: age, gender and level of education.

2. Smoking behavior: a) average daily cigarette consumption; b) quitting attempts (abstained for at least 24 hours) in the past and between assessments; c) stages of change: pre-contemplation (not intending to quit within 6 months), contemplation (intending to quit within 6 months) and prepared for action (intending to quit within 30 days) (14); d) addiction, defined by: 1) smoking at least 25 cigarettes per day, or 2) smoking 16 to 24 cigarettes per day and smoking within 30 minutes after awakening, or smoking when sick and in bed, or finding it hard to refrain from smoking for 24 hours $(15,16)$; d) abstinence: not having smoked during the last 7 days before measurement. As a bogus pipe-line procedure, subjects were informed about conceivable validation of self-reported smoking behavior by means of a voluntary saliva-test among 50\% of the subjects. No actual assessments were made, since this procedure has been reported to be sufficient for enhancing the validity of self-reports $(17,18)$.

3. Cognitive factors: a) beliefs concerning positive and negative outcomes of smoking cessation (pro's: reducing cancer risk, improving the health of others, improving physical condition, reducing the inconvenience for others, $\alpha=0.59$; cons: gaining weight, losing an opportunity for relaxation, getting nervous, $\alpha=0.50$ ), scored on 4-point scales; b) social support, conceptualized as the summation of ratings of perceived positive social stimulus from important others (partner, children, other family members, friends, colleagues and general practitioner, scored on 7-point scales, $\alpha=0.52$ ); c) self-efficacy, conceptualized as the summation of confidence ratings (5-point scale) regarding the ability to refrain from smoking when feeling stressed, after dinner, when seeing others smoke, when drinking alcoholic beverages, and when drinking coffee or tea $(\alpha=0.77)$.

\section{RESULTS}

\section{Participation rates and base-line characteristics}

In the intervention city, the potential target group under study was estimated to contain 16,800 smokers between 25 and 65 years of age $(1,19)$. Of this potential 
target group, $1 \%(n=118)$ participated in the group program, and $2 \%(n=294)$ requested a manual for individual use.

Of both groups of participants, $80 \%$ participated in the follow-up interview. Gender was the only factor that was associated with drop-out: more men than women dropped out of the study (Odds Ratio $(\mathrm{OR})=2.46,95 \%$ Confidence Interval $(\mathrm{CI})=1.03-5.85)$. Attrition did not differ between group and self-help modalities.

Table 1. Base-line characteristics of applicants to the quit-line and of a population panel of smokers.

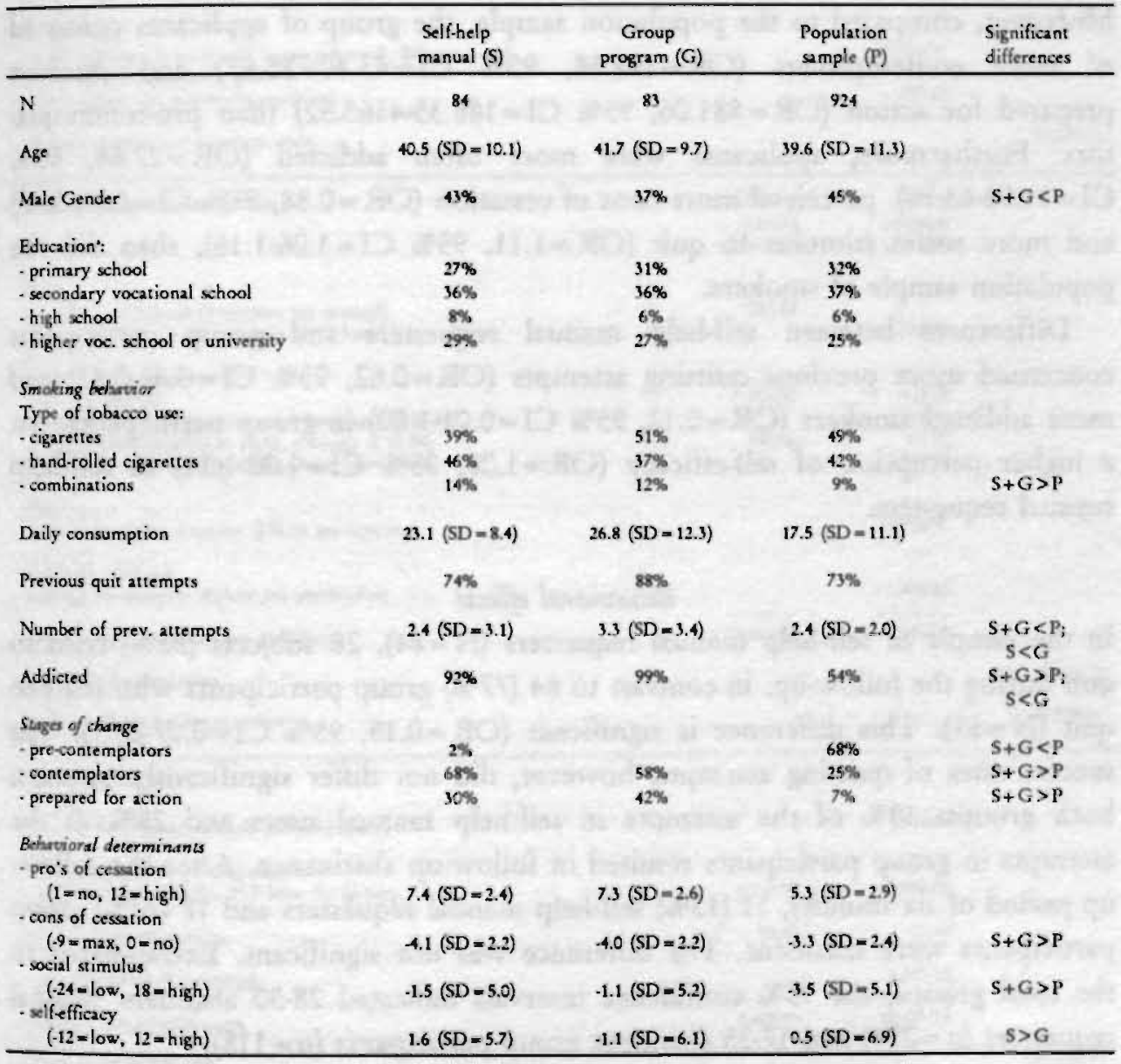

- In the Netherlands two major school types for adolescents prevail: vocational schools prepare students for vocational and domestic jobs, while high schools prepare studenes for continued education and university. 
Table 1 presents base-line characteristics of both groups of participants and the population sample. Because of overlapping variables (e.g. daily consumption and addiction, or gender and education), stepwise logistic regression was applied to detect differences between groups. In this procedure, odds ratios are adjusted for the influence of other factors in the equation and may therefore disagree with first sight differences. In comparison to the general population of smokers, applicants to the quit-line (self-help manual requesters and group participants together) were less often men ( $\mathrm{OR}=0.58,95 \% \mathrm{CI}=0 / .35-0.97)$, more of them smoked combinations of tobacco products $(\mathrm{OR}=3.34,95 \% \mathrm{CI}=1.36-8.23)$, and they had tried to quit less often in the past $(\mathrm{OR}=0.73,95 \% \mathrm{CI}=0.59-0.88)$. Moreover, compared to the population sample, the group of applicants consisted of more contemplators ( $\mathrm{OR}=184.58,95 \% \mathrm{CI}=43.40-785.67)$ and smokers prepared for action ( $\mathrm{OR}=881.06,95 \% \mathrm{CI}=186.35-4165.52)$ than pre-contemplators. Furthermore, applicants were more often addicted ( $\mathrm{OR}=27.68$, 95\% $\mathrm{CI}=11.98-63.96)$, perceived more cons of cessation $(\mathrm{OR}=0.88,95 \% \mathrm{CI}=0.79-0.99)$ and more social stimulus to quit $(\mathrm{OR}=1.11,95 \% \mathrm{CI}=1.06-1.16)$, than did the population sample of smokers.

Differences between self-help manual requesters and group participants concerned more previous quitting attempts $(\mathrm{OR}=0.62,95 \% \mathrm{CI}=0.46-0.83)$ and more addicted smokers ( $\mathrm{OR}=0.12,95 \% \mathrm{CI}=0.01-1.00)$ in group participants, but a higher perception of self-efficacy (OR $=1.08,95 \% \mathrm{CI}=1.02-1.14)$ in self-help manual requesters.

\section{Behavioral effects}

In the sample of self-help manual requesters $(\mathrm{N}=84), 28$ subjects (33\%) tried to quit during the follow-up, in contrast to $64(77 \%)$ group participants who tried to quit $(\mathrm{N}=83)$. This difference is significant $(\mathrm{OR}=0.15,95 \% \mathrm{CI}=0.07-0.31)$. The success rates of quitting attempts, however, did not differ significantly between both groups: $39 \%$ of the attempts in self-help manual users and $28 \%$ of the attempts in group participants resulted in follow-up abstinence. After the followup period of six months, 11 (13\%) self-help manual requesters and 18 (22\%) group participants were abstinent. The difference was not significant. Extrapolated to the total groups, the $95 \%$ confidence intervals indicated $28-50$ abstinent manual requesters $(n=294)$ and 17-35 abstinent group participants $(n=118)$.

Adjusting for the differences between self-help manual requesters and group participants with respect to previous quitting attempts, addiction, and selfefficacy, through multiple classification analysis led to success percentages of $12 \%$ 
in self-help manual requesters, and $23 \%$ in group participants. The $95 \%$ confidence intervals displayed $25-47$ abstinent manual requesters and $18-36$ abstinent group participants.

\section{Table 2. Cost estimates (in US-dollars)}

Sutring Grawt:

Start-up casrs and costs common wo both modalixies

Preparation:

- training (3 trainers, charge $\$ 109,89)$

- time required for training and preparation of group program

(3 irainers, 32 hours, 525 per hour)

- posters and lealless (design and printing)

\section{Recruirment:}

- saff quis-line ( 34 weeks, 15 hours per week, $\$ 25$ per hour)

$12,750.00$

supplies and equipment quit-line

(connection etc, answering machine)

Subrotal start-up and common costs

Suff

- handling of manual (3 minutes per manual)

367.50

- group counselling ( 90 meetings of 1,5 hour)

Supplies and equipment

- manuals $(53,24)$

- refreshments (118 participants, 9 beverages of 50,69 )

- postage (confirmation at \$0,55, manuals at \$1,84)

- additional srikten material (\$5,63 per participant)

Rent

- rooms for group program ( $\$ 41,21$ per meeting)

Costs for smokers

- charge for program (\$16,48 per participant)

Subtotal operating cosss per modality

$\frac{-1,944.64}{1,81.02} \quad \frac{6,983.60}{}$

Subtotal operating costs

Program Costs for Sieering Group

\section{Participans' Costs:}

- charge for program (\$16,48 per participant)

- time required for participation

(1,5 hour for selfhelp, 13,5 hour for group)

- cosis of eall to quit-line

- transportation ( 9 meetings)

Subtotal participants' costs 


\section{Costs}

Costs for both the steering group and participants are listed in table 2. Operating costs for the steering group with respect to the group program were 3.8 times higher than those for the self-help modality. From the perspective of group participants, costs were over 4 times higher than for self-help manual requesters. Participants' costs accounted for $46 \%$ of the total costs.

Table 3 provides an overview of cost-efficiency and cost-effectiveness ratios. With respect to operating costs for the steering group, the self-help modality was almost 10 times as cost-efficient as the group program. From the perspective of the participants, the self-help modality was almost 11 times as cost-efficient as the group program.

Table 3. Cost-efficiency and cost-effectiveness ratio's (in US-dollars)

\begin{tabular}{|c|c|c|c|}
\hline & $\begin{array}{l}\text { Self-help manual } \\
n=294 \text {, } \\
28-50 \text { abstainers }\end{array}$ & $\begin{array}{c}\text { Group program } \\
n=118 \\
17-35 \text { abstainers } \\
\end{array}$ & $\begin{array}{l}\text { All participants } \\
n=112 \\
45-90 \text { abstainers }\end{array}$ \\
\hline \multicolumn{4}{|l|}{ Steering Group: } \\
\hline $\begin{array}{l}\text { Program costs: } \\
\text { - costefficiency ( } n=412) \\
\text { - costeffectiveness ( } 45.90 \text { quitters) }\end{array}$ & & & $\begin{array}{r}67.81 \\
310.41-620.82\end{array}$ \\
\hline $\begin{array}{l}\text { Operating costs: } \\
\text { - costefficiency ( } n=412 \text { ) } \\
\text { - costeffectiveness ( } 45.90 \text { quitiers) } \\
\text { - cost-efficiency per modality } \\
\text { - costeffectiveness per modality }\end{array}$ & $37.22 \cdot 66.47$ & $\begin{array}{r}59.18 \\
199.53-410.80\end{array}$ & $\begin{array}{r}21.47 \\
98.27 \cdot 19.55\end{array}$ \\
\hline \multicolumn{4}{|l|}{ Participants: } \\
\hline $\begin{array}{l}\text { - costefficiency ( } n=412) \\
\text { - cosieffectiveness ( } 45-90 \text { quitters) } \\
\text { - cosiefficiency per modality } \\
\text { - costeffectiveness per modality }\end{array}$ & $\begin{array}{r}15.20 \\
89.38-159.60\end{array}$ & $556.89-1 \frac{165.18}{146.54}$ & $\begin{array}{r}58.16 \\
266.22 \cdot 532.44\end{array}$ \\
\hline \multicolumn{4}{|l|}{ Total Costs } \\
\hline $\begin{array}{l}\text { - cost-efficiency }(n=412) \\
\text { - costeffectiveness (45.90 quitter) }\end{array}$ & & & $\begin{array}{r}125 . \% 6 \\
576.63-1153.27 \\
\end{array}$ \\
\hline
\end{tabular}

For the estimation of cost-effectiveness ratios, the $95 \%$ confidence intervals of the quitting rates were taken into account. In order to compare modalities conservatively, the most detrimental ratio of the self-help modality was contrasted with most advantageous cost-effectiveness ratio of the group program. With respect to operating costs for the steering group, the self-help modality was at least 3 times as cost-effective as the group program ( $\$ 66.47$ versus $\$ 199.53$ ). For participants, the self-help modality was at least 3.5 times as cost-effective as the group program (\$159.60 versus $\$ 556.89$ ). 
When controlling for the differences between self-help manual requesters and group participants, the self-help modality still was at least 2.6 times as costeffective as the group program from the perspective of the steering group $(\$ 74.44$ versus $\$ 193.99$ ). For participants, the self-help modality was at least 1.9 times as cost-effective as the group program (\$279.34 versus $\$ 541.42)$, after correction for the differences.

\section{DISCUSSION}

Several major conclusions can be drawn from this study. First, from the perspectives of both the steering group and the participants, the self-help modality was considerably more cost-efficient (costs per participant) and cost-effective (costs per quitter) than the group program, even when applying the most conservative estimates of success for the self-help modality and the most optimistic for the group program. Costs per participant were about 10 times lower in the self-help condition than in the group condition, both from the perspective of the steering group and the participants. Compared to the group program, the cost-effectiveness of the self-help modality compared to the group program was at least 3 times as high for the steering group and at least 3.5 times for the participants.

Second, smoking cessation modalities attracted different types of smokers. Compared to the general local smoking population in a Dutch city, applicants to the local quit-line were more advanced in their stage of change, because of their articulated willingness to quit, and therefore probably had more prominent opinions about both the pro's and cons of quitting. They also perceived more social stimulus to quit than did smokers in the population panel. In addition, more "hard core cases" may have responded, since quitting has been shown to be more difficult for female and addicted smokers (20). Within the group of applicants, smokers who selected the self-help method probably were easier quitters: they had tried to quit less often, were less often addicted to tobacco, and had significantly higher perceptions of self-efficacy, than did group program participants. The present study suggests that smokers are able to select modalities according to their needs when they are advised by trained counsellors and when a choice of different methods is offered. Schoenbach et al. (21) found that smokers who volunteered for a self-help program were poor candidates for this method. However, the self-help participants in Schoenbach's study were comparable to the group participants in the present study (equal daily consumption, strong nicotine 
dependency and extensive quitting histories), and might have selected a group program if it had been available.

Third, as in most community-based smoking cessation interventions, the reach was low. Only $2.5 \%$ of the potential target population actually participated in the discussed modalities. Altman, Flora, Fortmann and Farquhar (9) reported a comparable participation rate of $2.1 \%$ of the potential smoking target population in group and self-help modalities in the Stanford Five-City Project. Other comparable American projects reached $1-8 \%$ of the target group, while activities in these projects were generally prolonged over several years (11). In another Dutch community-based intervention, smoking cessation modalities (group program and distribution of a self-help manual) reached $1 \%$ of the potential population (6). In the present study the effect was not observable on a population level: quitting rates in the intervention city and a comparable control city that did not receive the program did not differ at the end of the project (11).

Fourth, the identification of start-up and program costs and the viewpoints of the implementing steering group and the participants provided insight into the allocation of resources. The cost-category 'staff' accounted for a major part of the costs of the steering group, in all three stages of the project (preparation, recruitment and operation), as did the time required for the participants' participation. Operating costs accounted for less than one third of the program costs for the steering group, and conducting a group program proved to be relatively expensive, since operating costs for the group program were almost four times higher than those for the self-help modality. Participants contributed $46 \%$ of the total costs, and group participants invested over 4 times more than self-help manual requesters.

Fifth, total costs were substantially higher than in the study of Altman et al. (9), who reported total costs (including development cost) of $\$ 87.20$ per participant in self-help and group modality. In the present study, total costs per participants were $\$ 125.96$. The difference was caused by higher development costs, and possibly by the higher value placed on professionals' time, which was not specified by Altman et al. ( $\$ 25$ in the present study). These costs may be higher in the Netherlands due to higher taxes and social security contributions. To facilitate comparisons of cost-efficiency and cost-effectiveness across studies, a framework that explicitly defines the perspective of the study, enumerates cost categories and determines outcome measures, is required. Until now, no consensus about such a framework has been reached in the international literature. 
Sixth, the present study suggests that group treatments may have negative effects as well. The group program prompted significantly more smokers to attempt to quit than did the self-help manual. However, because attempts were equally successful in both treatments, more failures occurred in the group program. Since failure may lead to a decreased self-efficacy level (22), the probability of future success may be smaller for these failing smokers.

Because of the naturalistic setting of the community project, the present study provides effectiveness measures, i.e. measures which indicate the prograrn's impact under normal circumstances, rather than efficacy measures, which indicate the program's impact under ideal and highly controlled circumstances (4). Therefore, the observed effectiveness of both interventions examined in the present study may have been affected by three major measurement inadequacies: 1) the use of self-reports for smoking behavior, 2) selection caused by drop-out, and 3) lack of long-term follow-up measurements. A bogus-pipeline procedure was applied to enhance the correctness of self-reported smoking behavior, and considering drop-outs as smokers who did not try to quit provides a conservative estimate of the effectiveness of the two modalities. Since relapse rates in self-help modalities tend to be lower than in group programs (20), probably because group participants are heavier smokers with less chances to quit, long term follow-up measurements would presumably only have found greater differences between quit-rates of both smoking cessation modalities and may have confirmed the greater cost-effectiveness of the self-help modality.

Elixhauser (4) suggests that the subjects' self-selection of various treatment modalities may lead to faulty conclusions about cost-effectiveness. In the present study, less addicted smokers with less previous quit attempts and a higher level of self-efficacy level entered the self-help modality. When controlling for these factors, the cost-effectiveness advantage of the self-help modality decreased, but still was substantial: from the perspective of the steering group self-help was at least 2.6 times as cost-effective, while for participants self-help was at least 1.9 times as cost-effective as the group program. Although randomization thus might have led to somewhat less favorable conclusions with respect to the cost-effectiveness advantage of the self-help modality, the practical relevance of these outcomes is questionable since in a setting in which various modalities are offered, self-help treatments will as a rule attract the "easier" quitters. This illustrates the relativeness of cost-effectiveness comparisons in naturalistic settings in which smokers designate themselves to various treatment modalities, because "apples are being compared with oranges". Therefore, comparing the cost-effectiveness of treatment 
modalities within self-selected samples of smokers may be more informative, e.g., comparing various self-help methods within the group of smokers who are interested in self-help treatment.

Although cost-effectiveness comparisons of treatment modalities using educational, clinical and behavioral smoking cessation methods may help decision makers allocate resources to the most efficient alternatives, more information is needed about the cost-effectiveness of regulatory, environmental and preventive interventions, because of the possible impact they may have on smoking prevalence. Both Warner (23) and Elixhauser (4) suggest that price measures can potentially have substantial effects: every $10 \%$ increase in the price of cigarettes may result in a $4 \%$ decrease in smoking initiation among adults and a $14 \%$ decrease among teenagers. On the other hand, total smoking bans and current prevention programs show only a very limited impact on smoking prevalence (20). All of these efforts should be viewed as pieces of a puzzle interacting with one another.

From a health professional's viewpoint, self-help materials can be provided quickly, and may be more cost-effective for both society and the individual smoker than referral to group programs which cost more per quitter. In addition, group programs have much lower acceptance rates, especially from a physician's office, since patients value the physician's advice and counselling more and most smokers will not make the financial, behavioral and time commitments that group participation requires (24). Moreover, the present study supports the assertion that cost-effectiveness should not be the only criterion in policy-making and referral of smokers to treatment modalities, since the segment of the potential target group that prefers a group program will probably not benefit from selfhelp modalities. Selecting the most cost-effective treatment thus would imply that this segment may be ignored. The present study suggests that "easier quitters" with higher self-efficacy levels can be referred to cost-effective self-help modalities.

\section{REFERENCES}

1. Stichting Volksgezondheid en Roken. Jaarverslag 1991. 's-Gravenhage, NL: Stichting Volksgezondheid en Roken, 1992.

2. Lichtenstein E, Glasgow RE. Smoking cessation: What have we learned over the past decade? J Consult Clin Psychol 1992;60:518-27.

3. Green LW, Lewis FM. Measurement and evaluation in health education and health promotion. Palo Alto C: Mayfield, 1986. 
4. Elixhauser A. The cost of smoking and the cost-effectiveness of smoking-cessation programs. J Public Health Policy 1990;summer:218-37.

5. Mudde AN. Van het roken af. Maastricht, NL: University of Limburg, 1989.

6. Mudde AN, DeVries $H$, Willemsen MC, Van Assema P. Development and utilization of a selfhelp manual for community smoking cessarion interventions. In: Richmond $\mathrm{R}$, editor. Interventions for smokers: An international perspective. Baltimore, ML: Williams \& Wilkins, 1994:293-322.

7. Drummond MF, Stoddart GL, Torrance GW. Methods for the economic evaluation of health care programs. Oxford: Oxford Press, 1987.

8. Tarievenlijst 1989. Masstricht NL: University of Limburg.

9. Altman DG, Flora JA, Fortmann SP, Farquhar JW. The cost-effectiveness of three smoking cessation programs. Am J Public Health, 1987;77:162-5.

10. CBS. Statistisch Jaarboek 1992. 's-Gravenhage, NL: SDU, 1992:274.

11. Mudde AN, De Vries H, Dolders MGT. Evaluation of a Dutch community-based smoking cessation intervention. Accepted for publication in Preventive Medicine.

12. De Vries $H$, Dijkstra M, Kuhlman P. Self-efficacy: The third factor besides attitude and subjective norm as a predictor of behavioral intentions. Health Educ Res, 1988;3:273-282.

13. De Vries H, Bakbier MPH. Self-efficacy as an important determinant for smoking cessation among pregnant women: The $\varnothing$-phenomenon. Prev Med, 1994;23:167-74.

14. Prochaska JO, DiClemente CC. Stages and processes of self-change of smoking: Toward an integrative model of change. J Consult Clin Psychol, 1983, 51:390-5.

15. Henningfield JE. Improving the diagnosis and treatment of nicotine dependence (editorial). JAMA, 1988;260:1631.

16. Killen JD, Fortmann SP, Telch MJ, Newman B. Are heavy smokers different from light smokers? A comparison after 48 hours without cigarettes. JAMA, 1988;260:1581-5.

17. Murray RP, Connet JE, Lauger GG, Voelker HT. Error in smoking measures: Effects of intervention on relations of cotinine and carbon monoxide to self-reported smoking. Am J Public Health, 1993;83:1251-7.

18. Velicer WF, Prochaska JO, Rossi JS, Snow M. Assessing outcome in smoking cessation studies. Psychol Bull, 1992;111:23-41.

19. CBS. Statistisch Bulletin, 1987;16:6.

20. Schwartz JL. Review and evaluation of smoking cessation methods: The United States and Canada, 1978-1985. Bethesda ML: National Institutes of Health, 1987; NHI Publ No. 87-2940.

21. Schoenbach VJ, Orleans CT, Wagner EH, Quade D, Salmon, MAP, Porter, CQ. Characteristics of smokers who enroll and quit in self-help programs. Health Educ Res, 1992;7:369-80.22.

22. Marlatt GA, Gordon JR. Relapse prevention: Maintenance strategies in the treatment of addictive behaviors. New York: Guilford, 1985.

23. Warner KE. Health and economic implications of a tobacco-free society. JAMA 1987;258:20806.

24. Edmundson E, McAllister A, Murray D, Perry C, Lichtenstein E. Approaches directed to the individual. In: Shopland DR, Burns DM, Samet JM, Gritz ER, editors. Strategies to control tobacco use in the United States: A blueprint for public action in the 1990's. U.S. Department of Human Services, Public Health Service, National Institutes of Health, National Cancer Institute, NIH Publication No. (NIH) 92-3316, 1991: 147-99. 


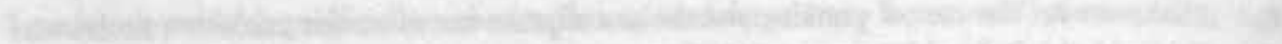
(1) 20 2.

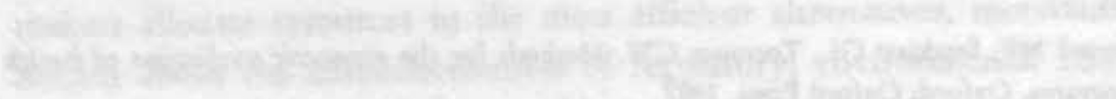

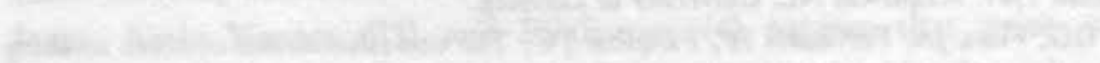

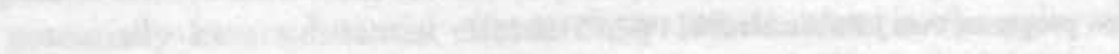
and 201720

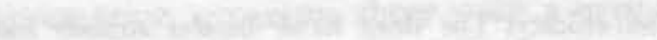

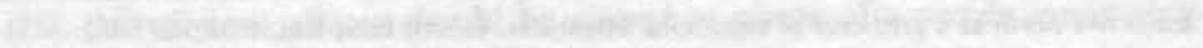

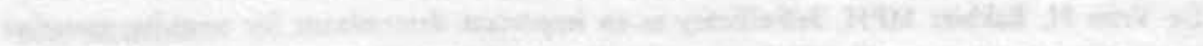

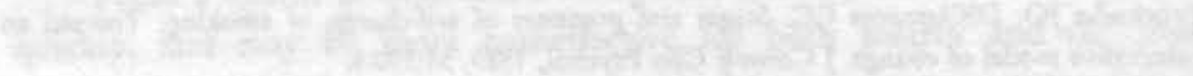

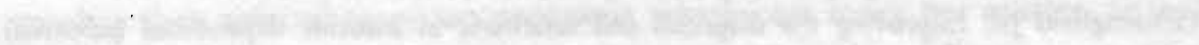
ran

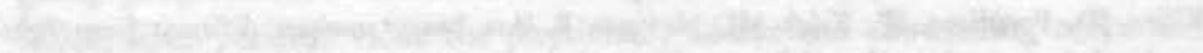

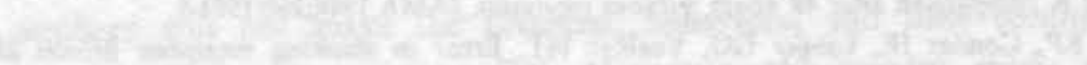
The 4.

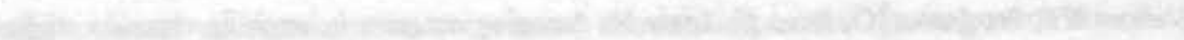

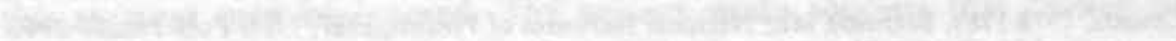

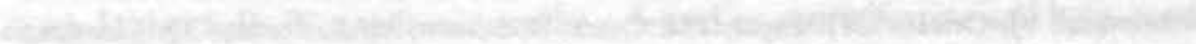

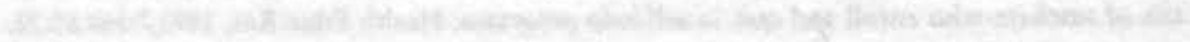

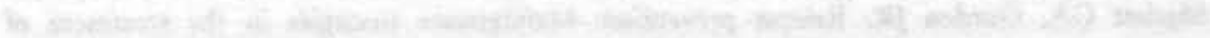
ats.

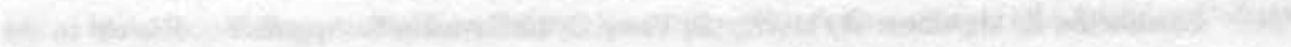

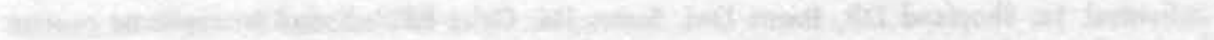

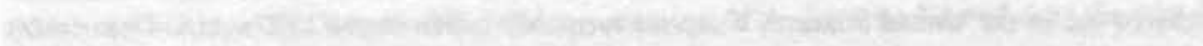

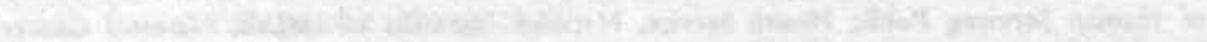

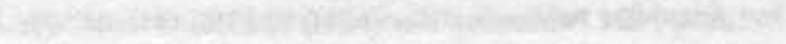




\title{
6
}

\section{REACH AND EFFECTIVENESS OF A}

\section{NATIONAL MASS-MEDIA-LED SMOKING CESSATION \\ CAMPAIGN IN THE NETHERLANDS.}

\author{
Aart N. Mudde \& Hein de Vries \\ Submitted for publication.
}

ABSTRACT

Objectives: The purpose of this study was to determine the reach and the effectiveness of a mass media led smoking cescation campaign that included a series of TV-shows, a TV-clinic, a national Quit.Line, local group programs and a comprebensive publicity campaign.

Methods: Random samples of non:smokers $(N=521)$ and smokers $(N=1338)$ were interviewed by telephone before and after the campaign. The smokers sample was also interviewed after 10 montbs follow-up. To examine conceivable test effects, a second sample of base-line smokers $(N=508)$ was only subjected to the posttest and follow-up.

Results: The campaign was noticed by $83 \%$ of the smokers and $67 \%$ of the non-smokers, and recall of campaign elements was high: $55 \%$ of the smokers and $38 \%$ of the non-smakers recalled at least one element correctly. Dose-response relations were found between exposure and quitting behuvior. Follow-up abstinence attributable to the campaign was estimated to be $4.5 \%$, controlled for test-effects and secular trends.

Conclusions: In contrast with cessation rates in previous years, and a massive raise in tobacco promotion expenditures in the campaign year, the results are meaningful.

\section{INTRODUCTION}

Since the early sixties, the percentage of smokers of 15 years of age and older has declined yearly with 1 to 2 percent in the Netherlands. From 1988, however, this percentage has stalled at about $34 \%$, as a result of the constant or even slightly increasing prevalence in the age groups between 19 and 65 years of age, and a substantially increasing prevalence in adolescents between 15 and 19 years of age (18\% in 1989 and $22 \%$ in 1992) (1). Due to ambivalent government policies, the tobacco industry is hardly restricted in promoting and selling its products (2). Only television, radio and cinema commercials are prohibited. Since 1983, a gradual increase of tobacco promotion budgets has been observed, and in 1990, a $72 \%$ increase in tobacco promotion expenditures was observed, from 66 million 
US-dollars in 1989 to 113 million dollars in 1990 (2). This probably caused the increase of smoking among adolescents, because almost all advertisements were aimed at recruiting new young tobacco consumers, and the tobacco industry is a main sponsor of events aimed at young visitors, such as popconcerts and adventuregames $(1,2)$.

The Dutch Smoking and Health Foundation (DSHF), financed by the Dutch Cancer, Heart and Asthma Foundations and the Department of Public Health, developed and implemented programs for smoking prevention in schools, conducted information campaigns about the health hazards of smoking, stimulated smoking policies in the workplace, and carried out smoking cessation group programs. In 1988, the DSHF formulated a strategy including campaigns to stimulate more smokers to quit, to meet the government goal of a smoking prevalence of $20 \%$ in the year $2000(3,4)$. A national steering group was formed, constituted, consisting of representatives of national health promotion institutes, universities, networks, local and regional health services, and the Department of Public Health. Based on the results of a pilot study (5), the DSHF and the steering committee developed a mass media led smoking cessation campaign, which was implemented in 1991.

In a review of the role of mass media in cessation education, Flay (6) concluded that only four of the seven reviewed mass media campaigns led to substantial changes in the smoking behavior of the population, although all campaigns achieved very high exposure. The success of the campaigns was attributed to governmental control or monopoly over the mass media (in Greece, Norway and Australia). The results of the "Chicago Televised Smoking Cessation Program", which combined self-help facilities with a TV-clinic, were an exception to this rule. However, due to the inevitable lack of appropriate control groups when applying national mass media that cover the whole of a country, it is practically impossible to determine the effects of such interventions (7). Therefore, conclusions with respect to the impact of the mass media should be considered with caution.

In this paper the results of a comprehensive study among the general public will be reported by discussing the exposure of smokers and non-smokers to the campaign and the impact of exposure on smoking behavior. Finally, the magnitude of the behavioral effects of the campaign is estimated. 


\section{METHOD}

\section{The Campaign}

A mass media campaign "Quit smoking together" was developed and included several elements:

1. 'Come on, Quit' TV-shows: a series of 15 informative and entertaining TV-shows, broadcast from December 30th, 1990 until April 7th, 1991. Famous people were followed in their attempts to quit smoking by means of various treatments, such as acupuncture, relaxation therapy, nicotine replacement therapy, group treatment and hypnotherapy. Experts provided feedback about the advantages of quitting. A matching booklet summarized this information and gave suggestions for self-help cessation (8). The booklet cost about US $\$ 3$ and could be ordered by mail.

2. A TV-clinic 'Quit Smoking': six weekly television and radio episodes, broadcast from February 11th until March 18th 1991. The matching manual (9), costing about US $\$ 10$, was available in bookstores or by mail. Six "normal" every day life role-models discussed their quitting experiences on TV. A psychologist commented on these reports and linked them to the manual, which was based on cognitive cessation strategies such as relapse prevention (10). In the radio episodes, experts provided additional background information, and answered relevant questions posed on the national quit-line (see 4).

3. Local group programs: 73 cooperating local and regional organizations (local health services, organizations for home care and regional cancer centers) conducted group programs, which cost about US $\$ 30$ and included 8 meetings in three weeks and a matching manual.

4. A National Quit-line: every workday and on broadcasting evenings of the TV-shows and TV-clinic, a national quit-line, staffed with trained counselors, was available.

5. A Publicity Campaign: Advertisements, posters, and leaflets were disseminated during the campaign to attract attention to the TV elements, the quit-line and a self-help manual (11) that could be ordered by mail. A special brochure was sent to general practitioners to inform them about the campaign and to offer them guide-lines for effective smoking cessation counseling.

The local group programs and the national quit-line were continued during 1991 and subsequent years. The extra costs of this campaign and the evaluation 
study were financed with grants to the DSHF by the Department of Public Health, the Prevention Fund, The Dutch Cancer Foundation, the Heart Foundation and the Asthma Foundation.

\section{Design and sampling procedures}

Exposure to campaign elements and behavioral impact were evaluated in a random sample of smokers of 15 years os age and older. This group (pretested smokers, $\mathrm{N}=1338$ ) was subjected to three computer-assisted telephone interviews: a pretest before the start of the campaign (December 1990), a posttest after the campaign (April 1991) and after a 10 month follow-up (February 1992). The follow-up was conducted within one year, to avoid confounding by a new campaign that started in March of 1992. Conceivable testeffects of the pretest on exposure and cessation were examined by incorporating a second independent random sample of smokers: non-pretested smokers $(\mathrm{N}=508)$, who were only subjected to the posttest and follow-up. A random sample of non-smokers $(\mathrm{N}=521)$, included to check for the conceivably selective perception of smokers, was subjected to a pretest and posttest. The samples of smokers and non-smokers were selected by means of a telephone screening of independent random samples drawn from national private telephone numbers.

\section{Questionnaires}

The questionnaires for the computer-assisted telephone interviews contained:

* demographic variables: age, gender and level of education;

* smoking behavior variables: a) average daily cigarette consumption or former consumption (for non-smokers); b) type of tobacco consumption: pre-manufactured cigarettes, hand-rolled cigarettes, or combinations (both types of cigarettes or one of both types with cigars or pipes); c) addiction, defined by: 1) smoking at least 25 cigarettes a day, or 2) smoking 16 to 24 cigarettes a day and either smoking within 30 minutes after awakening, or smoking when sick and in bed, or finding it hard to refrain from smoking for 24 hours $(8,9)$. d) quitting attempts (abstained for at least 24 hours) in the past and between assessments; e) abstinence (not having smoked during the last 7 days before measurement.

* magnitude of the program: a) post-campaign awareness of the campaign and campaign elements through both recall (impulsive reaction) and recognition after prompting by the interviewer. Recall of campaign elements and subjects' descriptions of posters and advertisements were categorized according to 
correctness; b) participation in, use of, or watching of elements; c) acquisition of written materials.

\section{Drop-out}

Drop-out was either caused by subjects' refusal to cooperate or the inability to reach subjects. For the estimation of behavioral outcomes, refusers were judged as smokers without quitting attempts, while the non-reached were assumed to have acted as cooperative subjects. In all other analyses only subjects with complete datasets were included.

\section{Analyses}

Multiple logistic regression analyses were applied to assess: a) selection caused by drop-out, b) comparability of both samples of smokers, c) the effect of the pretest on exposure in smokers, and d) exposure differences between pretested smokers and non-smokers. Because of conceivably overlapping variables (e.g., daily consumption and addiction, or recall and recognition of campaign elements), the variables in these analyses were entered by means of stepwise selection. Since this procedure adjusts odds ratios for the influence of other variables in the equation, the order of selection is insignificant. The test-effect of the pretest on behavioral outcomes (quitting attempts and point prevalence abstinence) was assessed by means of univariate logistic regression analyses.

The reach or coverage of the campaign was computed from self-reports in this study and extrapolated to the total Dutch population. These results were compared with more objective data such as viewing rates and sales figures. To assess the relations between exposure and behavioral outcomes in smokers, multiple logistic regression analyses were applied. While controlling for base-line differences between pretested smokers and non-pretested smokers and for the conceivable test-effect of the pretest, exposure variables were entered through stepwise selection. To detect indirect test-effects, interaction effects between participation in the pre-campaign interview and exposure were entered by means of stepwise selection in the next step.

Since the number of TV broadcasts viewed was assessed in both subjects who independently recalled TV elements and in subjects who recognized TV elements after the interviewer prompted them, possible dose-response relations between numbers of TV elements and behavior change were analyzed in recallers and recognizers by means of chi-square testing. 


\section{RESULTS}

\section{Response and subject characteristics}

Table 1 presents percentages of subjects who participated in assessments, refused cooperation or were not reached. The latter reason for drop-out appeared to be the most important in all groups. Response rates did not differ significantly between samples of pretested and non-pretested smokers and non-smokers, and between measurement moments.

Table 1. Response and base-line characteristics of pretested smokers, non-pretested smokers and non-smokers.

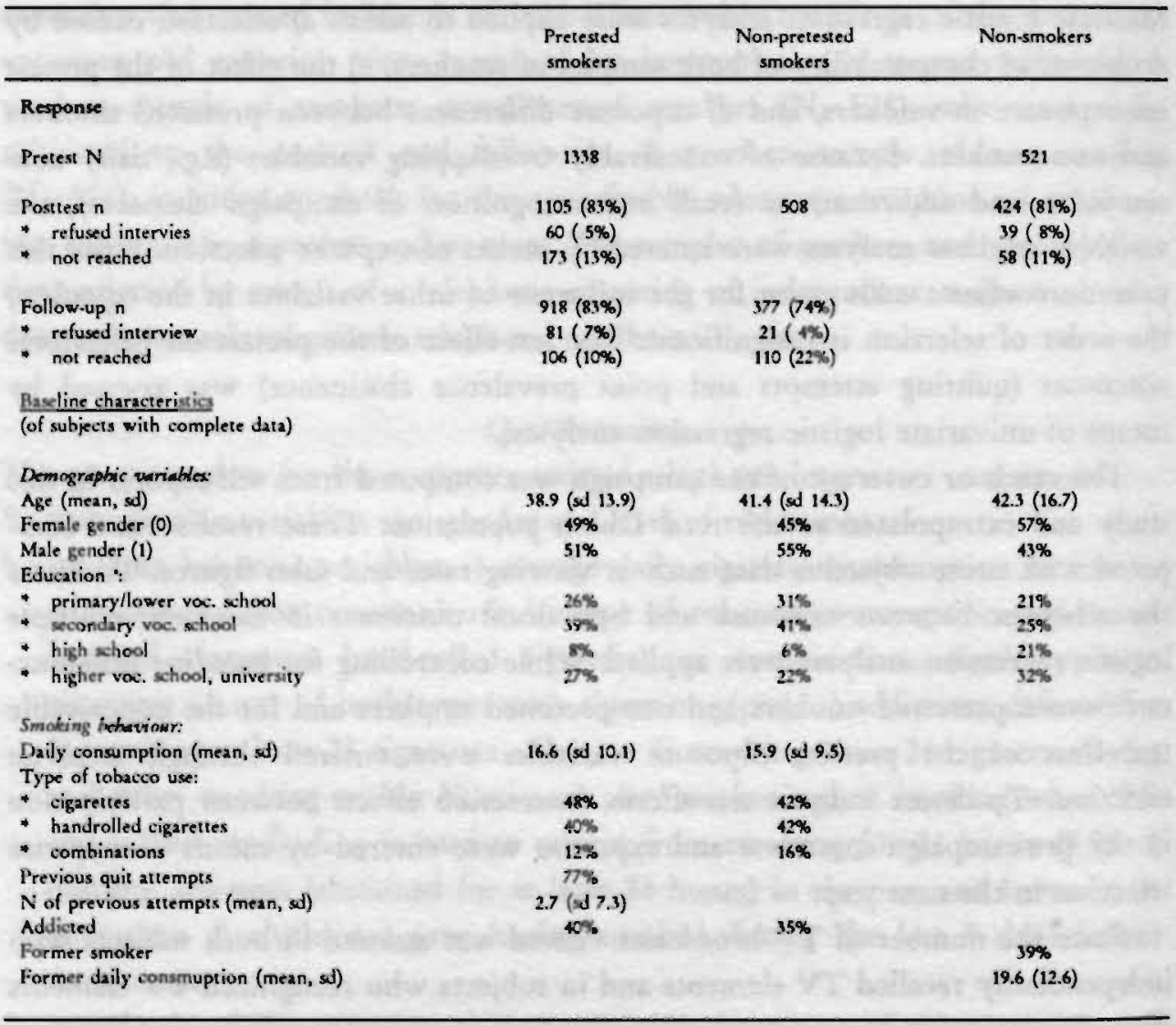

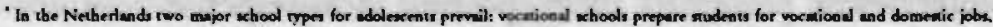

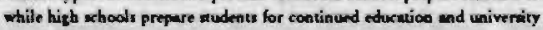

Participation of pretested smokers in the posttest was significantly higher in the age category $35-44(\mathrm{OR}=2.91,95 \% \mathrm{CI} 1.80-4.72, \mathrm{p}<.001)$, in smokers of handrol- 
led cigarettes $(O R=1.76,95 \% \mathrm{CI} 1.27-2.45, \mathrm{p}<.001)$ and combinations of tobacco products $(\mathrm{OR}=1.88,95 \% \mathrm{CI}=1.13-3.13, \mathrm{p}<.05)$, and in the two highest levels of education (resp. $\mathrm{OR}=3.49,95 \% \mathrm{CI} 1.52-8.03, \mathrm{p}<.01$; and $\mathrm{OR}=1.52,95 \% \mathrm{CI}$ $1.01-2.30, p<.05)$, but was lower among men $(O R=0.69,95 \%$ CI $0.50-0.94$, $\mathrm{p}$ <.05). No further selection in pretested smokers occurred during follow-up. Drop-out did not result in selection in non-pretested smokers and non-smokers.

Table 1 also shows base-line characteristics of the three samples. Pretested smokers were significantly younger than non-pretested smokers $(O R=0.99,95 \%$ CI $0.98-1.00, p<.01)$ and used significantly fewer combinations of tobacco products than did non-pretested smokers $(O R=0.64,95 \%$ CI $0.45-0.93, p<.05)$. In 1990 , the Dutch smoking population consisted of $31 \%$ women, had a mean age of 37 and smoked on average 22 cigarettes per day (computed from sales) (9). Hence, in both samples, women between 20 and 49 were significantly overrepresented $\left(\mathrm{X}^{2}(4)=18.1, \mathrm{p}<.01\right)$. In the sample of non-smokers, women of 20-34 and 50-64 years of age were also over-represented $\left(X^{2}(4)=11.4, p<.05\right)$, while the ages of the men were similar to the Dutch population (10).

\section{Recall, recognition and use}

The campaign was noticed by most smokers and non-smokers (see table 2). Correct recall of campaign elements was high: $55 \%$ of the pretested smokers, $45 \%$ of the non-pretest smokers and $38 \%$ of the non-smokers recalled at least one correct title or description of the campaign elements. Recall of TV elements was the highest. Prompting improved subjects' recognition of all elements, but TV elements remained the best known and a large number of subjects watched them. Relatively small percentages of subjects participated in local group programs or obtained written materials. Although more than $50 \%$ of the smokers and nonsmokers said they had seen posters and about $40 \%$ reported they had seen advertisements, only small proportions gave a correct description (see table 2).

Pretested smokers recalled more campaign elements (OR $=1.39,95 \%$ CI 1.15$1.68, \mathrm{p}<.001)$ and more pretested smokers saw at least one TV-clinic broadcast $(\mathrm{OR}=1.17,95 \% \mathrm{CI} 1.01-1.32, \mathrm{p}<.05)$ than did non-pretested smokers. However, fewer pretested smokers remembered having seen posters $(O R=0.54,95 \% \mathrm{CI}$ $0.42-0.70, p<.001)$ and advertisements $(O R=0.48,95 \%$ CI $0.31-0.62, p<.001)$, than did non-pretested smokers. Thus, the pretest enhanced awareness of campaign elements, although the evidence was not totally consistent. 
Table 2. Recall, recognition and use of campaign elements in pretested smokers ( $n=918)$, non-pretested smokers $(n=377)$ and non-smokers $(n=424)$.

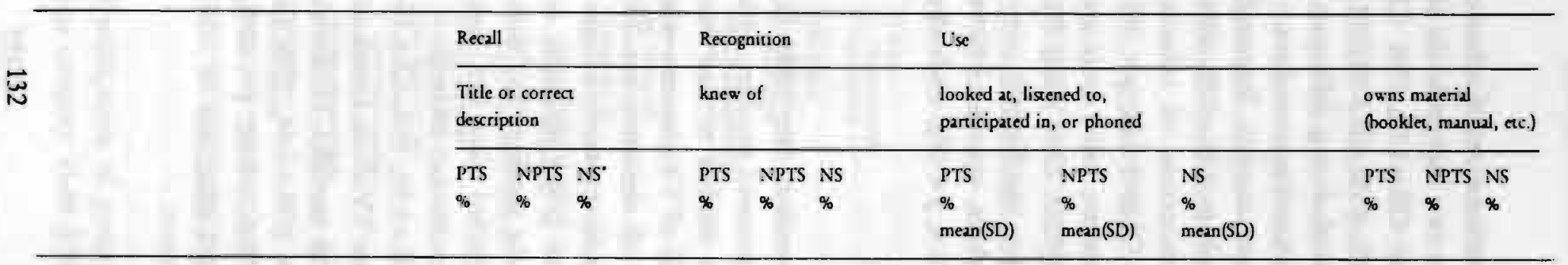

\section{Campaign}

At least 1 correct title or description

Mean of correctly recalled elements (n)

$\begin{array}{lll}55 & 45 \quad 38\end{array}$

\section{Campaign elements:}

1. 'Come on, Quit' TV-show's

2. TV-clinic 'Quit Smoking':

- television broadcass

- radio episodes

\section{Local group program}

\section{National Quit-line}

5. Publicity Campaign

* Leaflet

- Self-help manual

- Posser

- Advertisement

$\begin{array}{lll}83 & 88 \quad 67\end{array}$

$\begin{array}{lll}1.2 & 1.2 & 1.1\end{array}$

$\begin{array}{lll}43 & 34 & 29 \\ 11 & 6 & 4 \\ 2 & 1 & 1\end{array}$

82

51

$84 \quad 75$

$47 \quad 43$

$\begin{array}{lll}36 & 39 \quad 33\end{array}$

$\begin{array}{lll}14 & 14 & 12\end{array}$

$\begin{array}{lll}8 & 8 & 5\end{array}$
47

$2.5(2.0)$

43

$2.3(1.3)$

40

$3.0(2.4)$

$11 \quad 11 \quad 5$

$2.1(1.4) \quad 2.2(1.4) \quad 2.3(1.3)$

$10.3 \quad 1$

$\begin{array}{lll}3.0(1.7) & 2 & 3.6(1.7)\end{array}$

10.3

$5.8(2.6) \quad 7$

0.2

0.4

0.2 
Compared to non-smokers, more smokers were familiar with the campaign ( $\mathrm{OR}=2.34,95 \% \mathrm{CI} 1.81-3.04, \mathrm{p}<.001)$, and saw at least one TV-clinic broadcast $(\mathrm{OR}=1.64,95 \%$ CI $1.02-2.65, \mathrm{p}<.05)$.

\section{Reach and use of the campaign}

For the estimation of reach, exposure data of non-pretested smokers was used, because these were not biased by the pretest. Campaign elements reached $97 \%$ of the non-pretested smokers at least once. This was achieved mainly by the TV elements, since $17 \%$ of the non-pretested smokers reported ordering manuals or booklets, participating in a group program, or calling the quit-line. In the Netherlands, the estimated population of smokers before the campaign was approximately 4.15 million smokers (1). It is estimated that 705,500 Dutch smokers may have been stimulated by the campaign to take action and order materials, participate in groups or call the quit-line.

Furthermore, use of TV elements or viewing rates, computed from recall and recognition data, were extrapolated to the total Dutch population of 15 years of age and older (4.15 million smokers and 8.05 million non-smokers) (12). Recall with respect to the "Come on, quit" TV-show ( $30 \%, 3.7$ million smokers) was significantly lower than prompted recognition ( $45 \%, 5$ million smokers) $(O R=1$.91, $95 \% \mathrm{CI}=1.03-3.56)$. Network ratings showed that the TV-shows were watched by 400,000 viewers per show, and 1.5 million viewers watched the first and last show, which were broadcast on prime time (13). As was observed in this study, a coverage of $27 \%$ was achieved when each viewer watched 2.5 shows derives, when each viewer watched 2.5 shows, as observed in the present study $(3.3$ million smokers and non-smokers of 15 years of age and older watched at least one show). This estimation is comparable to the coverage computed from recall, but differed from coverage based on recognition ( $\mathrm{OR}=2.21,95 \% \mathrm{CI}=1.17-4.18)$.

Recall with respect to the TV-clinic (5\%, 571.000 viewers) did not differ from the $7 \%$ coverage ( 870.000 viewers) based on recognition. Network ratings showed that the TV-clinic was watched by 300,000 viewers per broadcast (13), resulting in a $7 \%$ coverage when each viewer watched 2 broadcasts (over 820.000 viewers watched at least one broadcast). This measure was comparable with self-reported recall and recognition. Self-report suggested that more than 12.000 people bought the TV-clinic manual ( $0.3 \%$ of the smokers). The educational network sold 7.000 TV-clinic manuals in 1991 ( $0.2 \%$ of the smokers) (13).

Furthermore, extrapolation from self-reports suggested that over 12 thousand people participated in local group programs ( $0.3 \%$ of the smokers), and that there 
were almost 25 thousand self-reported calls to the quit-line $(0.2 \%$ of smokers and non-smokers). However, registrations showed that local group programs were actually attended by 1300 participants ( $0.03 \%$ of the smokers), and the quit-line was called 7500 times $(0.18 \%$ of smokers and non-smokers). Since the numbers of active participants, bookbuyers and quit-line callers were relatively small, the differences between self-report and objective measures were not significant.

Based on self-reports, $1.2 \%$ of the potential target group may have actively participated by means of buying books, participating in group programs or calling the quit-line, while estimates based on objective measures revealed a $0.4 \%$ active participation.

\section{Behavioral effects}

Figures $1 \mathrm{~A}$ and $1 \mathrm{~B}$ depict behavioral changes in pretested and non-pretested samples of smokers as measured in the three subsequent measurements. A shortterm testeffect was only indicated with respect to enhancing quitting attempts between pre- and posttest. Significantly more pretested smokers $(29 \%)$ tried to quit between the pre- and posttest, than did non-pretested smokers (18\%) $(\mathrm{OR}=1.96,95 \% \mathrm{CI} 1.50-2.55, \mathrm{p}<.001)$. Quitting attempts were equally effective in both groups: respectively $22 \%$ and $21 \%$ of attempts resulted in post-campaign abstinence.

Pretest

Posttest

Follow-up

\section{CAMPAIGN}

Abstinent
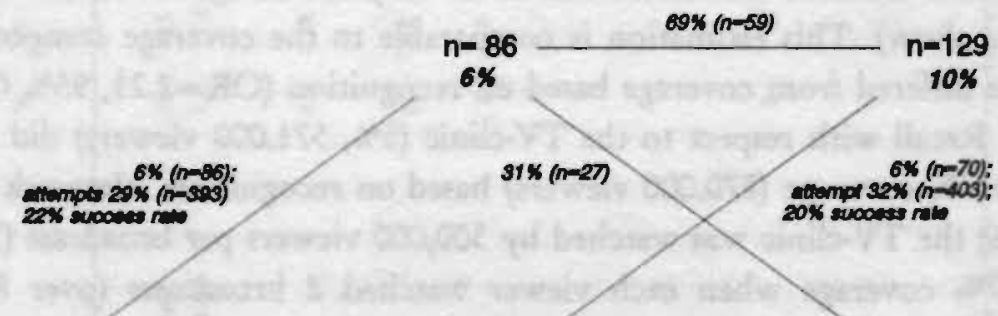

Smoker

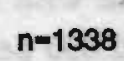

$9(\%(n-1252)$

$n=1252$ $n-1209$

Figuur 1A. Abstinence in pretested smokers. 


\section{CAMPAIGN}

Abstinent
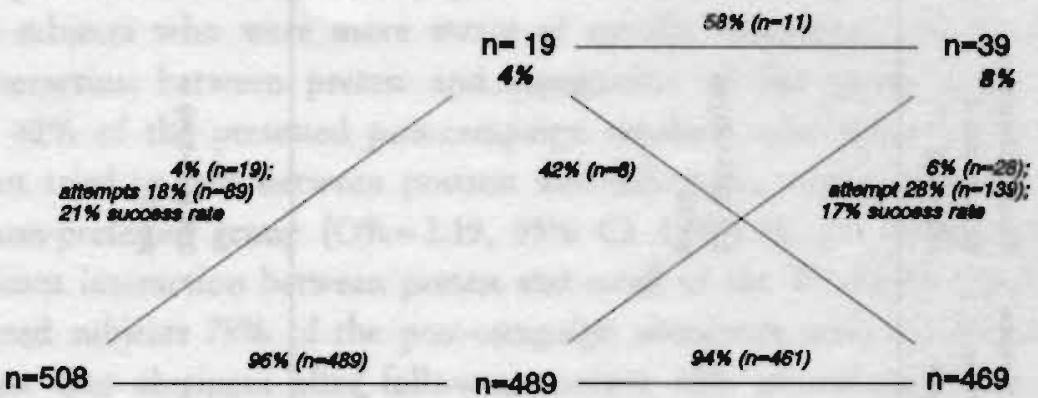

Figuur 1B. Abstinence in non-pretested smokers

Post-campaign abstinence was significantly higher in pretested smokers compared to non-pretested smokers ( $\mathrm{OR}=1.77,95 \% \mathrm{CI} 1.04-3.04, \mathrm{p}<.05)$. No influence of the pretest was detected on cessation behavior between the posttest and followup, since the percentages of posttest abstainers who were also abstinent in the follow-up did not differ significantly between pretested and non-pretested subjects, as did the percentages of posttest smokers who were abstinent in the follow-up. Moreover, the percentages of quitting attempts between posttest and follow-up, $32 \%$ in pre-tested smokers and $28 \%$ in non-pretested smokers, did not differ significantly. These attempts were also equally effective (respectively $20 \%$ and $17 \%$ ), and the follow-up abstinence rates of pretested smokers (10\%) and nonpretested smokers ( $8 \%$ ) did not differ either.

\section{Relation between exposure and behavior}

Recall and recognition variables were related to attempting to quit between preand posttest (see table 3 ). The number of correctly recalled campaign elements, TV-shows and TV-clinic broadcasts viewed were positively related to attempting to quit. Repeated abstinence at the posttest and follow-up, as well as quitting attempts between posttest and follow-up, were not directly related to exposure. However, the influence of watching more TV-clinic broadcasts sustained and also enhanced follow-up abstinence.

Testeffects of the pretest were also related to attempts to quit or repeated abstinence. The pretest appeared to have stimulated non-exposed smokers to try to quit, as was revealed by a significant interaction between number of recalled 
Table 3. Relations between exposure and behavioral outcomes and test-effects, in pretest- and non-pretest smokers, controlled for base-line differences.

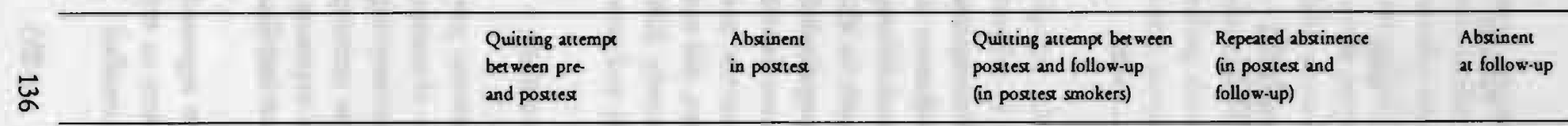

Direct effects of exposure on behavioral outcomes:

Number of correctly recalled eiements

Recall of TV-shows 'Come on, Quit'

Recognition of TV-shows 'Come on, Quit'

Number of TV-shows looked at

Recognition of TV-elinic

Number of TVclinic broadeass looked at

Recognition of group program

Direct and indirect testeffects:

Group (pretest smokers 1; nonpretes

smokers 0 )

Interaction Group * Number of correctly recalled elements
$1.82(1.22-2.72)$
$p=.003$
$0.63(0.420 .96)$
$p=.031$

$1.46(0.85-2.49) \mathrm{ns}$ $\mathrm{p}=.17$
$3.00(1.19 \cdot 2.81)$
$p=.019$
$1.92(1.15-3.20)$
$\mathrm{p}=.012$
$1.37(1.15-1.62)$
$\mathrm{p}=.0003$

$1.15(1.05-1.26)$

$p=.003$

$1.27(1.09-1.48)$

$p=.002$

\begin{tabular}{|c|c|}
\hline \multirow{2}{*}{$\begin{array}{l}1.66(1.14-2.40) \\
p=.008\end{array}$} & \\
\hline & $\begin{array}{l}3.00(1.19 \cdot 2.81) \\
p=.019\end{array}$ \\
\hline $1.15(1.05-1.26)$ & \\
\hline \multicolumn{2}{|l|}{$p=.003$} \\
\hline & $1.92(1.15-3.20)$ \\
\hline & $p=.012$ \\
\hline $1.27(1.09-1.48)$ & $1.37(1.15-1.62)$ \\
\hline$p=.002$ & $p=.0003$ \\
\hline
\end{tabular}

$0.21(0.03-1.81) \mathrm{ns}$

$p=.16$

Interaction Group * Recall of 'Come on, Quit' TVshows

\section{$1.12(0.79 \cdot 1.57) \mathrm{ns}$ $p=.53$}

$0.75(0.46$
$p=.23$

$0.75(0.46-1.21) \mathrm{ns}$
$1.27(1.09-1.48)$

$\mathrm{p}-.003$
$0.30(0.05-1.96) \mathrm{ns}$

$\mathrm{p}-.21$

16.19 (1.41-186.24)

p-.026
1.88 (1.242.88) $\mathrm{p}=.03$ 
elements and pretest: $26 \%$ of the non-recalling pretested smokers tried to quit between pre- and posttest versus $18 \%$ in non-pretested smokers (OR $=1.64,95 \%$ CI 1.06-2.53, p<.05). Furthermore, the pretest enhanced attempts or repeated abstinence in subjects who were more aware of specific campaign elements. A significant interaction between pretest and recognition of the group program revealed that $42 \%$ of the pretested post-campaign smokers who recognized the group program tried to quit between posttest and follow-up, versus $25 \%$ in the comparable non-pretested group ( $O R=2.19,95 \%$ CI 1.38-3.48, p<.001). Moreover, a significant interaction between pretest and recall of the TV-shows showed that in pretested subjects $78 \%$ of the post-campaign abstainers who recalled the TV-shows were also abstinent after follow-up, versus $46 \%$ in comparable nonpretested subjects who recalled the TV-shows $(\mathrm{OR}=4.33,95 \%$ CI 2.24-8.43, $\mathrm{p}<.0001)$.

Dose-response relations between numbers of TV elements and behavior change were analyzed in subjects who either recalled or recognized these elements. Significant dose-response relations were observed in subjects who recalled the TV-shows. Watching more shows was related with attempting to quit between pre- and posttest $\left(\mathrm{X}^{2}(5)=22.59, \mathrm{p}<.001\right)$, while in subjects who only recognized the shows after they were prompted, this relation was not found. Similarly, in subjects who recalled the TV-clinic, a significant relation was observed between the number of broadcasts viewed and attempting to quit between pre-and posttest $\left(X^{2}(7)=17.64, p<.05\right)$. This was not the case for subjects who recognized the clinic. With respect to abstinence (post-campaign and postfollow-up), no differential relations were found in subjects who recalled and/or recognized TV elements.

\section{DISCUSSION}

\section{Summary of major findings}

A multi-faceted mass media smoking cessation campaign was developed by the Dutch Smoking and Health Foundation (DSHF) and was implemented in the first three months of 1991. Through conjunction of various national and regional health services, universities and broadcasting corporations, the campaign included a series of informative TV-shows, a TV-clinic, local group programs, a national quit-line and a comprehensive publicity campaign. 
The present study among smokers and non-smokers revealed that the campaign was noticed by most smokers and non-smokers, and correct recall of campaign elements was high: $55 \%$ of the smokers and $38 \%$ of the non-smokers spontaneously recalled at least one element. Recognition of elements was improved when the interviewer prompted the interviewee. Significantly more smokers were aware of the campaign and reported having watched the TV-clinic broadcasts, than did non-smokers. Active participation in program modalities, however, was relatively low.

In the research group of base-line smokers, $29 \%$ tried to quit between pre- and posttest, resulting in $6 \%$ abstinence in the posttest. Of the abstainers in the posttest, $69 \%$ were also abstinent in the follow-up and $32 \%$ of the posttest smokers tried to quit between posttest and follow-up. Follow-up abstinence was $10 \%$.

Exposure may have stimulated quitting attempts and enhanced short and longterm abstinence, since dose-response relations were found to suggest a positive relation between numbers of recalled elements and TV elements viewed and attempts to quit between pre- and posttest. Furthermore, positive relations were found between numbers of watched TV elements and abstinence in the posttest and follow-up.

Incorporation of a non-pretested group of base-line smokers showed that participation in the pretest enhanced awareness of the campaign, although the evidence was not consistent for all elements. Furthermore, the pretest enhanced quitting attempts between the pre and posttest, especially in non-exposed smokers. As a result, posttest abstinence was higher in pretested smokers. However, the pretest did not affect the effectiveness of attempts and long-term abstinence. Moreover, indications were found for indirect influences of the pretest through exposure, enhancing repeated abstinence and quitting attempts between posttest and follow-up in exposed smokers.

\section{Validity of measurement}

Self-reports may be poor conceptualizations of actual exposure and behavior change. Self-report is acceptable for the assessment of smoking behavior $(14,15)$. However, the present study illustrates the drawbacks of self-reported recognition measures. First, relatively small proportions of subjects gave correct descriptions of the advertisements and posters they remembered. Secondly, a considerable discrepancy was revealed between self-reported recognition and use of campaign elements and more objective measures, such as independent network ratings, 
TV-clinic booksales, and registrations of participation in group programs and calls on the quit-line. Apparently, prompting led to over-reporting, possibly because the interviewers' description of campaign elements also fitted modalities that might have been implemented earlier and did not belong to the campaign. Recall of TV elements provided more legitimate estimates of actual exposure, than did prompted recognition. The accuracy of recall was supported by the fact that only in subjects who recalled TV elements, relations were found between numbers of broadcasts viewed and attempts to quit during the campaign. Inaccurate recollection, but also the social desirability effect (7), may have caused over-reporting in recognition questions.

\section{Interpretation of observed results}

The evaluation of mass media campaigns incorporates unpreventable threats to internal validity (7), which might partially account for the observed effects. Selection through sampling and drop-out may have contributed to finding higher abstinence rates, because easier quitters may have been sampled and participation of abstinent subjects in the post-campaign interview may have been higher. Women and lighter smokers were overrepresented in the present study. Since women's success-rates are lower than men's (16), and self-reported daily cigarette consumption probably was underestimated, quitting rates may not have been affected unacceptably. Furthermore, during follow-up no selection with respect to post-campaign abstinence was found.

In the present study, history may have been a threat to validity that could not be controlled for. In a small country as the Netherlands, national media have the potential to reach everyone. Therefore, it was impossible to incorporate a comparable control-group of whom was known beforehand that they would not be exposed. However, because the DSHF coordinates almost all smoking cessation activities and has contacts with all other organizations in the field, it is known that during the campaign no extraneous events took place that may have caused (part of) the effects. Furthermore, the observed abstinence rates may have been the result of a secular trend in smoking prevalence. However, an ongoing trendstudy by the DSHF (1) showed that since 1988 smoking prevalence was $34 \%$, and even $36 \%$ in the second half of 1990 . In the first and second trimesters of 1991, smoking prevalence was substantially lower (resp. $24 \%$ and 32\%), although the average smoking prevalence in 1991 was $34 \%$ (1). This might indicate a campaign effect. However, it does not provide insight into the percentage of smokers who stopped smoking, since prevalence figures involve both new 
smokers and continued smokers. Based on non-published results of the before mentioned trend study (B. Baan \& M. Wiebing, personal communication, 1992), it is estimated that as of 1988 , yearly $2 \%$ of the Dutchmen who smoked on January 1st, were abstinent at the end of the year. For the study period of 14 months, the secular trend was estimated to be $2,5 \%$.

Another threat to internal validity is the test-effect that was found in the present study which resulted in a higher abstinence rate in the posttest because of the pretest. The posttest may also have affected follow-up abstinence. The magnitude of this effect after a 10 month follow-up was estimated to be $1 \%$, supposing that the post-campaign interview also resulted in a $2 \%$ short-term abstinence, of which $50 \%$ was abstinent at follow-up (based on quitting rates in naturalistic samples) (16).

Through subtraction of estimates of the secular trend and the test-effect from the final cessation rate found in non-pretested smokers, thus coming to the most conservative observation of abstinence, a conclusive campaign effect of $4.5 \%$ abstinence attributable to the campaign is estimated.

\section{Conclusions}

Since the abstinence rate, attributable to the campaign, exceeds objective rates of active participation, the conclusion emerges that the campaign established the most substantial results in smokers who were only exposed to mass media messages. In contrast with cessation rates in previous years, and a $72 \%$ raise in expenditures on tobacco promotion in 1990 in the Netherlands (from 66 million US-dollars in 1989 to 113 million US-dollars in 1990 (2)), the results of the present study are meaningful. Compared with the results of the Chicago Televised Smoking Cessation Program (17), reporting a point-prevalence abstinence of $3 \%$ in a population panel after follow-ups of 6 months and 12 months (not corrected for testeffects), the results of the present study are impressive. Positive dose-response relations between self-reported exposure and smoking cessation made the effect claim for the campaign more convincing and supported causal relations, although the non-preventable lack of a control group and the proved inaccuracy of self-reports complicates conclusions.

The effect of this campaign is also remarkable since no governmental control exists over the media in the Netherlands. Flay (6) suggests that this control may be the main reason for the success of media interventions. The absence of governmental control lines this campaign up with the Chicago Televised Smoking Cessation Program as exceptions to Flay's rule. On the other hand, because the 
DSHF depended on voluntary cooperation of TV networks with respect to the implementation of the TV elements, this type of mass media campaign may only be implemented occasionally. Others have stressed the importance of media coverage of smoking cessation campaigns (6). The results of the present study, especially the impact of the TV-clinic, which remained noticeable after follow-up, support this statement.

\section{REFERENCES}

1. Stichting Volksgezondheid en Roken. Jaarverslag 1992. 's-Gravenhage NL: Stichting Volksgezondheid en Roken, 1993.

2. Dresscher I, Elzinga A, Koldenhof E. Evaluatie tabakswet en zelfregulering tabaksreclame. Leiden NL: Research voor Beleid BV, 1991.

3. Stichting Volksgezondheid en Roken. Meerjaren voorlichtingsprogramma niet-roken. 's-Gravenhage NL: Stichting Volksgezondheid en Roken, 1988.

4. Tweede Kamer. Nota 2000, Gezondheid als uitgangspunt. Vergaderjaar 1985-1986, kamerstuk 19 500, nrs 1-2-3. 's-Gravenhage NL, 1986.

5. Rijt GAJ, Van den Nieuwenhuizen JJ, Moonen IPP, Meerkerk GJ, Derks EMA, Breteler MHM. Samen stoppen, een regionaal stoppen met roken experiment. Eindverslag van de evalautie van een regionale pilotactie. Nijmegen NL: Katholieke Universiteit Nijmegen, 1990.

6. Flay BR. Mass media and smoking cessation: A critical review. Am J Public Health 1987;77:15360.

7. Green LW, Lewis FM. Measurement and evaluation in health education and health promotion. Mountain View CA: Mayfield Publishing Company, 1986.

8. Van der Meer H. Dagboek Hou nog toch op. Kampen NL: La Rivière \& Voorhoeven, 1990.

9. Mudde AN, Zeeman, G. Stoppen met roken. Utrecht NL: Teleac, 1990.

10. Marlatt GA, Gordon JR. Relapse prevention: Maintenance strategies in the treatment of addictive behaviors. New York, London: Guildford Press, 1985.

11. Mudde AN. Van het roken af. Maastricht NL: Universitaire Pers, 1989.

12. Centraal Bureau voor de Statistiek. Statistisch Bulletin 1987;16:6.

13. Baan B. Voorlopige resultaten van de evaluatie van de actie "Samen stoppen met roken." 'sGravenhage NL: Stichting Volksgezondheid en Roken 1992.

14. Murray RP, Connett JE, Lauger GG, Voelker HT. Error in smoking measures: Effects of intervention on relations of cotinine and carbonmonoxide to self-reported smoking. A J Public Health 1993;83:1251-7.

15. Velicer WF, Prochaska JO, Rossi JS, Snow M. Assessing outcome in smoking cessation studies. Psychol Bull 1992;111;23-41.

16. Schwartz JL. Review and Evaluation of Smoking Cessation Methods:The United States and Canada, 1978-1985. U.S. Department of Health and Human Services; Public Health Service; National Institutes of Health; National Cancer Institute. NIH Publications No. 87-2940, 1987.

17. Flay BR, Gruder CL, Warnecke RB, Jason LA, Peterson P. One year follow-up of the Chicago televised smoking cessation program. Am J Public Health 1989;79:1377-80. 


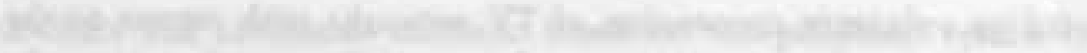

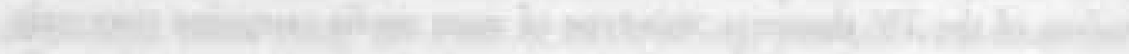

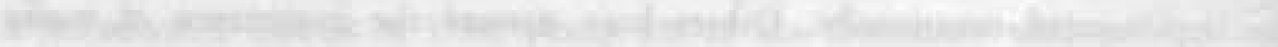

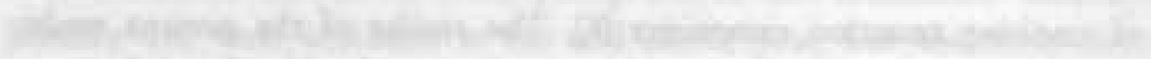

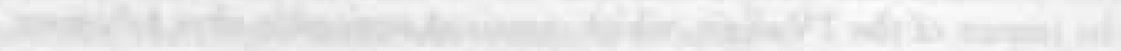

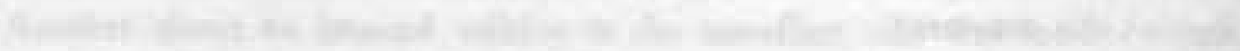
.

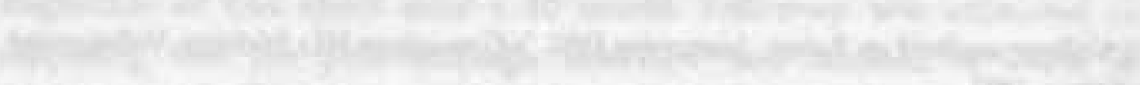

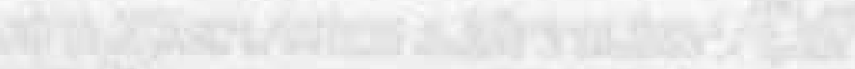

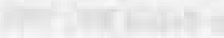

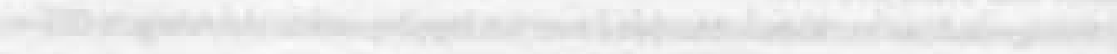

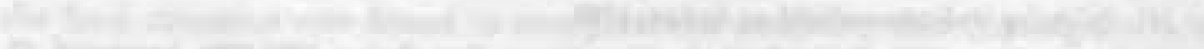
(20) $\cdot 2$

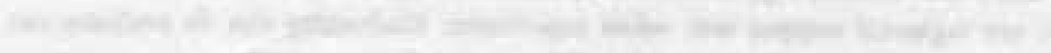

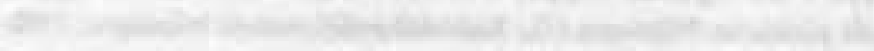

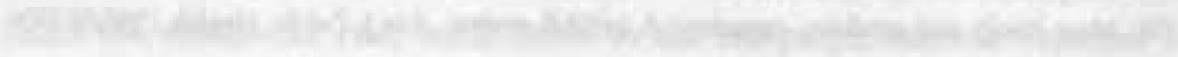




\section{SUMMARY}

This dissertation describes the development and evaluation of two smoking cessation interventions. Smoking is the leading cause of preventable morbidity and mortality in the Netherlands. Approximately $33 \%$ of the people aged 15 years and above in the Netherlands smoke. In 1993, in the Netherlands over 28,000 deaths were ascribed to smoking. The morbidity and mortality associated with smoking have serious implications for society's expenditures and economic productivity, as well as for individuals' life expectancy and quality of life.

Initially, the recognition that most smokers who wanted to quit were unable to do so on their own, led to the development of programs that would produce change within smokers to help them to break their addiction, in spite of environmental influences that promote smoking. The limited impact of these cessation programs, together with growing recognition of the importance of environmental factors in smoking behavior, led to a shift in tobacco control strategies towards influencing the environment. The current state of the art in controlling tobacco use recognizes that no single approach is best for all smokers and that different smokers are most attracted to and most affected by different programs.

Chapter one of this dissertation briefly summarizes the already extensively and thoroughly investigated evidence concerning the relation between smoking and the resulting health damage and the state of the art of smoking cessation interventions. Furthermore, the various projects and studies described in this dissertation are placed in the stages of Analysis, Behavior Change and Continuation of the ABC-model. Finally, a broad outline of the studies is provided.

In chapter two, the predictive value of the behavioral determinant self-efficacy for smoking cessation is investigated in a prospective study. A change in belief about the ability to successfully refrain from smoking (self-efficacy) was supposed to mediate the initiation and maintenance of smoking cessation of 123 participants in the standard group program of the Life and Health Foundation. Smoking behavior and self-efficacy were assesses by questionnaires at pre- and posttreatment and after follow-up periods of six weeks and one year after treatment. The main conclusion emerging from this study is that self-efficacy was predictive for cessation success. Although pre-treatment self-efficacy was not a very reliable predictor for short-term cessation (post-treatment and post-six-weeks follow-up), post-treatment self-efficacy, as well as the increase of self-efficacy during treatment, predicted long term success of those who were abstinent after treatment. Since none of the post-treatment smokers succeeded in quitting again during the one year follow-up period, prediction of future abstinence was point- 
less in this group. This results of this study showed that self-efficacy is a determinant of future behavior, and that in order to enhance the efficacy of smoking cessation programs, participants' self-efficacy towards non-smoking should be enhanced sufficiently during treatment.

Chapter three describes the use of pretest research in the development process of a Dutch smoking cessation self-help manual. Self-help materials have a number of advantages which make them a critical element in many comprehensive smoking cessation interventions: their acceptability to many smokers, their relatively low costs, and their potential to reach much more smokers than do more intensive interventions. A manual distributed by the American Lung Association was chosen as a model for a Dutch manual. Cultural differences between the United States and the Netherlands were considered and it was decided that, in order to comply with Dutch customs and preferences, the manual should be thoroughly pretested. Target group participation was facilitated by involving two separate samples of 177 and 178 Dutch smokers. Moreover, eight experts in the field of health education and communication were consulted to consider the conceptualizations of theoretical principles applied in the manual. The pretests revealed that many elements of the American manual were not suitable for use in the Netherlands, and translation alone would have been insufficient. Furthermore, chapter three discusses application of the manual in three community interventions: a community-based smoking cessation project in Den Bosch (of which the effect evaluation is reported in chapter 4 of this dissertation), a workplace smoking cessation project, and a local health project in a small municipality. The effectiveness of the manual was confirmed, and it was positively evaluated by its users. The fact that in all three applications, the vast majority of the manual requesters knew of the availability of a group program but still preferred the self-help method, indicates the existence of a specific target group for smoking cessation self-help manuals.

In chapters four and five, the effects of a community-based smoking cessation intervention in Den Bosch are reported. It was hypothesized that the community approach is a strategy that has great potential to reach larger segments of the smoking population for sustained periods. In Den Bosch, a local steering committee, in which three local health care organizations participated, was responsible for development and implementation of the intervention in cooperation with the research team. The intervention incorporated local media, posters and the involvement of general practitioners in order to attract the attention of smokers and to motivate them to call a telephone quit-line. The quit-line was staffed with 
trained counsellors who advised smokers about the choice between modalities: a free self-help manual, or a three-week group program at $\$ 15$ (US-dollars). Telephone counselling was optional for all applicants, and a brief protocol was developed to help general practitioners to advise and counsel their smoking patients more effectively. The intervention started in March 1990. The behavioral impact of the intervention on a population level was investigated in random panels of 550 smokers each in Den Bosch and Apeldoorn, that served as a control city. The panels were subjected to three telephone interviews in October 1989, and June and December 1990 . In the treatment city $6-11 \%$ of the potential target population were actively reached by intervention modalities (self-help manual, group program, physician advice, telephone quit-line). On a population level, no differences were found between treatment and control city concerning numbers of quit attempts during the study and abstinence at the end of the study $7 \%$ in the treatment city and $9 \%$ in the control city). However, success rates of quit attempts differed between cities in two periods of the study: in the first eight months of the study quit attempts in the control city were more successful, while in the second period of six months smokers in the treatment city were more successful. Since two-thirds of all intervention activities were conducted in the second period of the study, the differing success rates may suggest an intervention effect in the treatment city.

To obtain an indication of the quality of the intervention, the effectiveness of two treatment modalities was examined in groups of participants. During 1990, 118 smokers participated in the group program, and 294 smokers requested a manual for individual use. The group program and the self-help manual showed post-six months results of respectively $22 \%$ and $13 \%$ abstinence, which is comparable to other studies. Furthermore, in chapter five, a comparison was made between the two treatment modalities in terms of cost-efficiency (costs per participant) and cost-effectiveness (costs per quitter). Moreover, characteristics of both groups of participants were compared. Costs per participant in the self-help condition were at least ten times lower than in the group condition, both from the perspective of the steering group and the participants. The cost-effectiveness of the self-help modality was at least three times as high as the cost-effectiveness of the group modality for both the steering group and the participants. Besides, both modalities attracted different types of smokers: self-help was selected by 'easier quitters' who tried to quit less often, were less addicted to tobacco, and had significantly higher perceptions of self-efficacy, than did group program participants. Even when controlling for these differences, the self-help modality still 
was more cost-effective than the group program. Since those smokers who prefer a group program will probably not benefit from self-help modalities, selecting the most cost-effective treatment would imply ignoring the needs of this group.

Chapter six describes the evaluation study of a national mass-media-led smoking cessation campaign, that was implemented in the first three months of 1991 by the Dutch Smoking and Health Foundation in cooperation with TVnetworks and local health services. The campaign included TV-shows, a TVclinic, local group programs, a national Quit-line, and a publicity campaign (advertisements, posters, leaflets, brochures for general practitioners). Exposure to campaign elements and behavioral impact were evaluated in random samples of 1864 smokers and 521 non-smokers. The campaign was noticed by most smokers and non-smokers, and spontaneous recall of campaign elements was high: $55 \%$ of the smokers and $38 \%$ of the non-smokers recalled at least one element. Campaign elements covered $97 \%$ of the smokers at least once (based on self-reports). Estimates based on network ratings indicated that $27 \%$ of the smokers watched the TV-shows at least once, and $7 \%$ saw at least one TV-clinic episode. Twentynine percent of the smokers tried to quit between pre- and posttest, resulting in $6 \%$ post-campaign abstinence. After ten months follow-up, abstinence was $10 \%$. It was estimated that almost half of this $10 \%(4.5 \%)$ could be attributed to the campaign, after correction for conceivable test-effects and secular trends. Positive dose-response relations between self-reported exposure and smoking cessation made the effect claim for the campaign more convincing and supported causal relations, although the non-preventable lack of a control group complicates conclusions. Remarkable is that the major part of the result was established in smokers who did not actively participate, since active participation was limited: $0.4 \%$ of the smokers engaged in buying the TV-clinic manual, calling the quit-line or participating in a group program. In contrast with cessation rates in previous years, the results of the campaign are meaningful, especially in the light of the 72\% raise in expenditures on tobacco promotion in 1991.

A major conclusion of this dissertation is that the self-help manual showed to be a promising and cost-effective treatment modality that is applicable in various settings. Futhermore, smoking cessation interventions, either local or national, need the attention of the media, in order to attract more smokers to treatment modalities, but most important to bring information to smokers that may help them to quit. 


\section{SAMENVATTING}

Dit proefschrift beschrijft de ontwikkeling en evaluatie van twee stoppen met roken interventies. Roken is de belangrijkste oorzaak van te voorkomen morbiditeit en mortaliteit in Nederland. Ongeveer 33\% van de Nederlandse bevolking van 15 jaar en ouder rookt. Meer dan 28,000 sterfgevallen werden in 1993 aan roken toegeschreven in Nederland. De aan roken geassocieerde morbiditeit en mortaliteit heeft zowel belangrijke gevolgen voor de uitgaven en economische produktiviteit van de samenleving, als voor de levensverwachting en de kwaliteit van het leven van individuen.

Oorspronkelijk leidde de constatering dat de meeste rokers die willen stoppen met roken hier niet zelfstandig in slagen, tot de ontwikkeling van programma's die rokers in staat zouden stellen om met hun verslavign te breken, ondanks tegengestelde invloeden van buitenaf. De geringe uitwerking van deze programma's, tezamen met een groeiende erkenning van het belang van omgevingsfactoren in verband met roken, gaf aanleiding tot een verschuiving van de tabakgebruik beperkende strategieën naar beïnvloeding van de omgeving. De huidige kennis over beperking van het tabakgebruik impliceert dat geen enkele benadering de beste genoemd kan worden voor alle rokers en dat verschillende rokers door verschillende programma's worden aangetrokken en beïnvloed.

Het eerste hoofdstuk van dit proefschrift vat de reeds uitvoerig en grondig onderzochte verbanden tussen roken en de daaruit voortkomende schade voor de gezondheid samen en geeft een bondig overzicht van de stand van zaken met betrekking tot stoppen met roken interventies. Vervolgens worden de verschillende projecten en studies, die in dit proefschrift worden beschreven, in de stadia van Analyse, Gedragsverandering en Continuering van het zgn. ABC-model geplaatst, waarna een kort overzicht over deze studies wordt gegeven.

In hoofdstuk twee wordt een prospectieve studie beschreven naar de voorspellende waarde van de gedragsdeterminant 'eigen effectiviteit' voor stoppen met roken. Er werd verondersteld dat een verandering in de inschatting van de eigen be$k w a a m h e i d$ om niet te roken (eigen effectiviteit) zou leiden tot het ondernemen en volhouden van een poging om te stoppen met roken bij 123 deelnemers aan het standaard groepsprogramma van de Stichting Leven en Gezondheid. Het rookgedrag en de eigen effectiviteit werden voor en direct na de cursus, en zes weken en een jaar na afloop van de cursus door middel van vragenlijsten gemeten. De belangrijkste conclusie is dat de eigen effectiviteit het stopsucces voorspelt. Hoewel eigen effectiviteit voor de cursus geen erg betrouwbare voorspeller was voor stoppen op korte termijn (direct na de cursus en zes weken later), 
voorspelden eigen effectiviteit aan het eind van de cursus en de stijging van de eigen effectiviteit gedurende de cursus het stopsucces op lange termijn van hen die aan het eind van de cursus gestopt waren. De uitkomsten van deze studie toonden aan dat eigen effectiviteit een determinant is van toekomstig gedrag en dat, om de doeltreffendheid van stoppen met roken cursussen te verhogen, de eigen effectiviteit van de deelnemers in voldoende mate moet worden verhoogd tijdens de cursus.

Hoofdstuk drie beschrijft het gebruik van pretest onderzoek in het ontwikkelings proces van een Nederlandse stoppen met roken zelf-hulp gids. Zelf-hulp materiaal heeft een aantal voordelen waardoor het een onontbeerlijk element is van veel stoppen met roken interventies: acceptabel voor veel rokers, relatief goedkoop, en een groter potentieel bereik dan meer intensieve interventies. Een gids die door de American Lung Association wordt verspreid, diende als voorbeeld. Gezien de culturele verschillen tussen de Verenigde Staten en Nederland, werd besloten de gids grondig te pretesten, om zodoende aan te sluiten bij Nederlandse gebruiken en voorkeuren. Opinies van de doelgroep werden gepeild in twee groepen van respectievelijk 177 en 178 rokers. Daarnaast werden acht deskundigen op het gebied van gezondheidsvoorlichting en communicatie geraadpleegd om de theoretische principes in de gids te beoordelen. De pretest toonde aan dat veel elementen van de Amerikaanse gids niet geëigend waren voor gebruik in Nederland, en uitluitend vertalen ontoereikend zou zijn geweest. In hoofdstuk drie worden verder nog toepassingen van de gids in drie community interventies besproken: een community-based stoppen met roken project in Den Bosch (de evaluatie van dit project wordt in de hoofdstukken vier en vijf van dit proefschrift beschreven), een stoppen met roken project in een bedrijf en een lokaal gezondheidsproject in een kleine gemeente. De effecten van de gids bleken overtuigend te zijn en de gids werd positief beoordeeld door zijn gebruikers. Een indicatie voor de aanwezigheid van een specifieke doelgroep voor stoppen met roken zelf-hulp materiaal, blijkt uit het feit dat de grote meerderheid van aanvragers in de drie projecten op de hoogte was van de mogelijkheid om een cursus te volgen, maar toch de voorkeur gaf aan de gids.

In de hoofdstukken vier en vijf worden de effecten van een community-based stoppen met roken interventie gerapporteerd. Er werd verondersteld dat de community aanpak een strategie is die de potentie heeft om grotere delen van de rokende bevolking gedurende langere tijd te bereiken. Een plaatselijke stuurgroep in Den Bosch, waar drie lokale gezondheidsdiensten in samenwerkte, was verantwoordelijk voor de ontwikkeling en uitvoering van de interventie, in samenwer- 
king met het onderzoeksteam. De interventie omvatte lokale media, posters, en de inspanning van huisartsen om de aandacht van rokers te trekken en hen te stimuleren om een lokale telefonische stop-lijn te bellen. Bij deze stop-lijn gaven getrainde adviseurs rokers raad over de keuze tussen een gratis zelf-hulp gids en een groepscursus die fl.30,- kostte. De mogelijkheid om telefonisch advies te krijgen tijdens het stopproces werd aan alle bellers aangeboden. Bovendien werd een kort protocol ontwikkeld om huisartsen in staat te stellen om hun rokende patiënten effectiever te stimuleren om te stoppen. De interventie startte in maart 1990. De gedragseffecten werden onderzocht op bevolkingsniveau in twee willekeurige steekproeven van elk 550 rokers in Den Bosch en de controle stad Apeldoorn. De steekproeven rokers werden aan drie telefonische interviews onderworpen in oktober 1989 en juni en december 1990. In de interventie stad werd 6-11\% van de potentiële doelgroep bereikt door onderdelen van de interventie (zelf-hulp gids, groepscursus, stop-lijn, advies van huisarts). Op bevolkingsniveau werden geen verschillen gevonden tussen de interventie stad en de controle stad betreffende het aantal stoppogingen en het aantal gestopten aan het eind van de studie ( $7 \%$ in de interventie stad en $9 \%$ in de controle stad). Het succespercentage van stoppogingen verschilde echter tussen de beide steden in de twee perioden van het onderzoek: in de eerste acht maanden waren de pogingen in de controle stad doeltreffender, terwijl in de tweede periode van 6 maanden de rokers in de interventie stad succesvoller waren. Omdat tweederde van de activiteiten in het kader van de interventie in deze tweede periode werden uitgevoerd, kunnen deze verschillen in succespercentages van pogingen gezien worden als een interventie effect.

Om een indicatie te krijgen van de kwaliteit van de interventie, werd de effectiviteit van twee onderdelen van de interventie onder deelnemers onderzocht. Gedurende 1990 namen 118 rokers deel aan de groepscursussen en vroegen 294 rokers een zelf-hulp gids aan voor individueel gebruik. Van de deelnemers aan de groepscursus en de aanvragers van de zelf-hulp gids was respectievelijk $22 \%$ en $13 \%$ gestopt, zes maanden na ontvangst van de gids of aanvang van de cursus. Dit is vergelijkbaar met de resultaten van andere onderzoeken. Vervolgens wordt in hoofdstuk vijf een vergelijking gemaakt tussen deze twee interventie onderdelen in termen van kosten-efficiëntie (kosten per deelnemer) en kosten-effectiviteit (kosten per gestopte roker). Bovendien worden de karakteristieken van beide groepen deelnemers vergeleken. De kosten per deelnemer waren in de zelf-hulp groep tenminste tien maal lager dan in de groepscursus, zowel gezien vanuit het perspectief van de stuurgroep als van de deelnemers. De kosten-effectiviteit van 
zelf-hulp was tenminste drie maal zo groot als die van de groepscursus, zowel voor de stuurgroep als voor de deelnemers. Daarnaast bleek dat beide programma onderdelen verschillende groepen rokers aantrokken: zelf-hulp werd gekozen door 'gemakkelijke stoppers', die minder vaak geprobeerden om te stoppen, minder verslaafd waren aan tabak, en een significant hogere inschatting van de eigen effectiviteit hadden. Zelfs als voor deze verschillen werd gecorrigeerd, bleef zelfhulp kosten-effectiever dan de groepscursus. Omdat die rokers die de voorkeur geven aan een groepscursus waarschijnlijk geen baat zullen hebben bij zelf-hulp, zou het kiezen van methoden op basis van kosten-effectiviteit betekenen dat niet aan de behoeften van deze groep wordt voldaan.

Hoofdstuk zes beschrijft de evaluatie van een nationale massa-mediale stoppen met roken campagne, die in de eerste drie maanden van 1991 werd uitgevoerd door de Stichting Volksgezondheid en Roken, in samenwerking met omroep organisaties en lokale gezondheidsdiensten. De campagne omvatte een reeks televisie shows, een televisie-cursus, plaatselijke groepscursussen, een nationale telefonische stop-lijn en een publiciteitscampagne (advertenties, posters, folders, brochures voor huisartsen). Blootstelling aan onderdelen van de campagne en gedragsverandering werd onderzocht bij steekproeven van 1864 rokers en 521 niet-rokers. De campagne werd opgemerkt door de meeste rokers en niet-rokers en de spontane herinnering van onderdelen was groot: $55 \%$ van de roker en $38 \%$ van de nietrokers wist tenminste een onderdeel te noemen. De campagne bereikte $97 \%$ van de rokers tenminste een maal (gebaseerd op zelfrapportage). Schattingen gebaseerd op kijkcijfers gaven aan dat $27 \%$ van de rokers tenminste een keer naar de tvshows keek, en dat $7 \%$ tenminste een aflevering de tv-cursus zag. Negenentwintig procent van de rokers ondernam een stoppoging gedurende de campagne. Dit resulteerde in $6 \%$ gestopte rokers na de campagne en $10 \%$ gestopte rokers 10 maanden na afloop van de campagne. De schatting is dat van deze $10 \%$ bijna de helft (4.5\%) toe was te schrijven aan de campagne, na correctie voor mogelijke test-effecten en normale trends in het stopgedrag. Positieve dosis-respons relaties tussen zelf gerapporteerde blootstelling en stoppen met roken versterken de effect claim van de campagne en steunen causale relaties, hoewel het niet te voorkomen gebrek aan een vergelijkbare controle groep het trekken van conclusies bemoeilijkt. Opmerkelijk is dat het grootste deel van het resultaat werd bewerkstelligd in de groep rokers die niet actief deelnamen aan campagne onderdelen, omdat de actieve deelname beperkt was: slechts $0.4 \%$ van de rokers kocht het tv-cursus boek, belde de stop-lijn of nam aan een cursus deel. Vergeleken met de stopper- 
centages in voorgaande jaren is het resultaat van deze campagne aanzienlijk, zeker gezien de uitgaven voor de promotie van tabak in 1991 met $72 \%$ stegen.

Een belangrijke conclusie van dit proefschrift is dat de zelf-hulp gids een veelbelovende en kosten-effectieve methode blijkt, die in verschillende omstandigheden kan worden ingezet. Voorts werd duidelijk dat stoppen met roken interventies, zowel lokaal als nationaal, de aandacht van de media behoeven om rokers aan te trekken om deel te nemen aan behandelingsmethoden, maar nog belangrijker, ook om informatie over te brengen aan rokers die hen kan helpen om te stoppen. 


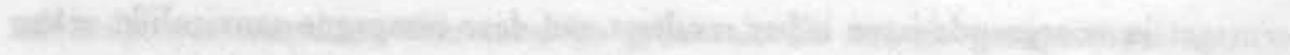

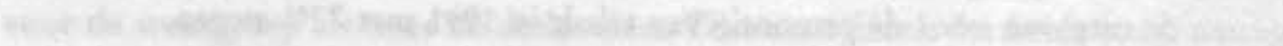

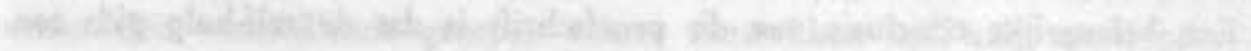

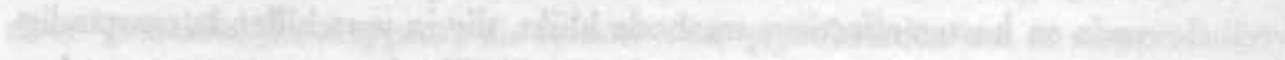

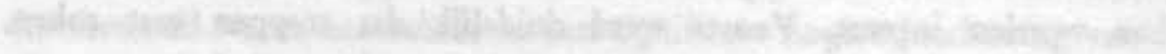

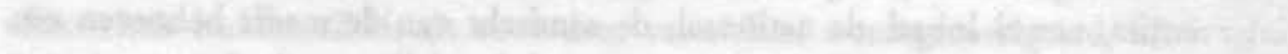

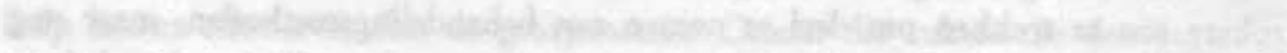

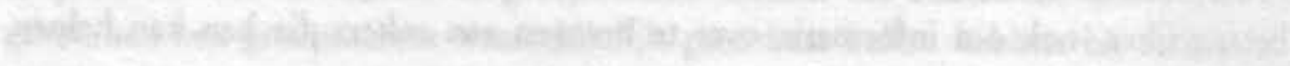

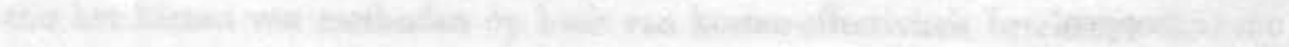

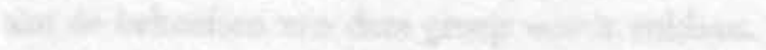

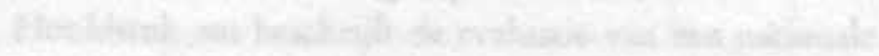

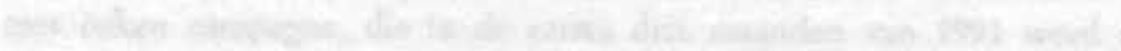

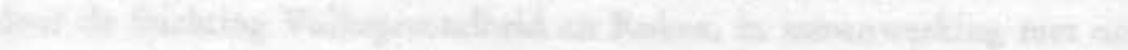

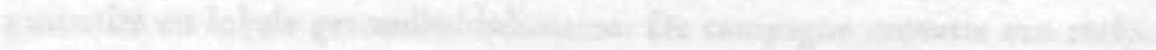

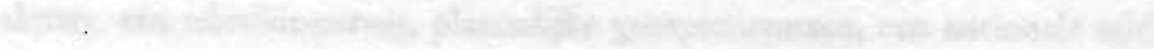
and

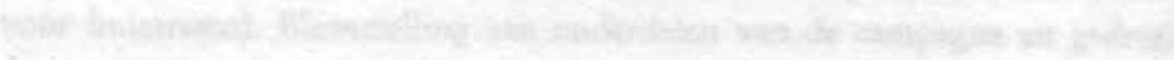

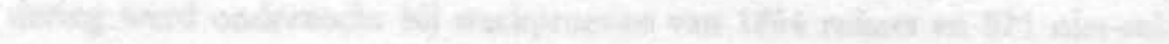

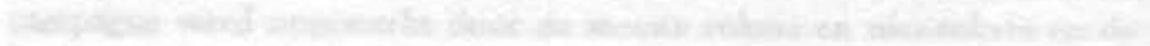

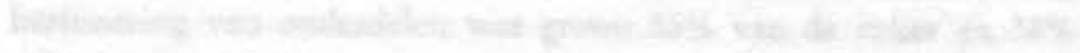

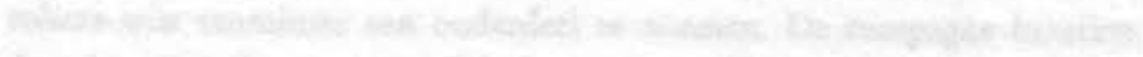

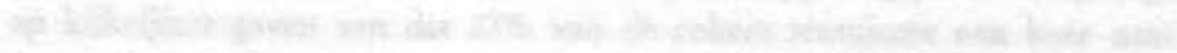

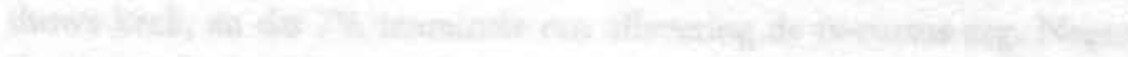

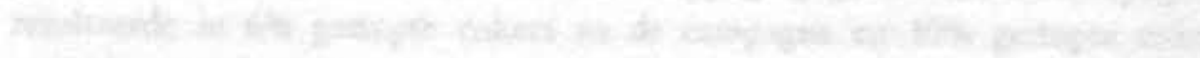

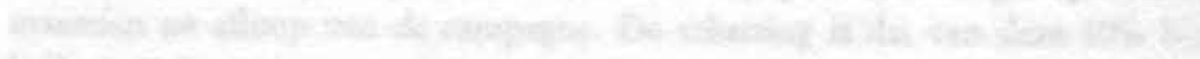

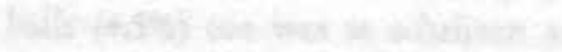

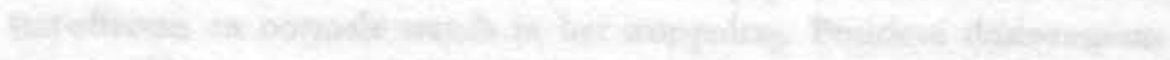

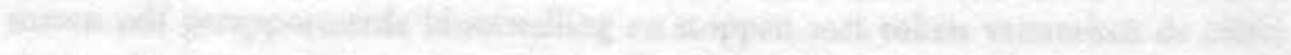

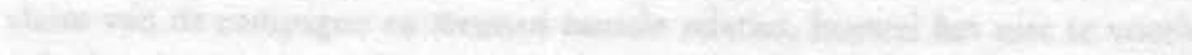

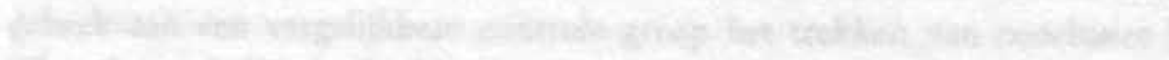

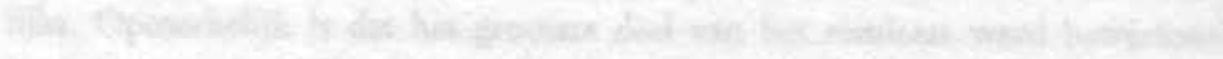

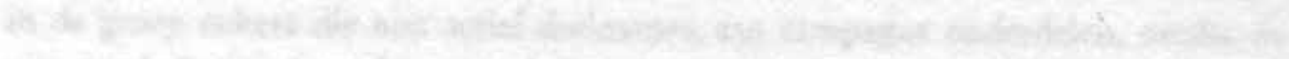

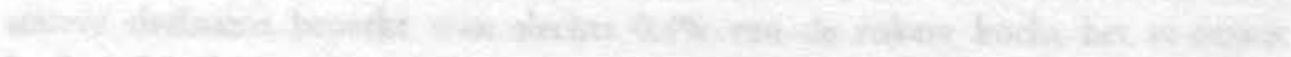

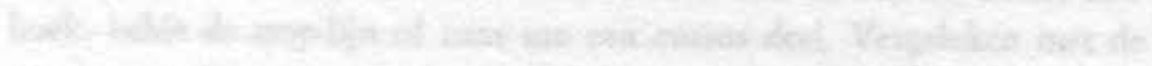


De auteur van dit proefschrift werd op 16 november 1953 in Eindhoven geboren. In 1972 behaalde hij het HBS-B diploma aan het Protestants Lyceum in Eindhoven. Aansluitend bezocht hij gedurende vier jaar de Rijks Hogere School voor Tuin- en Landschapsarchitectuur. Daarna was hij zeven jaar werkzaam bij Vallen Landschapsplanning BV te Roermond. In 1983 begon hij zijn studie Gezondheidswetenschappen aan de Rijksuniversiteit Limburg, die hij in 1987 afsloot met als specialisatie Gezondheidsvoorlichting. Vanaf oktober 1987 tot en met maart 1988 werkte hij als onderzoeksassistent bij de vakgroep Gezondheidsvoorlichting van de Rijksuniversiteit Limburg. In april 1988 startte hij bij dezelfde vakgroep met een drie-jarig onderzoeksproject naar de effecten van een community-based stoppen met roken interventie, dat door de Nederlandse Kankerbestrijding werd gefinancierd en dat in de hoofdstukken 2, 3 en 4 van dit proefschrift wordt besproken. Aansluitend voerde hij een evaluatie studie uit met betrekking tot een nationale stoppen met roken campagne (zie hoofdstuk 6 van dit proefschrift). Dit laatste onderzoek werd gefinancierd door de Stichting Volksgezondheid en Roken. Sinds oktober 1992 werkt hij aan een onderzoeksproject ter ondersteuning van lokale voedingsvoorlichting, dat door het ministerie van Landbouw, Natuurbeheer en Visserij wordt gefinancierd. 
